INSTITUTO DE PESQUISAS ENERGÉTICAS E NUCLEARES Autarquia associada à Universidade de São Paulo

\title{
AVALIAÇÃO DOS EFEITOS DA RADIAÇÃO IONIZANTE EM MATERIAIS UTILIZADOS EM RESTAURAÇÕES DENTÁRIAS
}

MIRÉIA FLORENCIO MAIO

Dissertação apresentada como parte dos requisitos para obtenção do Grau de Mestre em Ciências na Área de Tecnologia Nuclear - Aplicações.

Orientador:

Prof. Dr. Adimir dos Santos 
Aos meus primos José Caio dos Santos Rodrigues e Orlanda Nicoletti, meu eterno amor e gratidão. 


\section{Agradecimentos}

A Deus, por ter me dado vida, saúde, força e coragem. Por fazer parte da minha vida, fazendo com que ela seja cada vez mais maravilhosa.

Ao meu professor, Dr. Adimir dos Santos, pelos seus valiosos ensinamentos, dedicada orientação, confiança e amizade.

Ao Instituto de Pesquisas Energéticas e Nucleares (IPEN - CNEN/SP), pelo suporte técnico fornecido.

A Comissão de Energia Nuclear (CNEN), que me apoiou financeiramente durante todo o trabalho.

Ao Centro de Engenharia Nuclear (CEN), pelo apoio, incentivo e oportunidade na realização desse trabalho.

Ao Prof. Dr. Marco Antônio Rodrigues Fernandes, pela infinita ajuda, incentivos e colaboração indispensável.

Ao pessoal

do setor de radioterapia do Hospital das Clínicas da Faculdade de Medicina de Botucatu, em especial ao Dr. Batista de Oliveira Junior, ao físico Antonio Cesar Pernomian, ao técnico Natanael Izidora, pelo apoio e colaboração durante todos os procedimentos de irradiação das amostras.

A Profạ. Drạ. Cristiane Furuse e ao Dr. Adilson Yoshio Furuse, pela colaboração, ajuda, conselhos, ensinamentos e amizade.

A todos os amigos do CEN, pela amizade, sugestões, críticas e ajudas.

A todos do IPEN que participaram direta ou indiretamente para a realização deste trabalho.

A minha avó Iraci Nicoleti, meu avó Cindulfo Florencio (in memorian), por me ensinarem a caminhar.

A minha mãe Tânia Aparecida Florencio e meu pai Orlando Miguel Maio (in memorian) pelo apoio e por sempre estarem ao meu lado.

A todos os meus familiares que me apoiaram e acreditaram em mim.

A todos os meus amigos que sempre estiveram comigo, me apoiando, incentivando e ajudando. 


\section{Um dia você aprende}

Um dia você aprende que...

Depois de algum tempo você aprende a diferença, a sutil diferença, entre dar a mão e acorrentar uma alma.

E você aprende que amar não significa apoiar-se, e que companfia nem sempre significa segurança.

E começa a aprender que beijos não são contratos e presentes não são promessas.

E começa a aceitar suas derrotas com a cabeça erguida e olhos adiante, com a graça de um adulto e não com a tristeza de uma criança.

$\mathcal{E}$ aprende a construir todas as suas estradas no hoje, porque o terreno do amanhã é incerto demais para os planos, e futuro tem o costume de cair em meio ao vão.

Depois de um tempo você aprende que o sol queima se ficar exposto por muito tempo.

$\mathcal{E}$ aprende que não importa o quanto você se importe, algumas pessoas simplesmente não se importam... E aceita que não importa quão boa seja uma pessoa, ela vai feri-lo de vez em quando e você precisa perdoá-la, por isso.

Aprende que falar pode aliviar dores emocionais.

Descobre que se leva anos para se construir confiança e apenas segundos para destruí-la, e que você pode fazer coisas em um instante, das quais se arrependerá pelo resto da vida.

Aprende que verdadeiras amizades continuam a crescer mesmo a longas distâncias.

E o que importa não é o que você tem na vida, mas quem vocêé na vida.

E que bons amigos são a família que nos permitiram escolher.

Aprende que não temos que mudar de amigos se compreendemos que os amigos mudam, percebe que seu melhor amigo e você podem fazer qualquer coisa, ou nada, $e$ terem bons momentos juntos.

Descobre que as pessoas com quem você mais se importa na vida são tomadas de você muito depressa, por isso sempre devemos deixar as pessoas que amamos com palavras amorosas, pode ser a última vez que as vejamos.

Aprende que as circunstâncias e os ambientes tem influência sobre nós, mas nós somos responsáveis por nós mesmos.

Começa a aprender que não se deve comparar com os outros, mas com o melhor que você mesmo pode ser.

Descobre que se leva muito tempo para se tornar a pessoa que quer ser, e que o tempo é curto. 
Aprende que não importa onde já chegou, mas onde está indo, mas se você não sabe para onde está indo, qualquer lugar serve.

Aprende que, ou você controla seus atos ou eles o controlarão, e que ser flexível não significa ser fraco ou não ter personalidade, pois não importa quão delicada e frágil seja uma situação, sempre existem dois lados.

Aprende que heróis são pessoas que fizeram o que era necessário fazer, enfrentando as conseqüências.

Aprende que paciência requer muita prática.

Descobre que algumas vezes a pessoa que você espera que o chute quando você cai é uma das poucas que o ajudam a levantar-se.

Aprende que maturidade tem mais a ver com os tipos de experiência que se teve e o que você aprendeu com elas do que com quantos aniversários você celebrou.

Aprende que há mais dos seus pais em você do que você supunha.

Aprende que nunca se deve dizer a uma criança que sonhos são bobagens, poucas coisas são tão humilhantes e seria uma tragédia se ela acreditasse nisso.

Aprende que quando está com raiva tem o direito de estar com raiva, mas isso não the dá o direito de ser cruel.

Descobre que só porque alguém não o ama do jeito que você quer que ame, não significa que esse alguém não o ama, pois existem pessoas que nos amam, mas simplesmente não sabem como demonstrar isso.

Aprende que nem sempre é suficiente ser perdoado por alguém, algumas vezes você tem que aprender a perdoar-se a si mesmo.

Aprende que com a mesma severidade com que julga, você será em algum momento condenado.

Aprende que não importa em quantos pedaços seu coração foi partido, o mundo não pára para que você o conserte.

Aprende que o tempo não é algo que possa voltar para trás.

Portanto, plante seu jardim e decore sua alma, ao invés de esperar que alguém the traga flores.

E você aprende que realmente pode suportar... que realmente é forte, e que pode ir muito mais longe depois de pensar que não se pode mais.

E que realmente a vida tem valor e que você tem valor diante da vida!

$\mathcal{N}$ ossas dúvidas são traidoras e nos fazem perder o bem que poderíamos conquistar, se não fosse o medo de tentar. 


\title{
AVALIAÇÃO DOS EFEITOS DA RADIAÇÃO IONIZANTE EM MATERIẢIS UTILIZADOS EM RESTAURAÇÕES DENTÁRIAS
}

\author{
Miréia Florencio Maio
}

\begin{abstract}
RESUMO
O trabalho consistiu na realização de estudos quantitativos dos efeitos provocados pela radiação ionizante sobre os materiais utilizados em restaurações dentárias (Titânio, Amálgama, Resina Composta e lonômero de Vidro), visando amenizar os possíveis efeitos deletérios quando da radioterapia em pacientes portadores de tumores de cabeça e pescoço, observados quando a dentição restaurada está compreendida no campo de radiação. Corpos de provas foram submetidos a feixes de radiação-X de $6 \mathrm{MV}$ provenientes de um acelerador linear, marca VARIAN modelo $2100 \mathrm{C}$, comumente utilizados nos tratamentos de cânceres da região da cabeça e pescoço, e disponíveis no Serviço de Radioterapia da Faculdade de Medicina de Botucatu. As amostras foram analisadas por técnica de fluorescência de raios-X comparando a composição química antes e depois da irradiação. Foram realizadas medidas de dosimetria das amostras com detectores de radiação do tipo Geiger-Müller e câmara de ionização a fim de se verificar a radiação residual nas amostras. As amostras também foram analisadas por espectrometria gama com detector de Germânio Hiper - puro (HPGe). Com estas análises, pretendeu-se verificar pequenas alterações nas composições dos corpos de prova devido à interação da radiação. Os resultados deste estudo poderão incentivar a realização de pesquisas de novas alternativas de materiais utilizados em restaurações dentárias que possam contribuir para melhoria da qualidade de vida daqueles pacientes portadores de tumores da boca.
\end{abstract}




\title{
EVALUATION OF EFFECTS OF IONIZING RADIATION ON MATERIALS USER IN DENTAL RESTORATIONS.
}

\section{Miréia Florencio Maio}

\begin{abstract}
This work consisted of quantitative studies of the effects caused by ionizing radiation on materials used in dental restorations (Titanium, Amalgam, Resin Composite and Glass Ionomer) aiming the deleterious effects of radiotherapy when patients with tumors in head and neck, arising when the teeth are restored within in the field of radiation. Samples were submitted to X-ray beams of 6 MV from a linear accelerator, VARIAN $2100 \mathrm{C}$ model. The samples were analyzed by X-ray fluorescence techniques to compare the chemical composition before and after the irradiation. The sample were submitted to Geiger-Müller detectors and the ionization chambers in order to verify any residual radiation in the samples. The samples were also analyzed by gamma spectrometry by a Germanium detector. These tests were performed to determine small changes in the composition in the samples due to the radiation interaction. The results of this study may encourage the development of new research for alternative materials in dental restorations that can contribute to improve the quality of life of those patients with tumors of the mouth.
\end{abstract}




\section{ÍNDICE}

CAPITULO 1 INTRODUÇÂO ....................................................... 14

1.1 CONSIDERAÇÕES GERAIS........................................................... 14

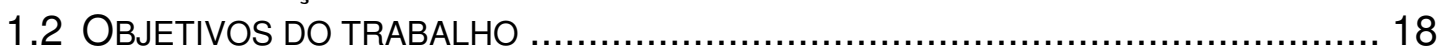

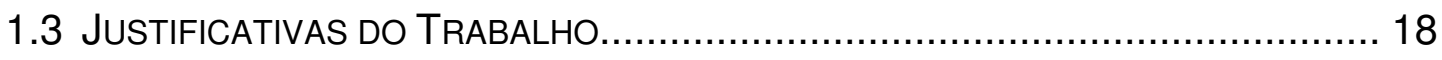

CAPITULO 2 MATERIAIS E MÉTODOS ..................................... 20

2.1 Materiais de RestauRaÇÃo DENTÁRIA .......................................... 20

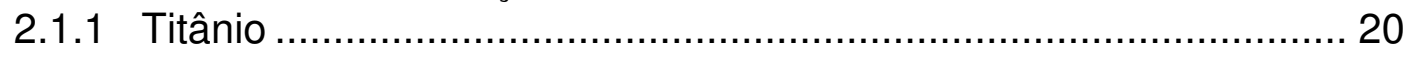

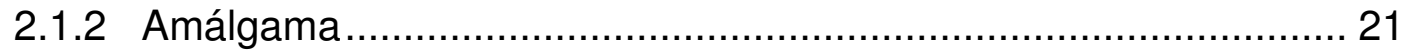

2.1.3 Resina Composta........................................................... 21

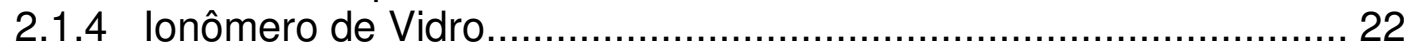

2.1.5 Compômero ......................................................................... 22

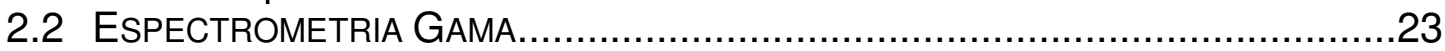

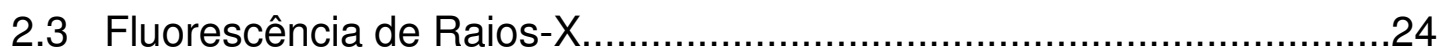

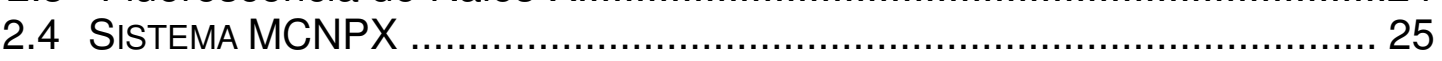

2.5 Confecção dos Corpos de Prova....................................................27

2.6 Métodos de Análise das Amostras................................................30

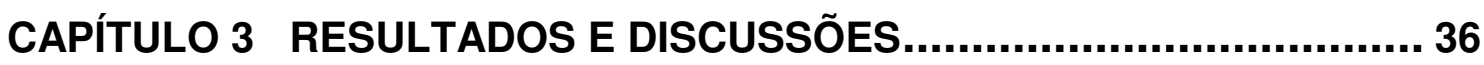

3.1 ANÁLISE DOS FOTO-PICOS ............................................................ 36

3.2 MEdIDAS DA DENSIDAdE DAS AMOSTRAS........................................... 47

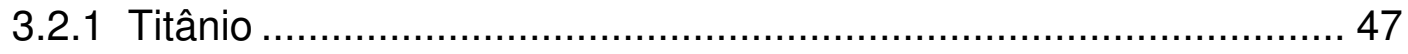

3.2.2 Amálgama.......................................................................... 49

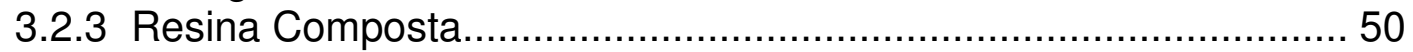

3.2.4 lonômero de Vidro................................................................. 52

3.3 ANÁLISE DA COMPOSIÇÃO QUÍMICA ................................................ 53

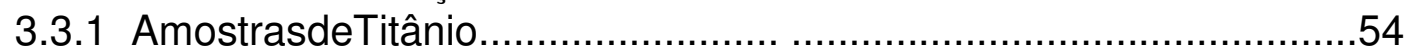

3.3.2 Amostras de Amálgama..................................................... 54

3.3.3 Amostras de Resina Composta ........................................... 55

3.3.4 AMOSTRAS DE IONÔMERO DE VIDRO...........................................56

3.3.5 Amostras Irradiadas com Cobalto - 60................................... 56

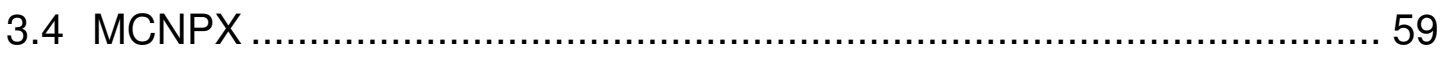

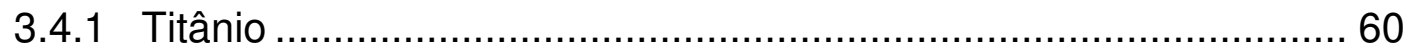

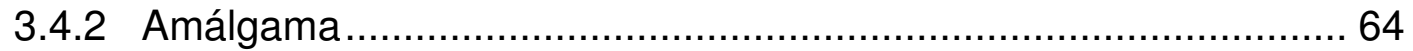

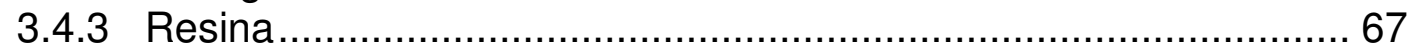

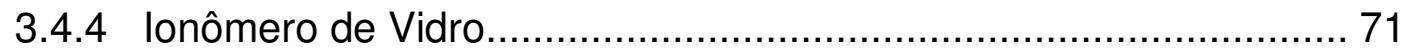

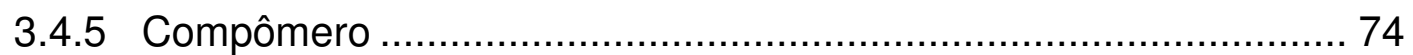

3.5 CÂMERA DE IONIZAÇÃO E DETECTOR GEIGER-MÜLLER...........................78

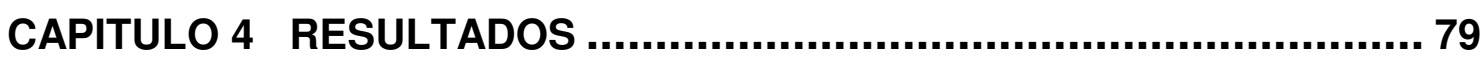

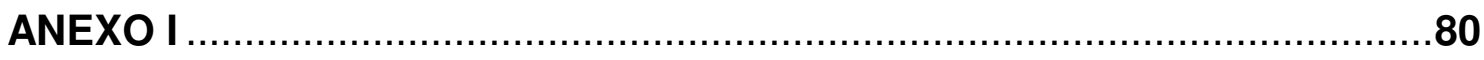

BIBLIOGRAFIA....................................................................... 84 


\section{Índice de Figuras}

FIGURA 1 - TIPOS DE CÂNCER MAIS INCIDENTES, ESTIMADOS PARA 2008, NA POPULAÇÃO

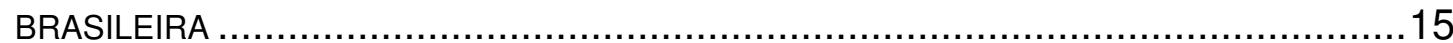

FIGURA 2 - ASPECTO BUCAL LOGO APÓS O TÉRMINO DA RADIOTERAPIA ...................16

FIGURA 3 - INÍCIO DO PROCESSO DE FORMAÇÃO DA CÁRIE POR RADIAÇÃO ................17

FIGURA 4 - OCORRÊNCIA COMPLETA DA CÁRIE............................................. 17

FIGURA 5 - NECROSE DA BASE DOS DENTES............................................... 17

FIGURA 6 - DESTRUIÇÃO DA REGIÃO GENGIVAL. ........................................... 17

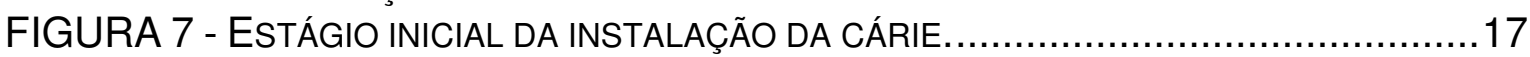

FIGURA 8 - DESTRUIÇÃO PARCIAL PELO AVANÇO DA CÁRIE.................................17

FIGURA 9 - DESTRUIÇÃO COMPLETA DOS DENTES. .......................................... 18

FIGURA 10 - DIAGRAMA DA ELETRÕNICA UTILIZADA PARA A ESPECTROMETRIA

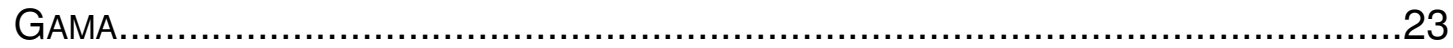

FIGURA 11 - CuRVA DE DECAIMENTO PARA O SISTEMA DE DETECÇÃo HPGE PARA a 6응

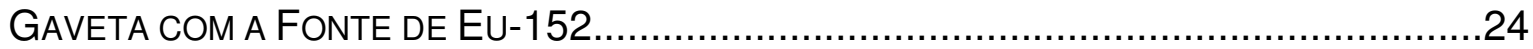

FIGURA 12 - ESQUEMA DA MONTAGEM EXPERIMENTAL.....................................25

FIGURA 13 - GEOMETRIA UTILIZADA PARA A SIMULAÇÃO COM O MCNPX, E A FIGURA DE

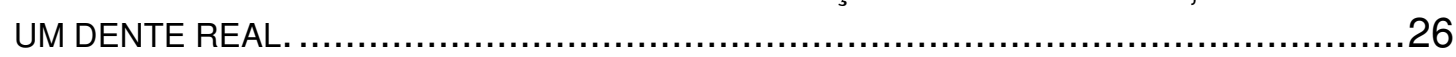

FIGURA 14 - MATERIAIS UTILIZADOS PARA A CONFECÇÃO DAS AMOSTRAS. ..................28

FIGURA 15 - POLIMENTO DA MATRIZ. ..................................................... 28

FIGURA 16 - RETIRADA DO MATERIAL COM O AUXÍLIO DA ESPÁTULA ...........................29

FIGURA 17 - MATERIAL SENDO COLOCADO NA MATRIZ. ........................................29

FIGURA 18 - FIXAÇÃO DO SUPORTE EM UMA PLACA DE VIDRO. .................................29

FIGURA 19 - INICIO DA FOTO FOTOPOLIMERIZAÇÃO.............................................29

FIGURA 20 - MATERIAL SENDO SUBMETIDO A FOTOPOLIMERIZAÇÃO. ......................29

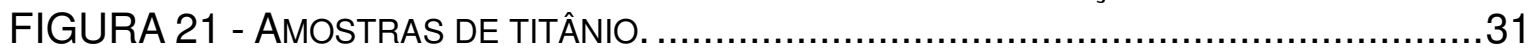

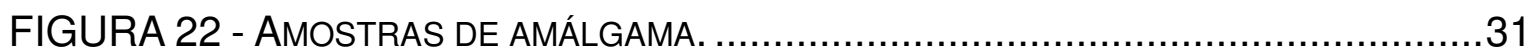

FIGURA 23 - AMOSTRAS DE RESINA COMPOSTA............................................... 31

FIGURA 24 - AMOSTRAS DE IONÔMERO DE VIDRO. .......................................... 31

FIGURA 25 - AMOSTRAS INSERIDAS EM UM PORTA AMOSTRAS PARA INICIO DA

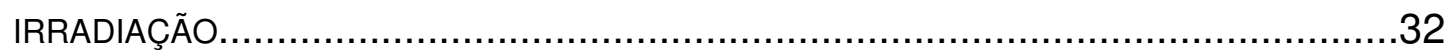

FIGURA 26 - AMOSTRAS POSICIONADAS PARA A IRRADIAÇÃO ...............................33

FIGURA 27 - ACELERADOR LINEAR E AS AMOSTRAS POSICIONADAS PARA IRRADIAÇÃO.33

FIGURA 28 - DETECTOR GEIGER MÜLLER.................................................. 33

FIGURA 29 - ELETRÔNICA DO DETECTOR DE GERMÂNIO HIPER - PURO (HPGE)..........34

FIGURA 30 - DETECTOR DE GERMÂNIO HIPER - PURO (HPGE) ...............................34

FIGURA 31 - PAQUÍMETRO UTILIZADO PARA MEDIR AS AMOSTRAS. ............................ 34

FIGURA 32 - BALANÇA UTILIZADA PARA PESAR AS AMOSTRAS. ............................. 34

FIGURA 33 - ESPECTRO DA AMOSTRA DE TITÂNIO SEM IRRADIAR. ...........................36

FIGURA 34 - ESPECTRO DA AMOSTRA DE TITÂNIO IRRADIADA COM 6 MV ....................37

FIGURA 35 - ESPECTRO DA AMOSTRA DE TITÂNIO IRRADIADA COM 10 MV .................37

FIGURA 36 - ESPECTROS SOBRE POSTOS DAS AMOSTRAS DE TITÂNIO SEM IRRADIAR E

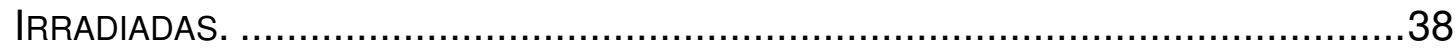

FIGURA 37 - ESPECTROS DA AMOSTRA DE AMÁLGAMA SEM IRRADIAR .......................38

FIGURA 38 - ESPECTROS DA AMOSTRA DE AMÁLGAMA IRRADIADA COM 6 MV .............39 
FIGURA 39 - ESPECTROS DAS AMOSTRAS DE AMÁLGAMA SEM IRRADIA E IRRADIADA...39 FIGURA 40 - ESPECTRO DA AMOSTRA DE RESINA COMPOSTA SEM IRRADIAR. ...........40 FIGURA 41 - ESPECTRO DA AMOSTRA DE RESINA COMPOSTA IRRADIADA COM 6 MV ...40 FIGURA 42 - ESPECTRO DAS AMOSTRAS DE RESINA COMPOSTA SEM IRRADIAR E IRRADIADA. .................................................................................. 41

FIGURA 43 - ESPECTRO DA AMOSTRA DE IONÔMERO DE VIDRO SEM IRRADIAR. ..........41

FIGURA 44 - ESPECTRO DA AMOSTRA DE IONÔMERO DE VIDRO IRRADIADA COM 6 MV.42 FIGURA 45 - ESPECTRO DAS AMOSTRAS DE IONÔMERO DE VIDRO SEM IRRADIAR E IRRADIADAS. .42

FIGURA 46 - ESPECTRO SOBRE POSTOS DE TODAS AS AMOSTRAS IRRADIADAS. .........43

FIGURA 47 - ESPECTRO SOBRE POSTOS DE TODAS AS AMOSTRAS SEM IRRADIAR. .......43

FIGURA 48 - ESPECTRO DA AMOSTRA DE RESINA COMPOSTA SEM IRRADIAR. ............44

FIGURA 49 - ESPECTRO DA AMOSTRA DE RESINA COMPOSTA IRRADIADA COM COBALTO $-60$.

FIGURA 50 - ESPECTRO SOBRE POSTOS DAS AMOSTRAS DE RESINA COMPOSTA SEM IRRADIAR E IRRADIADAS.

FIGURA 51 - ESPECTRO DA AMOSTRA DE AMÁLGAMA SEM IRRADIAR.......................45

FIGURA 52 - ESPECTRO DA AMOSTRA DE AMÁLGAMA IRRADIADA COM COBALTO - 60. .45

FIGURA 53 - ESPECTRO DAS AMOSTRAS DE AMÁLGAMA SEM IRRADIAR E IRRADIADA...45

FIGURA 54 - ESPECTRO DA AMOSTRA DE COMPÔMERO SEM IRRADIAR. ....................46

FIGURA 55 - ESPECTRO DA AMOSTRA DE COMPÔMERO IRRADIADA COM COBALTO - 60.

FIGURA 56 - ESPECTRO DAS AMOSTRAS DE COMPÔMERO SEM IRRADIAR E IRRADIADAS.

FIGURA 57 - ESPECTRO DE TODAS AS AMOSTRAS IRRADIADAS.

FIGURA 58 - QUANTIDADE DE FÓTON ABSORVIDO NAS CAMADAS DO DENTE COM IRRADIAÇÃO DE 6 MV PARA O TITÂNIO............................................................60

FIGURA 59 - QUANTIDADE DE ElÉTRON ABSORVIDO NAS CAMADAS DO DENTE COM IRRADIAÇÃO DE 6 MV PARA O TITÂNIO................................................................61

FIGURA 60 - QUANTIDADE DE FÓtON ABSORVIDO NAS CAMADAS DO DENTE COM

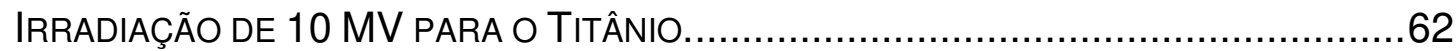

FIGURA 61 - QUANTIDADE DE ELÉTRON ABSORVIDO NAS CAMADAS DO DENTE COM

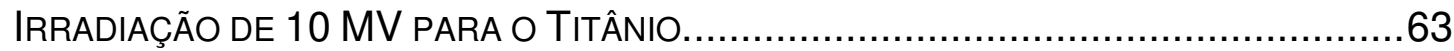

FIGURA 62 - QUANTIDADE DE FÓTON ABSORVIDO NAS CAMADAS DO DENTE COM

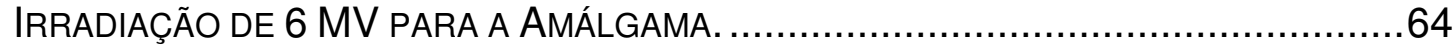

FIGURA 63 - QUANTIDADE DE ELÉTRON ABSORVIDO NAS CAMADAS DO DENTE COM

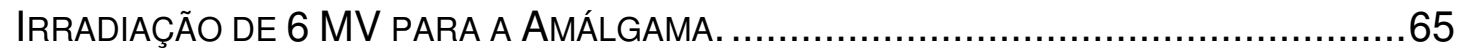

FIGURA 64 - QUANTIDADE DE FÓTON ABSORVIDO NAS CAMADAS DO DENTE COM

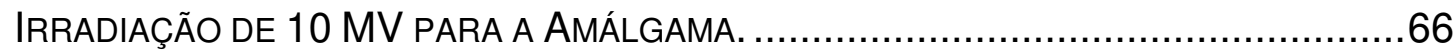

FIGURA 65 - QUANTIDADE DE ELÉTRON ABSORVIDO NAS CAMADAS DO DENTE COM

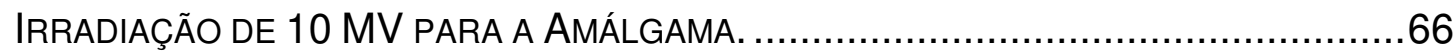

FIGURA 66 - QUANTIDADE DE FÓtON ABSORVIDO NAS CAMADAS DO DENTE COM IRRADIAÇÃO DE 6 MV PARA A RESINA COMPOSTA...........................................68

FIGURA 67 - QUANTIDADE DE ELÉTRON ABSORVIDO NAS CAMADAS DO DENTE COM IRRADIAÇÃO DE 6 MV PARA A RESINA COMPOSTA. 
FIGURA 68 - QUANTIDADE DE FÓtON ABSORVIDO NAS CAMADAS DO DENTE COM IRRADIAÇÃO DE 10 MV PARA A RESINA COMPOSTA........................................69

FIGURA 69 - QUANTIDADE DE ELÉTRON ABSORVIDO NAS CAMADAS DO DENTE COM IRRADIAÇÃO DE 10 MV PARA A RESINA COMPOSTA.........................................70

FIGURA 70 - QUANTIDADE DE FÓTON ABSORVIDO NAS CAMADAS DO DENTE COM IRRADIAÇÃO DE 6 MV PARA O IONÔMERO DE VIDRO.............................................71

FIGURA 71 - QUANTIDADE DE ElÉtRON ABSORVIDO NAS CAMADAS DO DENTE COM IRRADIAÇÃO DE 6 MV PARA O IONÔMERO DE VIDRO........................................72

FIGURA 72 - QUANTIDADE DE FÓTON ABSORVIDO NAS CAMADAS DO DENTE COM IRRADIAÇÃO DE 10 MV PARA O IONÔMERO DE VIDRO.......................................73

FIGURA 73 - QUANTIDADE DE ELÉTRON ABSORVIDO NAS CAMADAS DO DENTE COM IRRADIAÇÃO DE 10 MV PARA O IONÔMERO DE VIDRO......................................73

FIGURA 74 - QUANTIDADE DE FÓTON ABSORVIDO NAS CAMADAS DO DENTE COM IRRADIAÇÃO DE 6 MV PARA O COMPÔMERO..................................................75

FIGURA 75 - QUANTIDADE DE ELÉTRON ABSORVIDO NAS CAMADAS DO DENTE COM IRRADIAÇÃO DE 6 MV PARA O COMPÔMERO....................................................75

FIGURA 76 - QUANTIDADE DE FÓTON ABSORVIDO NAS CAMADAS DO DENTE COM IRRADIAÇÃO DE 10 MV PARA O COMPÔMERO..................................................76

FIGURA 77 - QUANTIDADE DE FÓTON ABSORVIDO NAS CAMADAS DO DENTE COM IRRADIAÇÃO DE 10 MV PARA O COMPÔMERO..................................................77 


\section{Índice de Tabelas}

TABELA 1 - QUADRO ILUSTRATIVO DO TIPO, GRUPO E QUANTIDADE DE AMOSTRAS........32

TABELA 2 - AMOSTRAS DE TITÂNIO ANTES DA IRRADIAÇÃO. ......................................36

TABELA 3 - AMOSTRAS DE TITÂNIO APÓS IRRADIAÇÃO (10 MV)................................37

TABELA 4 - AMOSTRAS DE TITÂNIO APÓS IRRADIAÇÃO (6 MV)..................................38

TABELA 5 - AMOSTRAS DE AMÁLGAMA ANTES DA IRRADIAÇÃO .................................38

TABELA 6 - AMOSTRAS DE AMÁLGAMA APÓS IRRADIAÇÃO (6 MV) ..............................39

TABELA 7 - AMOSTRAS DE RESINA ANTES DA IRRADIAÇÃO....................................40

TABELA 8 - AMOSTRAS DE RESINA APÓS IRRADIAÇÃO (6 MV)..............................4

TABELA 9 - AMOSTRAS DE IONÔMERO DE VIDRO ANTES DA IRRADIAÇÃO......................41

TABELA 10 - AMOSTRAS DE IONÔMERO DE VIDRO APÓS IRRADIAÇÃO (6 MV)...............42

TABELA 11 - DENSIDADE DAS AMOSTRAS DE TITÂNIO ANTES DA IRRADIAÇÃO. ……......47

TABELA 12 - DENSIDADE DAS AMOSTRAS DE TITÂNIO APÓS IRRADIAÇÃO (6 MV).......48

TABELA 13 - DENSIDADE DAS AMOSTRAS DE TITÂNIO APÓS IRRADIAÇÃO (10 MV).....48

TABELA 14 - DENSIDADE DAS AMOSTRAS DE AMÁlgamA ANTES DA IRRADIAÇÃO. ........49

TABELA 15 - DenSIDADE dAS AmOStRAS de Amálgama Após IRRADIAÇÃo (6MV) ....50

TABELA 16 - DeNSIDADE DAS AMOSTRAS DE RESINA COMPOSTA ANTES DA IRRADIAÇÃO.

tABELA 17 - Densidade das amostras de Resina Composta Após IrRadiaÇão

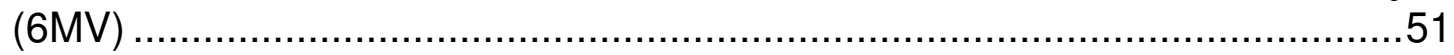

TABELA 18 - DENSIDADE dAS AMOSTRAS DE IONÔMERO DE VIDRO ANTES DA

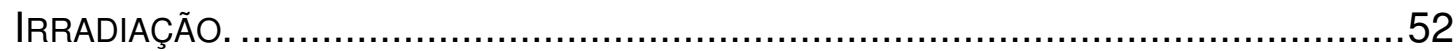

TABELA 19 - DENSIDADE DAS AMOSTRAS DE IONÔMERO DE VIDRO APÓS IRRADIAÇÃO. $(6 \mathrm{MV})$

TABELA 20 - COMPOSIÇÃO QUÍMICA DAS AMOSTRAS DE TITÂNIO. ………………......54

TABELA 21 - COMPOSIÇÃO QUÍMICA DAS AMOSTRAS DE AMÁLGAMA..........................54

TABELA 22 - COMPOSIÇÃO QUÍMICA DAS AMOSTRAS DE RESINA COMPOSTA. .............55

TABELA 23 - COMPOSIÇÃO QUÍMICA DAS AMOSTRAS DE IONÔMERO DE VIDRO..............56

TABELA 24 - COMPOSIÇÃO QUímICA dAS AMOStRAS de Amálgama IRRADIADAS

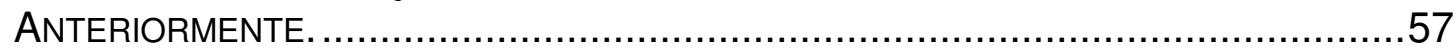

TABELA 25 - COMPOSIÇÃo QUímica dAs AMOStRAs de RESINA COMPOSTA

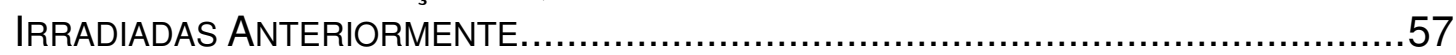

TABELA 26 - COMPOSIÇÃO QUÍMICA DAS AMOSTRAS DE COMPÔMERO IRRADIADAS

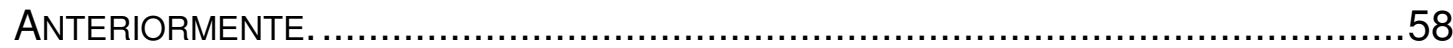

TABELA 27 - QUANTIDADE DE FÓTON ABSORVIDO PARA ENERGIA DE 6 MV PARA O

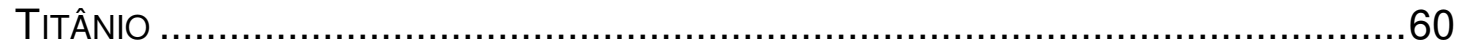

TABELA 28 - QUANTIDADE DE ElÉTRON ABSORVIDO PARA ENERGIA DE 6 MV PARA O

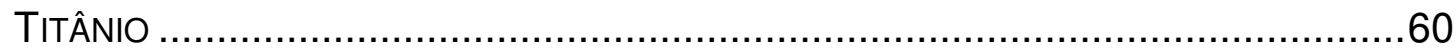

TABELA 29 - QUANTIDADE DE FÓtON ABSORVIDO PARA ENERGIA DE 10 MV PARA O

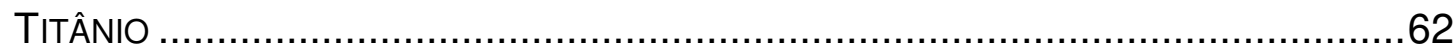

TABELA 30 - QUANTIDADE DE ELÉTRON ABSORVIDO PARA ENERGIA DE 6 MV PARA O TITÂNIO

TABELA 31 - QUANTIDADE DE FótON ABSORVIDO PARA ENERGIA DE 6 MV PARA A AMÁLGAMA. 
TABELA 32 - QuANTIDADE de ElÉtron ABSORVIDO PARA ENERGIA DE 6 MV PARA A AMÁLGAMA. 64

TABELA 33 - QUANTIDADE DE FÓTON ABSORVIDO PARA ENERGIA DE 10 MV PARA A

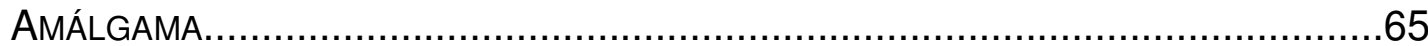

TABELA 34 - QUANTIDADE DE ELÉTRON ABSORVIDO PARA ENERGIA DE 6 MV PARA A AMÁLGAMA. 66

TABELA 35 - QUANTIDADE DE FótON ABSORVIDO PARA ENERGIA DE 6 MV PARA A

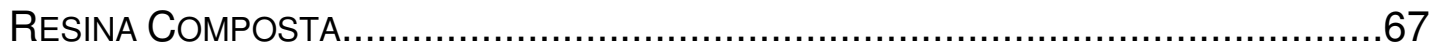

TABELA 36 - QUANTIDADE DE ELÉTRON ABSORVIDO PARA ENERGIA DE 6 MV PARA A

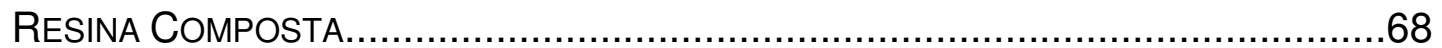

TABELA 37 - QUANTIDADE DE FÓTON ABSORVIDO PARA ENERGIA DE 10 MV PARA A RESINA COMPOSTA......................................................................

TABELA 38 - QUANTIDADE DE ElÉTRON ABSORVIDO PARA ENERGIA DE 10 MV PARA A RESINA COMPOSTA......................................................................

TABELA 39 - QUANTIDADE DE FÓTON ABSORVIDO PARA ENERGIA DE 6 MV PARA O IONÔMERO DE VIDRO.............................................................................

TABELA 40 - QuANTIDADE DE ELÉTRON ABSORVIDO PARA ENERGIA DE 6 MV PARA O IONÔMERO DE VIDRO...................................................................... 71

TABELA 41 - QUANTIDADE DE FÓtON ABSORVIDO PARA ENERGIA DE 10 MV PARA O IONÔMERO DE VIDRO...........................................................................72

TABELA 42 - QUANTIDADE DE ELÉTRON ABSORVIDO PARA ENERGIA DE 10 MV PARA O IONÔMERO DE VIDRO....................................................................

TABELA 43 - QUANTIDADE DE FÓTON ABSORVIDO PARA ENERGIA DE 6 MV PARA O COMPÔMERO...................................................................... 74

TABELA 44 - QUANTIDADE DE ELÉTRON ABSORVIDO PARA ENERGIA DE 6 MV PARA O

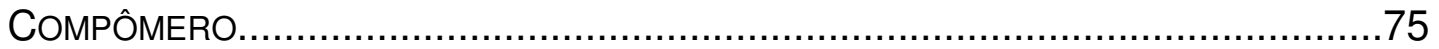

TABELA 45 - QUANTIDADE DE FÓtON ABSORVIDO PARA ENERGIA DE 10 MV PARA O COMPÔMERO......................................................................... 76

TABELA 46 - QUANTIDADE DE ELÉTRON ABSORVIDO PARA ENERGIA DE 10 MV PARA O COMPÔMERO 


\section{CAPITULO 1 INTRODUÇÃO}

\subsection{Considerações Gerais}

O Brasil enfrenta atualmente um grande desafio no controle do Câncer, pois sendo a segunda causa de morte por doença, pesquisas mostram um elevado desenvolvimento da doença ao longo dos anos ${ }^{1}$.

Em todo o mundo, o avanço da doença causa preocupações aos órgãos públicos e alerta as pessoas. No ano de 2005, o mundo teve um total de 58 milhões de mortes e dessas, 7,6 milhões foram ocasionadas pelo câncer, representando um total de $13 \%$ das mortes mundiais. Pesquisas mostram que em 2020 o número de casos anuais podem chegar a 15 milhões, e sua maior concentração se dará em países em desenvolvimento ${ }^{2}$.

No Brasil, espera-se que até 2009 serão registrados mais 466.730 novos casos de câncer, sendo esses mais de 14.000 na Cavidade Oral ${ }^{34} 5$. 


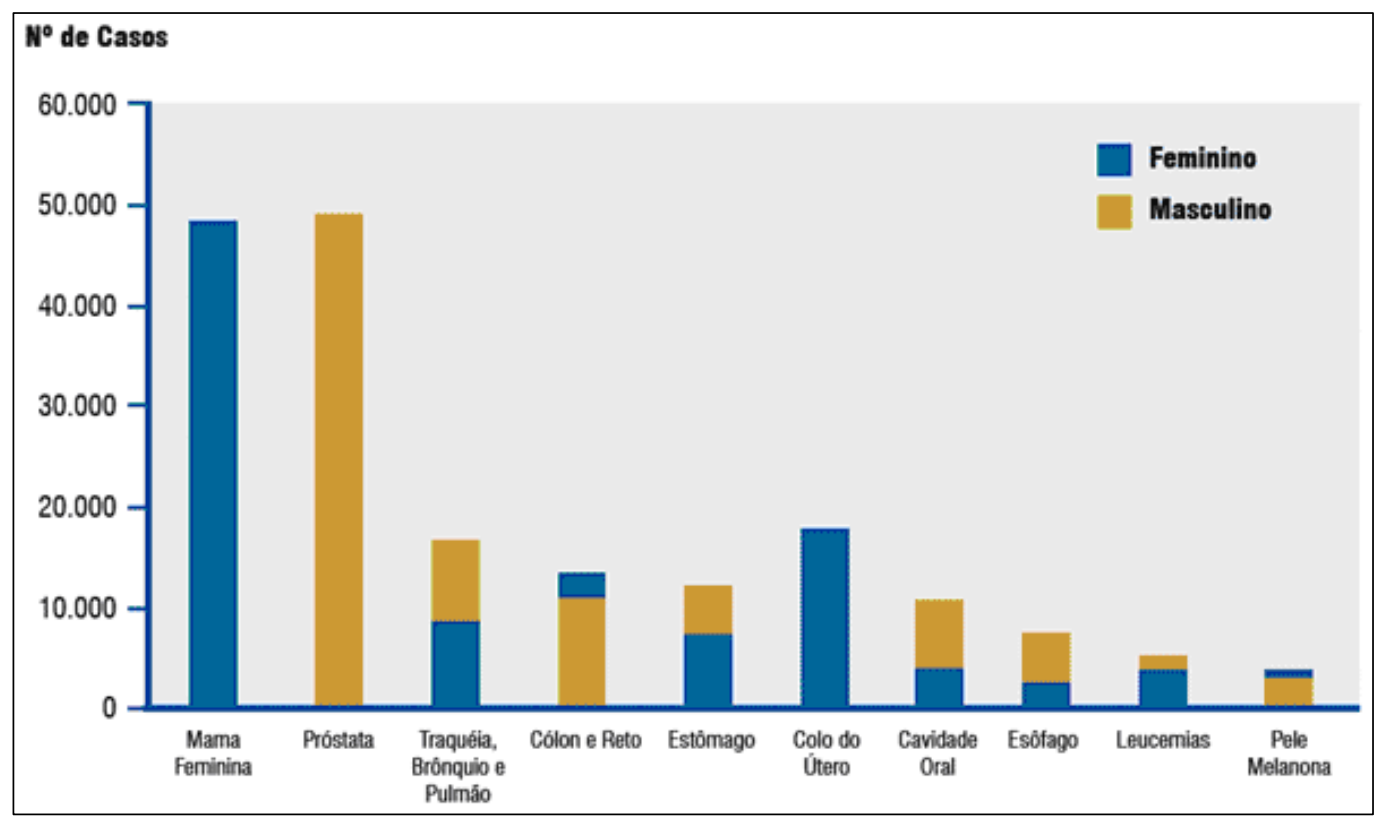

FIGURA 1 - Tipos de câncer mais incidentes, estimados para 2008, na população brasileira FONTE: MS/Instituto Nacional de Câncer - INCA

A incidência de tumores de cabeça e pescoço, ocupa lugar de destaque na base de dados do Instituto Nacional do Câncer (INCa) ${ }^{6}$. O tratamento preconizado para este tipo de doença é a cirurgia seguida de radioterapia e quimioterapia ${ }^{7}$.

Durante a realização da radioterapia com feixes externos (teleterapia), o paciente é submetido à radiação em um volume alvo que corresponde a grande parte da cavidade bucal, atingindo as glândulas salivares e toda a arcada dentária.

Além dos efeitos antitumorais, a radiação ionizante também causa danos nos tecidos normais localizados nos campo de radiação, provocando efeitos colaterais indesejáveis ${ }^{8}$. Os principais efeitos secundários da radioterapia em cabeça e pescoço estão divididos em efeitos agudos e efeitos crônicos. Os efeitos agudos de maior importância são: candidose, radiodermite, disgeusia, mucosite, xerostomia e alteração do paladar ${ }^{9}$. Os efeitos crônicos mais relevantes são: cárie de radiação, necrose do tecido mole, osteorradionecroce e trismo muscular 1011 
Apesar de terem sido desenvolvidos complexos protocolos para minimizar ou controlar as seqüelas orais agudas e crônicas, as conseqüências dos danos nas glândulas salivares e outras seqüelas orais ainda permanecem difíceis de controlar.

Estudos odontológicos correlacionam o surgimento de cáries em pacientes submetidos à radioterapia. A cárie por radiação apresenta aspectos diferenciados e sua evolução é rápida e geralmente indolor, podendo ocorrer após três meses do término da radioterapia. Ela afeta todas as superfícies dentais e está associada à xerostomia e às alterações de hábitos alimentares ${ }^{12}$.

Atualmente, as técnicas de prevenção de cárie por radiação constituem em aplicação tópica de flúor, bochechos com substâncias fluoretadas e uso de creme dental fluoretado ${ }^{1314}$. Uma vez estabelecida a cárie por radiação, o tratamento se resume na restauração com materiais fluoretados, amputação das coroas dentais e confecção de próteses ${ }^{15} 16$. Nestes casos os doentes são submetidos a terapias alternativas, mas somente com a finalidade paliativa de alívio dos sintomas. Por esta razão, alguns especialistas recomendam a extração dos dentes antes do paciente ser submetido à radioterapia ${ }^{17}$.

Desta forma é de fundamental importância estudos que analisam os verdadeiros efeitos da radiação sobre a dentição humana e que procurem desenvolver alternativas para amenizar ou mesmo eliminar os efeitos deletérios da radioterapia em pacientes de tumores da boca ${ }^{18}$.

As Figuras 2 a 9 ilustram a ocorrência e a evolução da cárie por radiação em um indivíduo submetido à radioterapia de cabeça e pescoço.

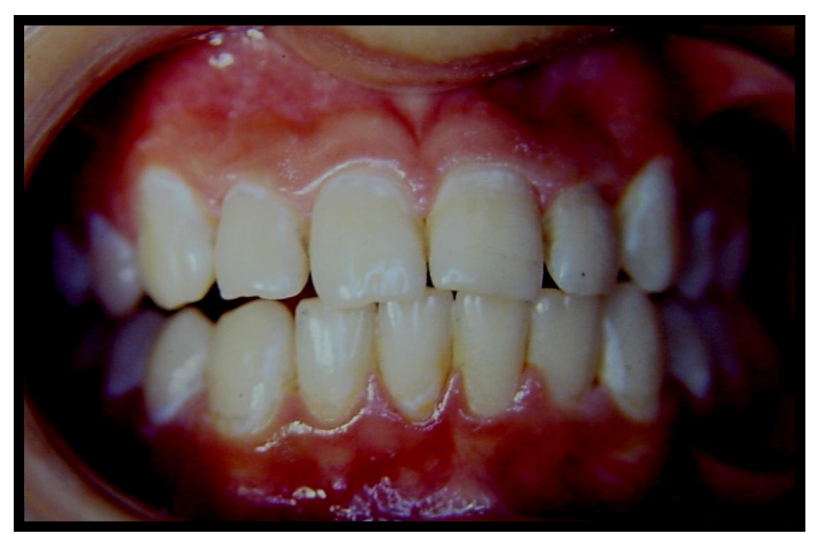

FIGURA 2 - Aspecto bucal logo após o término da radioterapia 
As Figuras 3, 4, 5 e 6 apresentam o aspecto bucal já totalmente comprometido com a instalação de cárie por radiação com áreas de amputação e necrose da base dos dentes. As Figuras 7, 8 e 9 mostram os resultados dos exames radiográficos realçando o avanço da cárie por radiação e a destruição dos dentes e regiões ósseas da arcada dentária.

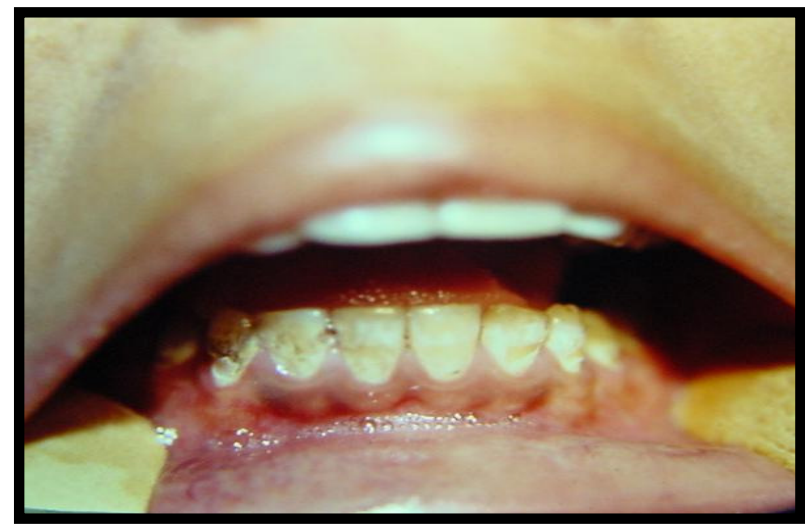

FIGURA 3 - Início do processo de formação da cárie por radiação

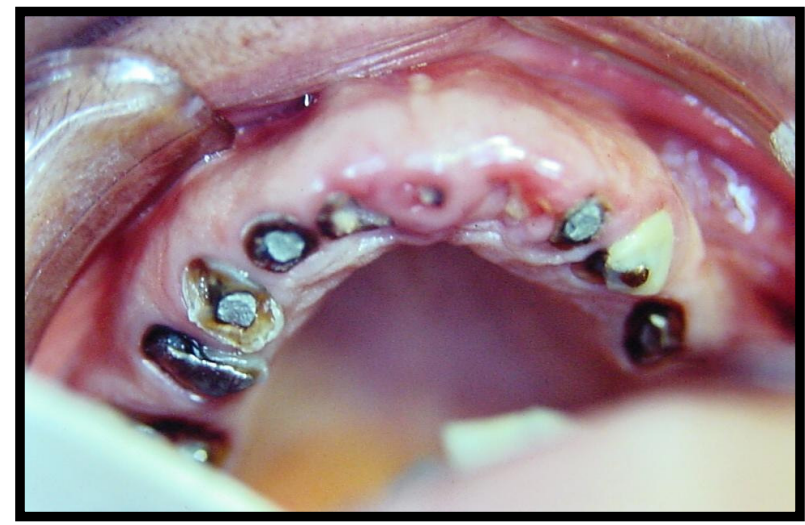

FIGURA 5 - Necrose da base dos dentes

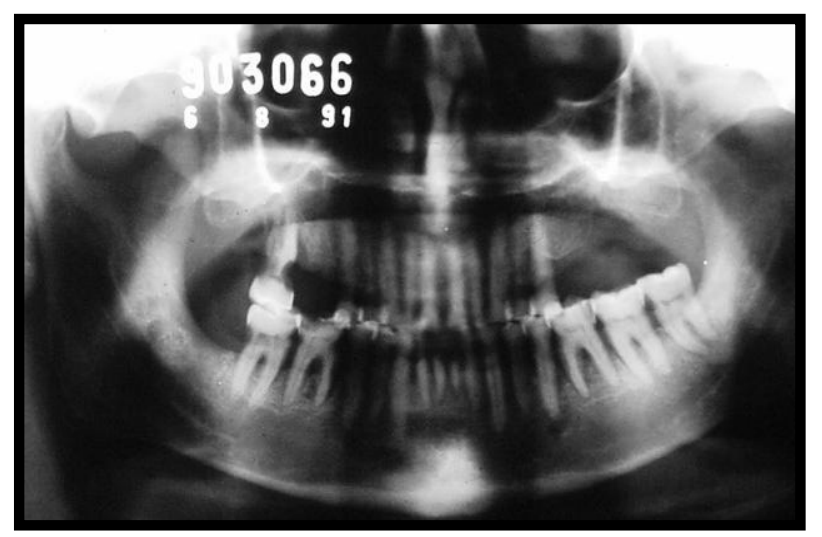

FIGURA 7 - Estágio inicial da instalação da cárie

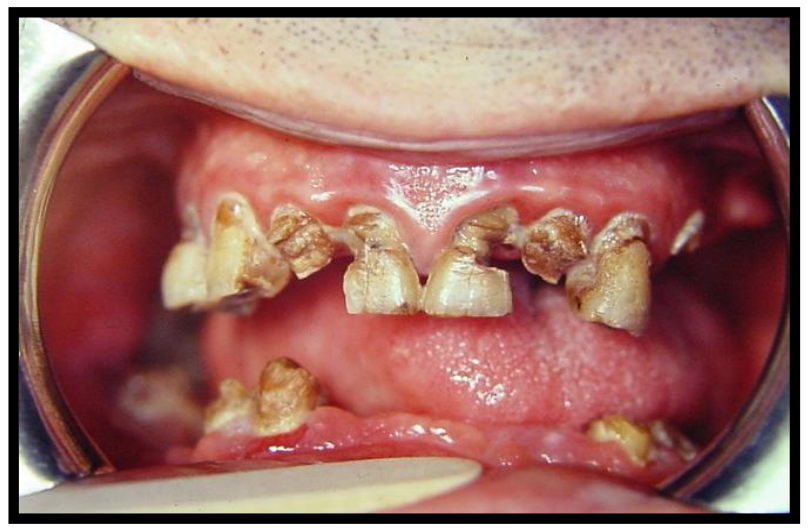

FIGURA 4 - Ocorrência completa da cárie

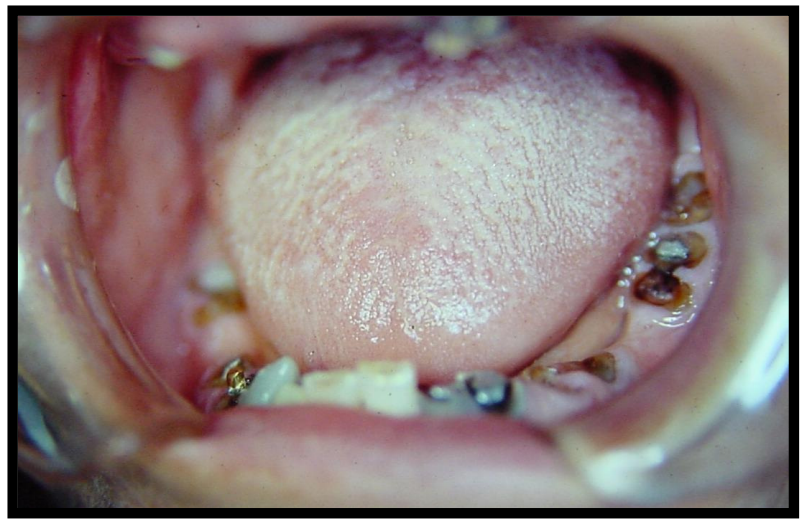

FIGURA 6 - Destruição da região gengival

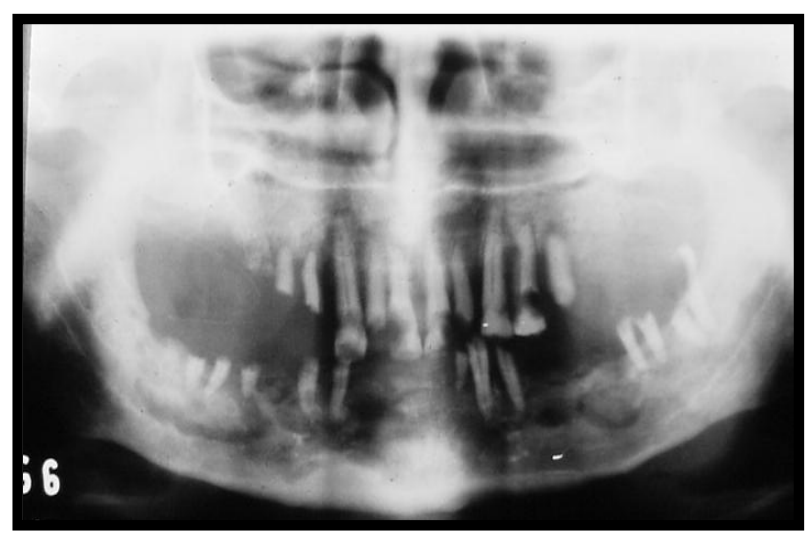

FIGURA 8 - Destruição parcial pelo avanço da cárie 


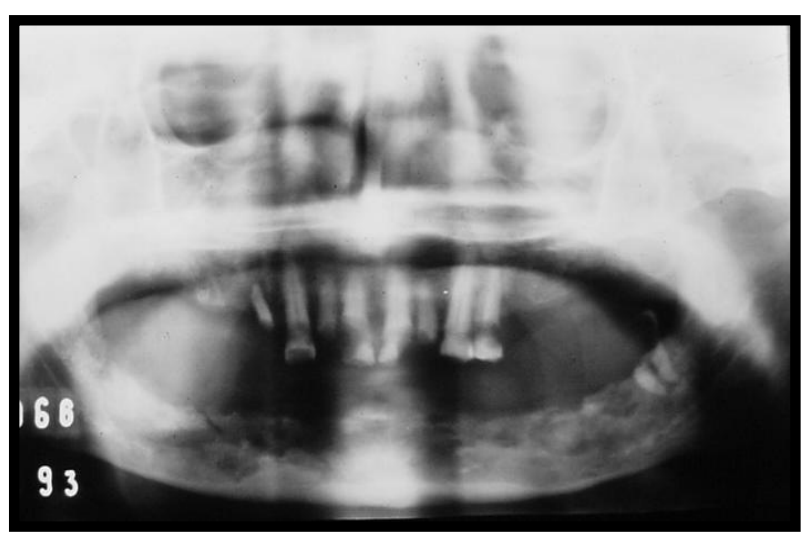

FIGURA 9 - Destruição completa dos dentes

\subsection{Objetivos do trabalho}

O objetivo deste trabalho é estudar as alterações nas características físicas e composição química de materiais utilizados em restaurações dentárias: Titânio, Amalgama, Compômero, Resina Composta e lonômero de Vidro, devido a exposição à radiação $\mathrm{X}$ de 6,0 Mega-Volt (MV) de energia produzida em um acelerador linear, de uso freqüente em radioterapia de tumores de cabeça e pescoço ${ }^{1920}$.

\subsection{Justificativas do Trabalho}

Mundialmente, os cânceres da cabeça e pescoço, correspondem a 10\% dos tumores malignos e aproximadamente $40 \%$ dos cânceres dessa localização ocorrem na cavidade oral ${ }^{2122} 23$. O câncer da cavidade oral ocupa $07^{0}$ lugar (14160 casos estimados para o ano de 2009) em incidências comparado com todos os outros tipos de câncer no Brasil, correspondendo ao 6ำ lugar no número de óbitos (3245 óbitos). Estes números estão entre os mais altos do continente americano, embora tais coeficientes estejam bem abaixo das áreas de maior incidência no mundo a exemplo da Índia, França e áreas da Oceania. Dados com base em registros hospitalares identificam o câncer da cavidade oral como o quinto mais freqüente em homens e o sétimo em mulheres no país.

Dados relevantes mostraram que a detecção precoce do câncer de boca permite uma sobrevida de 5 anos em 90\% dos casos, mas infelizmente, hoje em dia $60 \%$ desses tumores são rastreados em estágios avançados com uma taxa de sobrevida de 5 anos em $50 \%$ dos casos, sendo estes submetidos a 
tratamentos bastantes invasivos, seja ele cirúrgico, radioterápico, quimioterápico, bem como a associação destes, trazendo como conseqüência complicações pós tratamento.

Os efeitos deletérios da radioterapia, anteriormente explanados, dentre outras conseqüências, provocam dor para engolir e perda de apetite, intensificando o sofrimento dos pacientes oncológicos, que já se apresentam imunodeprimidos pela própria ocorrência da doença ${ }^{24} 25$. A incidência, bem como o avanço do estágio clínico da doença está relacionada com a população de mais baixa renda econômica, os quais são assistidos pelo Sistema Único de Saúde (SUS) e assim sem condições de atendimentos preventivos e de suporte oferecido aqueles de poder aquisitivo mais abastado ${ }^{26}$.

O trabalho multidisciplinar dos especialistas (médico radioterapêuta, físicomédico, cirurgião dentista, enfermeiro, psicólogo e nutricionista) tem como objetivo maior elevar a qualidade de vida do paciente, que já sofreu um impacto social e psicológico muito grande ${ }^{27} 28$. A qualidade de vida compreende dois fatores: a capacidade de realizar todas as atividades rotineiras, que refletem no bem estar físico, psicológico e social; e a satisfação do paciente com o controle da doença e/ou a diminuição dos sintomas. Para isso, se faz necessário uma rigorosa avaliação odontológica previamente à terapêutica escolhida e rigoroso acompanhamento posteriormente ${ }^{29}$.

Um dos procedimentos realizados previamente a radioterapia é a restauração das lesões cariosas com amálgama de prata, no entanto, estudos indicam alterações na mucosa adjacente às restaurações metálicas ${ }^{30} 31$ devido a incidência do feixe de radiação. 


\section{CAPITULO 2 MATERIAIS E MÉTODOS}

\subsection{Materiais de Restauração Dentária}

Os materiais analisados são utilizados na odontologia como restauradores, todos tem como finalidade restaurar a função, integridade e morfologia da estrutura do dente.

O Titânio é utilizado em restaurações de estruturas ausentes nos dentes ou ossos, os implantes dentários.

Os demais materiais (Amálgama, Resina Composta, lonômero de Vidro e Compômero) são utilizados em restaurações reparadoras, causadas por cáries ou traumas externos.

\subsubsection{Titânio}

A composição química do Titânio possui basicamente $0,03 \%$ de Nitrogênio, 0,08\% de Carbono, 0,015\% de Hidrogênio, 0,30\% de Ferro, 0,25\% de Oxigênio e cerca de $50 \%$ de Titânio. Foi descoberto em 1791, por William Gregor e recentemente vem sendo utilizado na odontologia como substituto do ouro em prótese dentária.

O Titânio apresenta alta resistência à corrosão, boas propriedades físicas e mecânicas e uma excelente biocompatibilidade, baixo peso específico, baixa condutibilidade térmica, e ausência de potencial alérgico, tornando-o assim um material amplamente utilizado em implantodontia e cirurgia ortognática.

Porém, por ser um material de difícil fundição, o que acaba resultando na ocorrência de porosidade e fundições incompletas, e possuir um custo elevado de equipamentos para a realização deste processo, possui limitações e um restrito alcance social ${ }^{32} 33$. 


\subsubsection{Amálgama}

O Amálgama de prata é o material mais antigo e comum para a realização de restaurações de dentes posteriores, sua composição mais comumente usada é $23 \%$ de prata, $15 \%$ de estanho e $8 \%$ de cobre e $54 \%$ de Mercúrio.

Foi descoberto em 1826, por Taveu, e sua composição inicial era apenas prata e mercúrio, onde a matéria prima empregada era a moeda de prata, que continha uma liga de prata e cobre.

Estudos ao decorrer dos séculos implantaram melhorias e descobriram quais eram as melhores maneiras de manipular o trabalho com o mercúrio para que seja possível evitar a contaminação em pacientes e nos consultórios odontológicos ${ }^{34} 3536$.

Atualmente, esse material é bastante utilizado pelos dentistas em razão do seu baixo custo, facilidade técnica, resistência ao desgaste e selamento marginal, porém pela presença do mercúrio e outros metais pesados, além da falta de estética existe uma crescente resistência ao seu uso ${ }^{37} 38$.

\subsubsection{Resina Composta}

Os elementos mais abundantes na Resina Composta, são: 40,1\% de silício, $33,1 \%$ de oxigênio e $24,2 \%$ de zircônio.

As Resinas Compostas foram desenvolvidas por Bown, na década de sessenta e proporcionaram uma revolução nos materiais restaurados, preenchendo uma lacuna existente com relação a um material estético utilizável em dentes anteriores com grandes perdas estruturais ${ }^{39} 40$.

Com o passar dos anos, foram se desenvolvendo técnicas e subsídios que tornaram as resinas mais resistentes ao desgaste, maior facilidade de manuseio, inserção ou condensação nos preparativos. Os desenvolvimentos de sistemas adesivos dentinários contribuíram para tornar o uso de resinas compostas em dentes posteriores uma prática rotineira ${ }^{4142}$. 


\subsection{4 lonômero de Vidro}

Em 1972, Wilson \& Kent, introduziram na Odontologia um material restaurador: o lonômero de Vidro, que se mostrou eficaz nas restaurações dentárias passando a ocupar um espaço cada vez maior dentro da Odontologia. Desde sua criação, ele vem sendo aperfeiçoado e amplamente utilizado. Os principais elementos químicos do lonômero de Vidro são: 26\% de alumínio, $36,7 \%$ de silício e $36,6 \%$ de estrôncio.

Por ainda estar em desenvolvimento, possui alta fragilidade, com baixa resistência a tração e ao cisalhamento, além de apresentar insuficiente translucidez.

Atualmente, esse material tem grande desenvolvimento na odontologia. O ionômero de vidro é o material com maior potencial de utilização, devido as suas características, propriedades e diversas utilizações ${ }^{43} 4$.

\subsubsection{Compômero}

O Compômero, tem como principais componentes de sua estrutura química 34,9\% de estrôncio, 29,0\% oxigênio, 15,7\% de silício, 8,6\% de alumínio e 6,6\% de flúor. Sua descoberta se deu em 1993, com a intenção de melhorar algumas propriedades dos cimentos de lonômero de Vidro modificados pela resina.

É um material de fácil uso, com boas propriedades físicas, estético e apto a liberar flúor ${ }^{45}$ mas, deixa a desejar em sua dureza e desgaste superficial ${ }^{47}$.

Os Compômeros apresentam bons resultados clínicos para restauração de dentes decíduos posteriores ${ }^{48}$. Sua performance em combinações de cores, integridade marginal e forma anatômica é comparável à da última geração de resinas compostas híbridas convencionais. Entretanto, sua performance clínica na descoloração marginal e no desgaste é inferior à das resinas compostas.

O Compômero é um material alternativo ao uso de resinas e ionômeros, podendo oferecer excelentes resultados clínicos, quando utilizado conforme suas indicações, levando-se em conta suas propriedades e limitações. 
Apesar da ampla indicação dos Compômeros nas diversas situações clínicas, seu uso está sendo gradativamente substituído por outros materiais de restauração com melhores propriedades e que apresentaram melhores resultados clínicos ${ }^{49}$.

\subsection{Espectrometria Gama}

Espectrometria gama é um sistema composto de um detector tipo Germânio Hiper - puro (HPGe), eletrônica associada e o software Maestro 3.2 ORTEC desenvolvido pelo fabricante dos equipamentos.

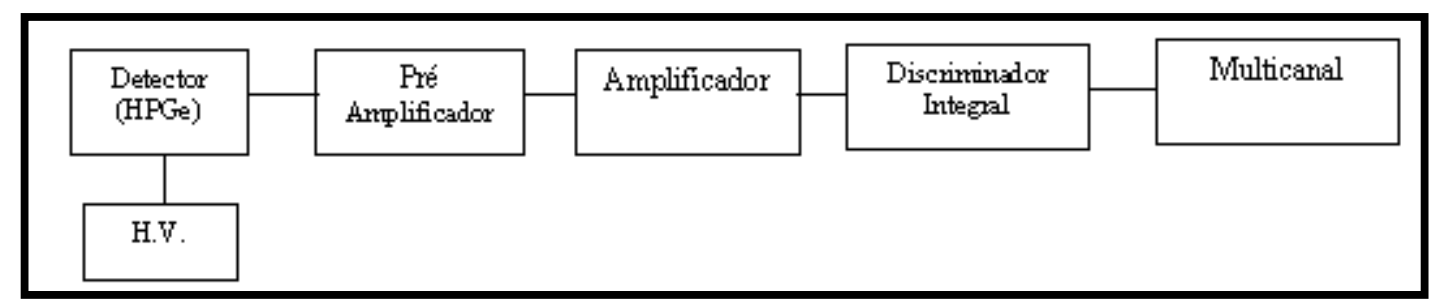

Figura 10: Diagrama da eletrônica utilizada para a espectrometria gama

No diagrama acima a função de cada dispositivo é:

a) Alta tensão (H.V.): polariza o detector reversamente aumentando a região de depleção do detector.

b) Detector semicondutor de Germânio Hiper - puro (HPGe).

c) Pré-Amplificador: Amplia o sinal para que este possa ser transmitido pelo cabeamento.

d) Amplificador: Amplia o sinal que vem do pré-amplificador.

e) Discriminador integral: Elimina o ruído eletrônico.

f) Multicanal: Registra a contagem da radiação com uma determinada energia em um canal.

O detector de Germânio Hiper-puro (HPGe), foi calibrado em energia, tendo sua curva de eficiência global obtida a partir de uma fonte padrão de Eu - 152.

A distância utilizada para a espectrometria gama do suporte contendo a amostra foi de aproximadamente $5,9 \mathrm{~cm}$ do detector, que corresponde a $6^{\circ}$ gaveta no castelo de chumbo do sistema do detector HPGe. O tempo de espera para o inicio da contagem foi de uma semana (7 dias) após o término da irradiação. 
Os espectros foram obtidos no programa Maestro e a partir daí foi possível determinar quais os elementos de cada amostra. Com o auxílio do programa Origin Graph, os espectros visualizados no programa Maestro, foram transformados em gráficos, onde foi possível visualizar a quantidade de canal em cada espectro.

A eficiência do detector de Germânio Hiper-puro para a 6ํㅗ gaveta está representado a baixo.

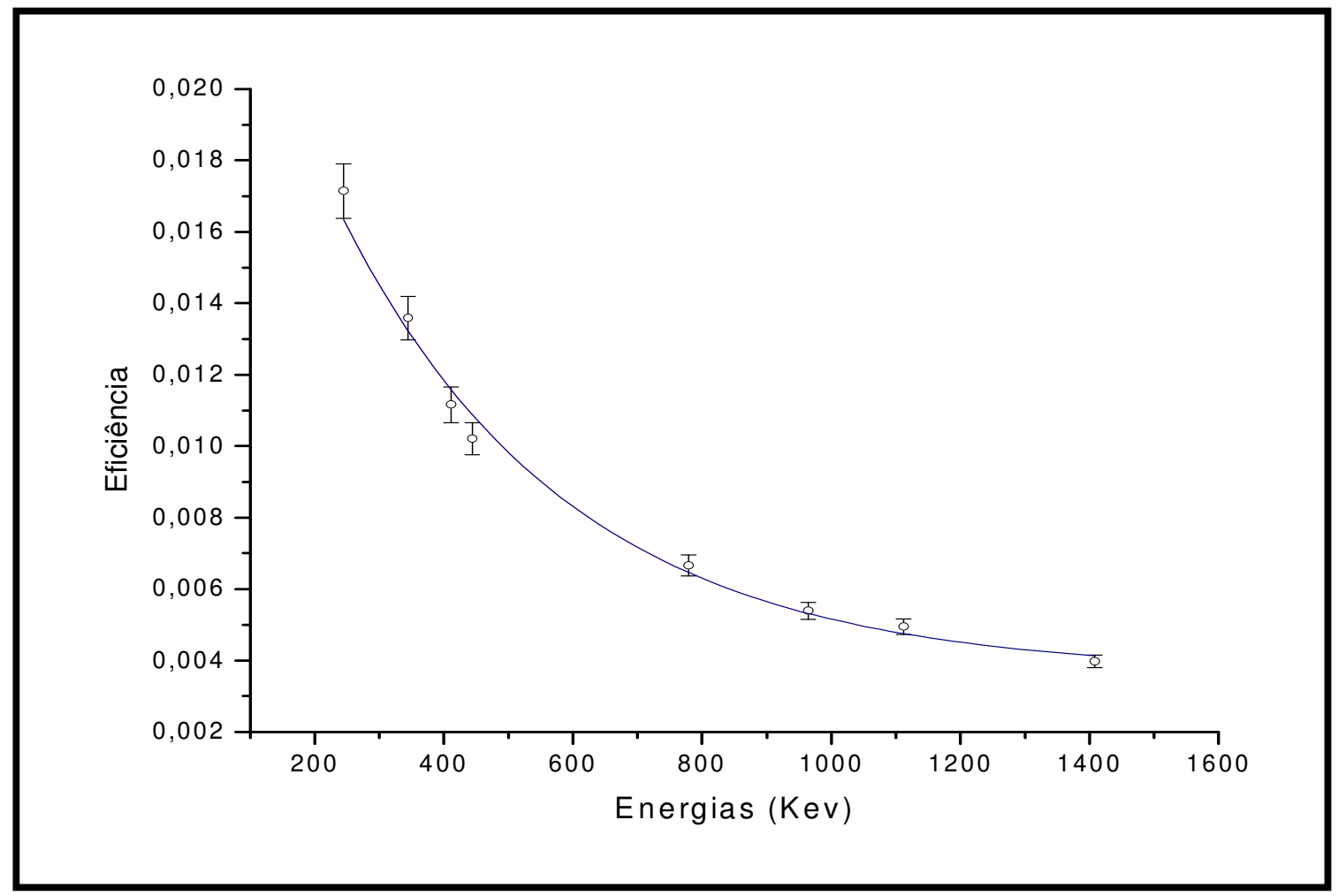

Figura 11: Curva de decaimento para o Sistema de Detecção HPGe para a $6^{a}$ gaveta, com a fonte de Eu-152

\subsection{FLUORESCÊNCIA DE RAIOS-X}

Essa técnica permite a análise qualitativa e quantitativa, de cada elemento encontrado na amostra. A técnica consiste em uma fonte de radiação gama utilizada para provocar a excitação dos átomos da substância analisada. Os fotões que foram emitidos pela fonte são absorvidos pelos átomos das amostras através do efeito fotoelétrico. Quando o átomo se desexcita , é possível observar os fotões $x$ correspondentes as transições electrónicas $L \rightarrow K, M \rightarrow K$ ou $M \rightarrow L$, etc. A partir desse espectro de energias destas transições é possível fazer a identificação dos elementos originais das amostras analisadas. 


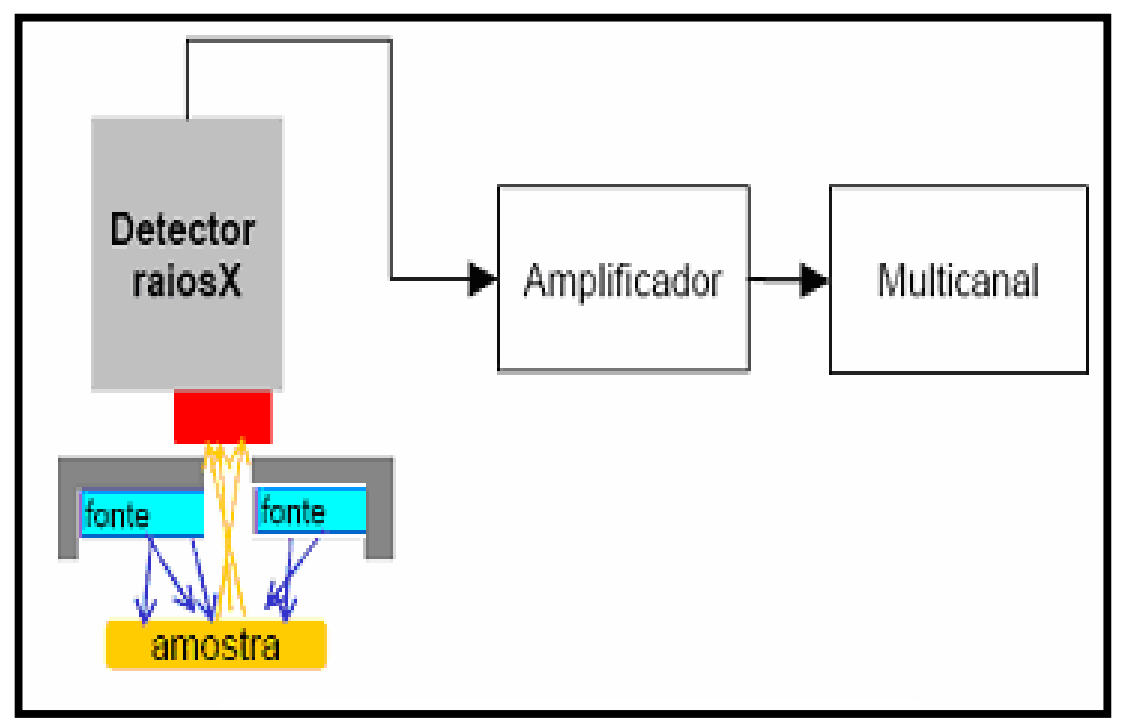

Figura 12: Esquema da montagem experimental

\subsection{Sistema MCNPX}

O código Monte Carlo N - Particle eXtended (MCNPX) ${ }^{50}$, é comumente utilizado em física de reatores e tem apresentado excelentes resultados para 0 transporte de partículas como fótons e elétron. O MCNPX tem como finalidade a modelagem da geometria de um sistema, de acordo com cada necessidade. Com ele é possível simular um feixe de radiação e a quantidade de dose absorvida por um determinado material, tendo-se assim os resultados aproximados da interação nuclear.

O MCNPX foi utilizado na simulação de um dente recebendo doses de radiação. Foi feito o esboço de um dente, dividindo-o em camadas, assim como um dente real.

A figura 13 ilustra a forma e a composição de um dente humano padrão e a geometria para simulação com o Código MCNPX adotado neste trabalho. 


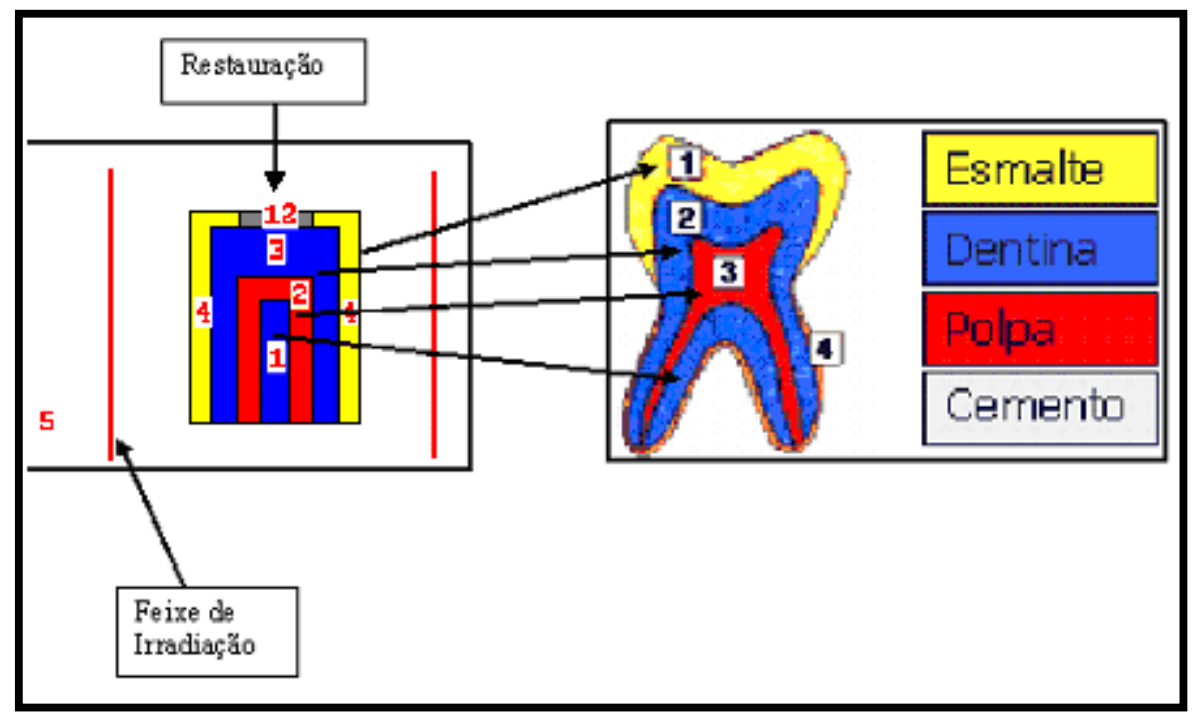

Figura 12 - Geometria utilizada para a simulação com o MCNPX, e a figura de um dente real

Utilizando o Código MCNPX, calculou-se a dose absorvida nas diferentes camadas que compõem um dente humano padrão em estudos odontológicos, simulando situações nas quais o dente sofreu restaurações com os materiais dentários que compõem os grupos de amostras analisadas neste trabalho.

Primeiro foi feito uma simulação onde o dente foi irradiado com uma fonte de Fóton, utilizando uma energia de $6 \mathrm{MV}$ em seguida foi feita uma outra simulação onde o dente continuava sendo irradiado com uma fonte de Fóton, porém com energia de $10 \mathrm{MV}$, nestas simulações foram calculados a quantidade de fóton e elétron absorvido pelas diferentes camadas do dente e para os diferentes materiais de restaurações analisados, para as duas energias utilizadas.

Para essa simulação foi utilizado um feixe monoenergético e o campo de irradiação, foi considerado um cilindro com tamanho aproximado de 0,70 cm. A abertura do campo de irradiação utilizado foi o suficiente para cobrir o dente simulado. O Tally Card utilizado foi o F6, que fornece a energia média em cada camada do dente.

A densidade de cada material de restauração utilizada para a simulação foi descriminada pelos fabricantes. A densidade das camadas do dente, foram feitas de acordo com o tamanho de cada uma.

$\mathrm{Na}$ construção do dente, foi considerado sua altura de aproximadamente $0,43 \mathrm{~cm}$, comprimento de 0,40 $\mathrm{cm}$ e espessura de 0,40 cm. As camadas internas (Esmalte, Dentina Radicular, Polpa, Dentina Radicular voltada para o Cépto Radicular, Esmalte e Restauração), foram divididas de acordo com orientações de dentistas, seguindo os tamanhos aproximados dos originais. 
O arquivo com os dados de entrada utilizados para a simulação está compilado no anexo I.

O código MCNPX (Código de Monte Carlo N - Particle eXtended), fornece os resultados em energia depositada por massa $(\mathrm{MeV} / \mathrm{g})$. Para a obtenção da Dose Absorvida é necessário fazer a transformação de $\mathrm{MeV} / \mathrm{g}$ em Dose Absorvida/Atividade (Gy/Bq.s), para isso utilizamos a fórmula:

$\frac{\text { Dose Absorvida }}{\text { Atividade }}=$ Energia Depositada $\times 1,602 \mathrm{E}-10 \times \frac{\text { oㅜ fótons/reação }}{\text { segundo }}$

Onde $1 \mathrm{MeV}$ corresponde a 1,602E-10 J/kg e $1 \mathrm{~J} / \mathrm{kg}$ corresponde a 1 Gy.

\subsection{Confecção dos corpos de Prova}

Os corpos de prova analisados foram divididos em 4 grupos. $O$ grupo 1 foi constituído de corpos de prova de Titânio, material mais recentemente estudado como principal alternativa em implantes dentários, requerendo ainda processo de importação. O grupo 2 corresponde a amostras de Amálgama, o grupo 3 de Resina Composta, o grupo 4 de lonômero de Vidro, materiais estes ainda bastante utilizados nas restaurações dentárias, e de fácil aquisição no mercado nacional.

Para a confecção do Amálgama de prata, constituinte do grupo 2, a marca utilizada é a DFL ALLOY, uma limalha com alto teor de cobre, cuja composição é de $45 \%$ de prata, $31 \%$ de estanho e $24 \%$ de cobre. Para a confecção dos corpos de prova, este material foi triturado pelo tempo de 20 segundos em um amalgamador mecânico ULTRALUX DOSMAT (DABI ATLANTE). Após a trituração, o amálgama foi homogeneizado em um lençol de camurça, tendo o excesso de mercúrio removido. Com o auxilio de um porta-amálgama, o material foi levado ao interior de uma matriz bipartida e condensado com um condensador de Werd $\mathrm{n}^{0}$ 2. Após 10 minutos, a matriz foi separada e o corpo de prova removido, sendo mantido em um umidificador por 48 horas, para completa cristalização.

A Resina Composta constitui o grupo 3, onde a confecção dos corpos de prova também foi realizada com o uso de matriz bipartida, como no grupo 2 . 
Com o auxílio de uma espátula de Thompson, a resina composta foi levada ao interior da matriz e acamada. Posteriormente foi feito a fotopolimerização pelo tempo de 50 segundos com um aparelho de luz alógena (DABI ATLANTE). Terminada a fotopolimerização, os corpos de prova permaneceram em um umidificador por 48 horas. Os constituintes da Resina Composta, apontado na literatura, são: bisfenol-A glicildimetacriletado (bisGMA), trietilenoglicoldimetacrilatto (TEGDMA), zircônio e sílica.

O grupo 4 é formado pelo lonômero de Vidro, para a confecção das amostras o pó foi soldado em um frasco e utilizou-se a proporção onde para cada colher de pó era misturado duas gotas de líquido. Com o auxílio de uma espátula de Thompson, o pó foi dividido em duas partes iguais e depois misturado a primeira porção com todo o líquido durante 15 segundos. Em seguida, introduziu-se a segunda porção do pó e misturou-se tudo durante 20 segundos, até atingir a consistência brilhante. Feito isto, o lonômero de Vidro, foi introduzido em uma matriz e acamado. Em seguida, iniciou-se a fotopolimerização por 20 segundos, com um aparelho de luz alógena (DABI ATLANTE). Ao término da fotopolimerização, os corpos de provas foram inseridos em um umidificador por 48 horas.

As figuras de 14 a 20 ilustram a confecção das amostras:

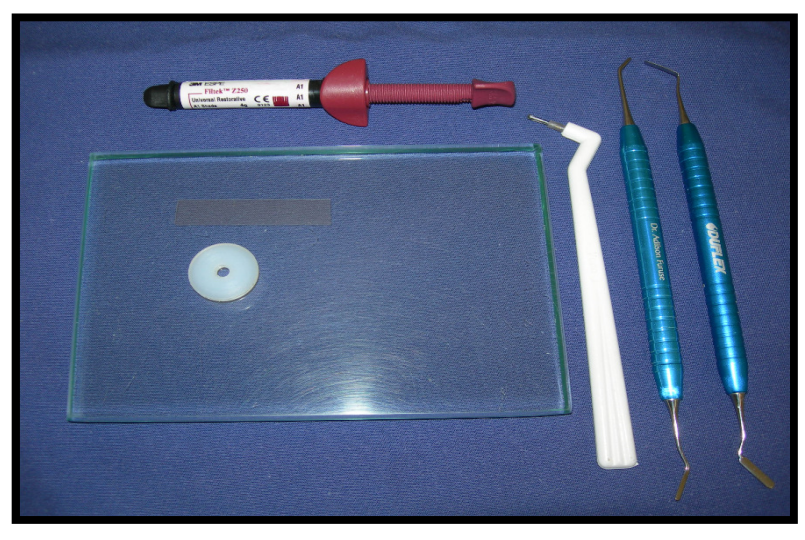

FIGURA 14 - Materiais Utilizados para a confecção das amostras

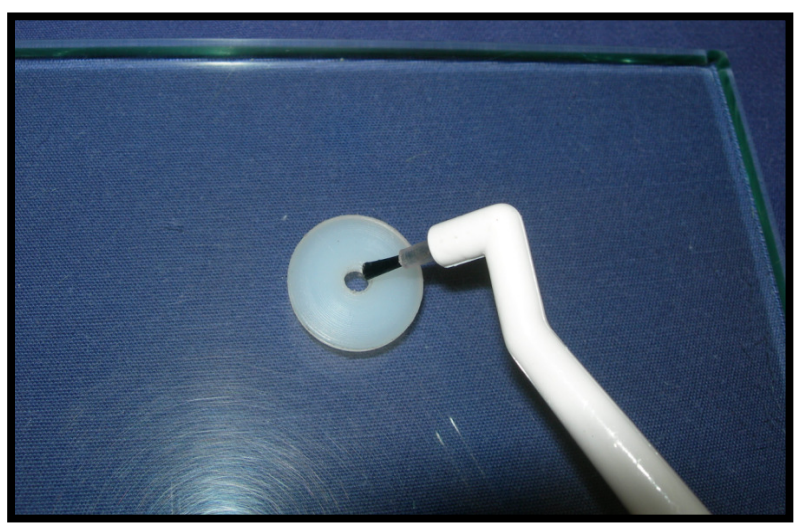

FIGURA 15 - Polimento da Matriz 

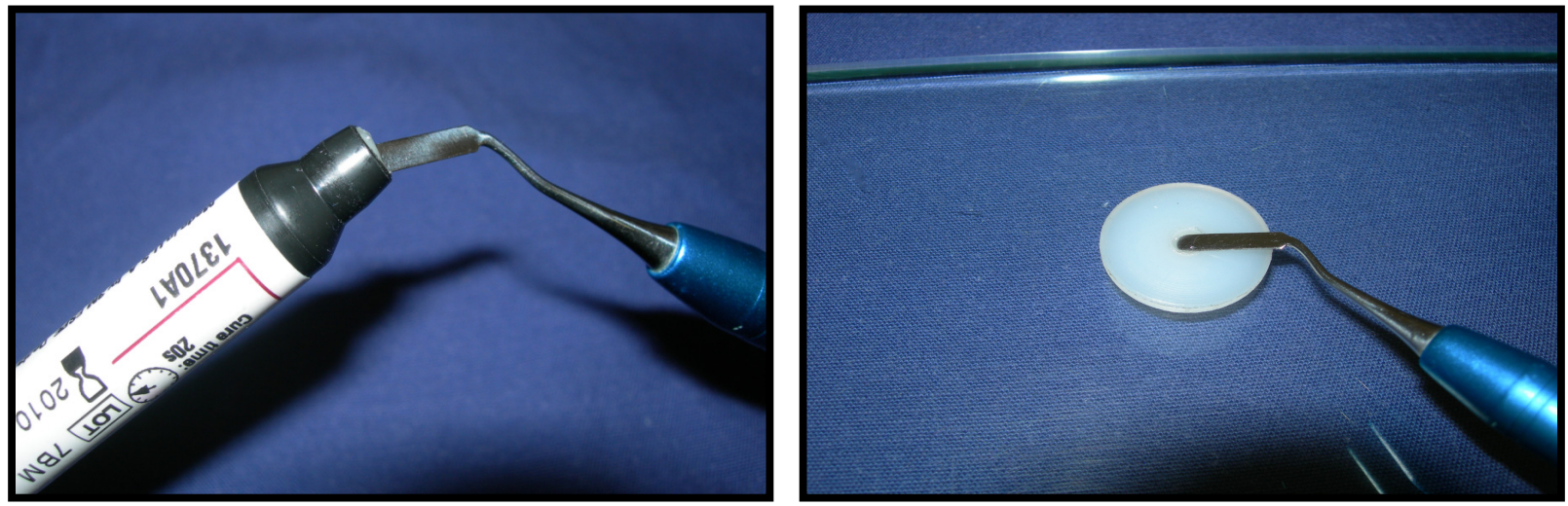

FIGURA 16 - Retirada do material com o auxílio FIGURA 17 - Material sendo colocado na matriz da espátula
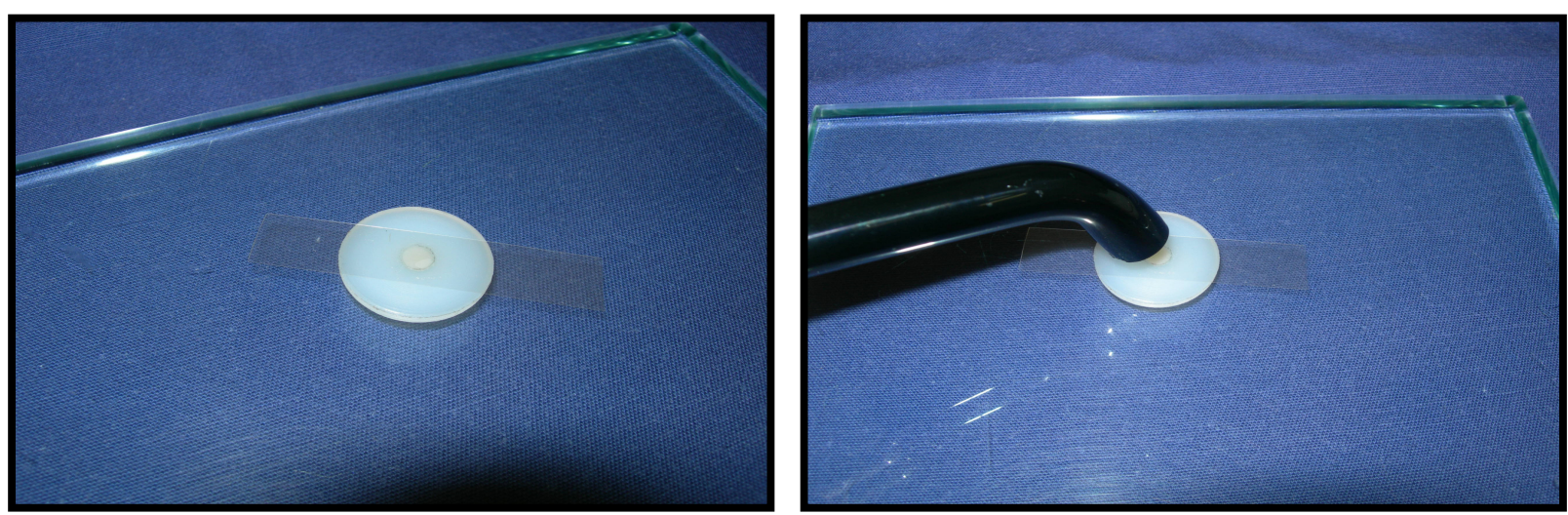

FIGURA 18 - Fixação do suporte em uma placa FIGURA 19 - Inicio da foto fotopolimerização de vidro

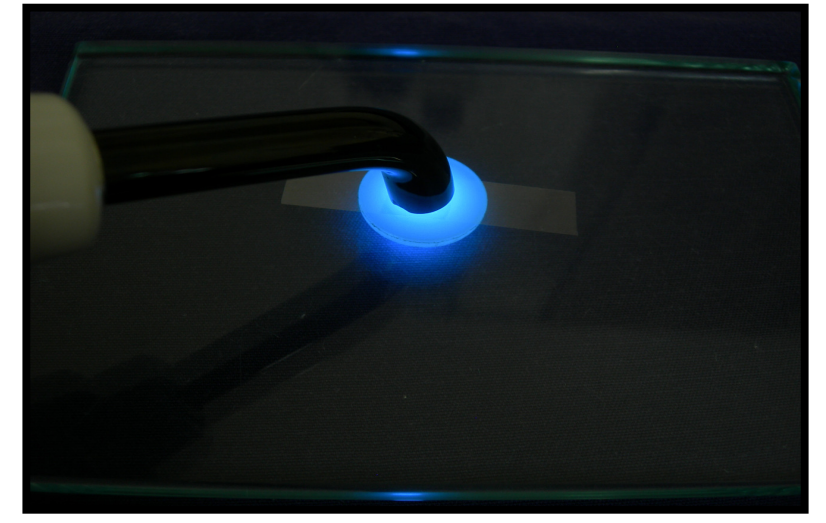

FIGURA 20 - Material sendo submetido a fotopolimerização 


\subsection{MÉTODOS DE ANÁLISE DAS AMOSTRAS}

Após serem confeccionados os corpos de prova foram divididos em dois conjuntos. Um conjunto piloto, na quantidade de 10 amostras para o grupo 1 e 5 amostras para cada um dos grupos 2, 3 e 4, os quais não foram submetidos a irradiação. $O$ outro conjunto de amostras na quantidade de 17 amostras para o grupo 1 e 15 amostras de cada dos outros grupos foi submetido ao feixe de radiação.

O conjunto piloto foi analisado, por técnica de fluorescência de raios- $\mathrm{x}$, para discriminar a exata composição química dos materiais a serem irradiados, já que cada elemento responde de maneira diferente à interação com a radiação.

Conhecidas as composições químicas das amostras, aquelas que compõem o conjunto a ser irradiado foram submetidos a feixes de raios-X de $6 \mathrm{MV}$ produzidos em um acelerador linear marca VARIAN modelo $2100 \mathrm{C}$ disponível no Serviço de Radioterapia da Faculdade de Medicina da UNESP de Botucatu. A dose de irradiação foi de 7000 cGy, que representa a dose de radiação recebida (média entre protocolos de tratamento) por pacientes com tumores de cabeça e pescoço quando submetidos à radioterapia em região cérvico-facial, que abrange grande quantidade da arcada dentária. A dose foi liberada em uma única aplicação, correspondendo à situação que proporciona maior intensidade dos efeitos radiobiológicos agudos e crônicos.

Logo após a irradiação, foram realizadas as mensurações da radiação residual ou emissão de energia das amostras irradiadas, por meio de equipamentos de dosimetria (detectores Geiger - Müller e Câmaras de Ionização). Estas amostras também foram submetidas à análise de espectrometria gama através de detector de Germânio Hiper - puro (HPGe) disponível no Laboratório de Medidas Nucleares da Unidade Critica (Reator IPEN/MB-01) do Centro de Energia Nuclear (CEN) do Instituto de Pesquisas Energéticas e Nucleares (IPEN). O objetivo desta análise foi obter a contagem dos foto-picos de energia emergentes das amostras e assim verificar se houve alterações de emissão dos corpos pilotos (não irradiados) e aqueles submetidos à irradiação. 
A composição química das amostras irradiadas foi analisada pela técnica de fluorescência de raios- $X$. Os resultados foram comparados com aqueles da análise dos corpos pilotos (não irradiados).

Em síntese, foram realizadas análises da composição química, medidas de radiação residual, espectrometria gama, e densidade das amostras irradiadas, comparando os resultados com aqueles obtidos para as amostras não irradiadas. As figuras 21 a 24 mostram os grupos das amostras analisadas.

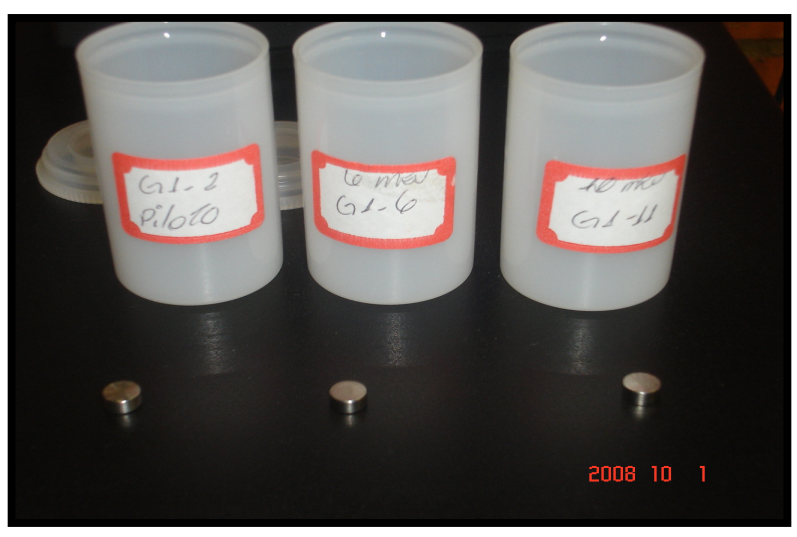

FIGURA 21 - Amostras de titânio

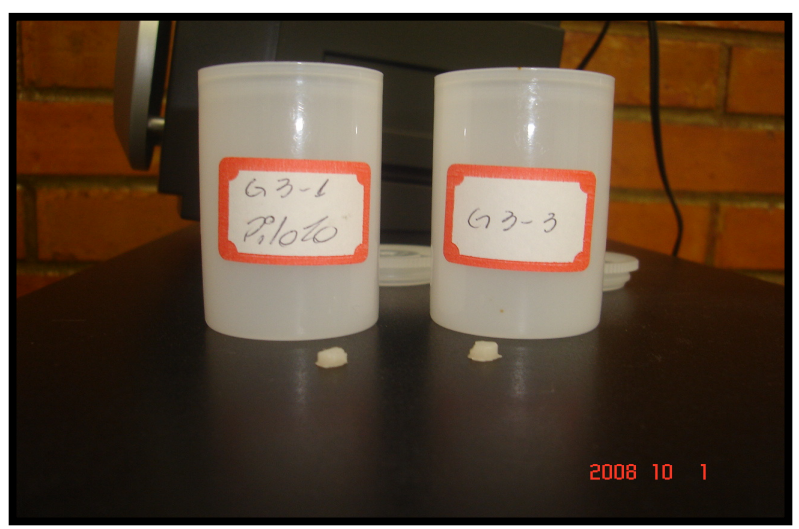

FIGURA 23 - Amostras de resina composta

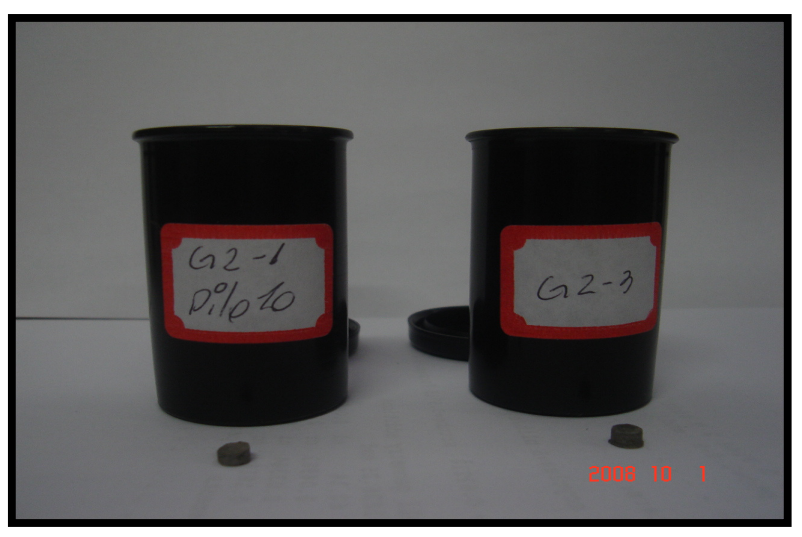

FIGURA 22 - Amostras de amálgama

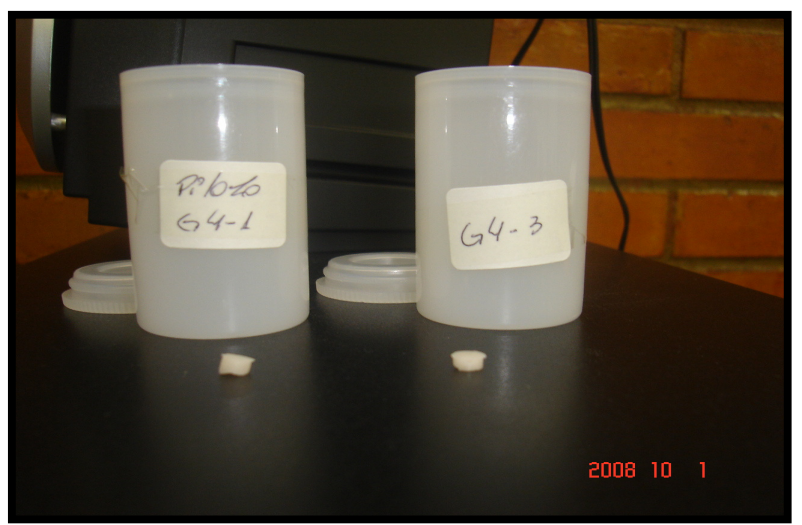

FIGURA 24 - Amostras de ionômero de vidro

$\mathrm{Na}$ tabela 1 tem-se a quantidade e tipo das amostras estudadas. $\mathrm{O}$ conjunto 1 representa as amostras não irradiadas e o conjunto 2 as amostras irradiadas 
TABELA 1 - Quadro ilustrativo do tipo, grupo e quantidade de amostras

\begin{tabular}{|c|c|c|c|}
\hline & & $\begin{array}{c}\text { Número de amostras } \\
\text { (Piloto) }\end{array}$ & Número de amostras \\
\hline Grupo & Conjunto 1 & Conjunto 2 \\
\hline 1 & Titânio & 10 & 17 \\
\hline 2 & Amálgama & 5 & 15 \\
\hline 3 & Resina Composta & 5 & 15 \\
\hline 4 & lonômero de Vidro & 5 & 15 \\
\hline
\end{tabular}

Após a confecção das amostras, as mesmas foram colocadas em um porta amostras apropriado para a irradiação. Na Figura 25 pode-se notar que as amostras ficaram posicionadas de forma que não houvesse contato umas com as outras e com uma distancia quase uniforme entre elas.

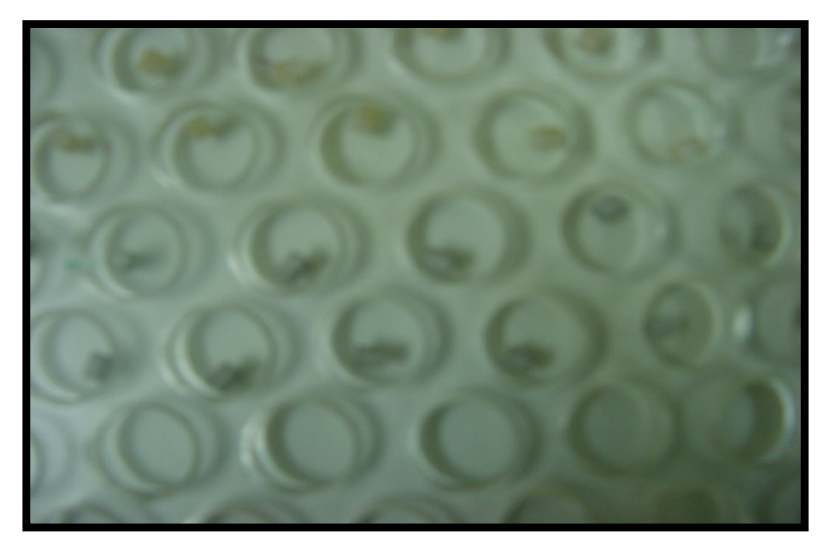

FIGURA 25 - Amostras inseridas em um porta amostras para inicio da irradiação

Em seguida, o porta amostras foi posicionado sobre a mesa de tratamento do acelerador linear. Para se produzir uma região de build'up (equilíbrio eletrônico) e assim garantir que a dose máxima atinja a superfície das amostras, foi colocado sobre estas uma placa de acrílico de $2,0 \mathrm{~cm}$ de espessura. Placas de acrílico, totalizando $20 \mathrm{~cm}$ de espessura, foram colocadas sob as amostras para se reproduzir o retro-espalhamento.

A seqüência dos procedimentos, desde o posicionamento das amostras no sistema de irradiação, até a rotina das medidas realizadas da radiação residual e da análise da variação de suas características físicas é ilustrada nas figuras 26 a 32. 


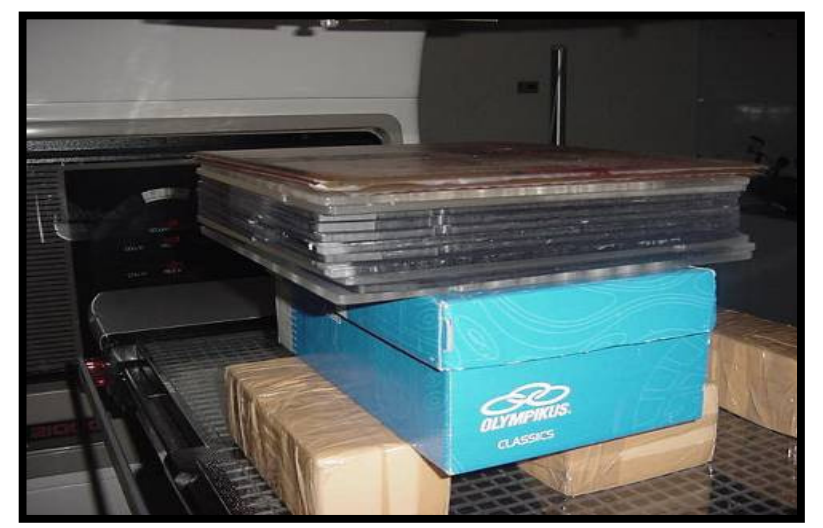

FIGURA 26 - Amostras posicionadas para a irradiação

Foram feitas duas sessões de irradiação, uma para as amostras que foram irradiadas com fótons $6 \mathrm{MV}$ e outra para as que foram irradiadas com fótons 10 MV. A irradiação foi feita com o campo de irradiação do acelerador linear aberto em $40 \mathrm{~cm} \times 40 \mathrm{~cm}$, para que fosse possível irradiar todas as amostras de uma única vez.

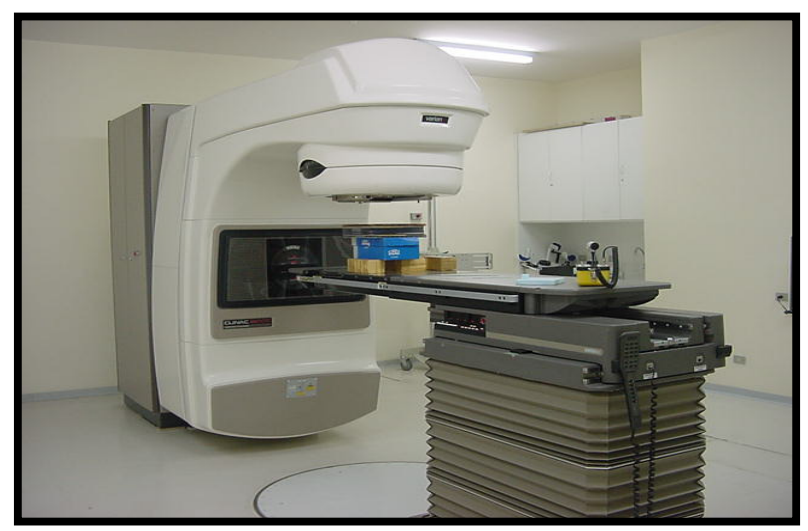

FIGURA 27 - Acelerador linear e as amostras posicionadas para irradiação

Logo em seguida a irradiação foram feitas medições nas amostras com o detector Geiger-Müller e Câmera de Ionização.

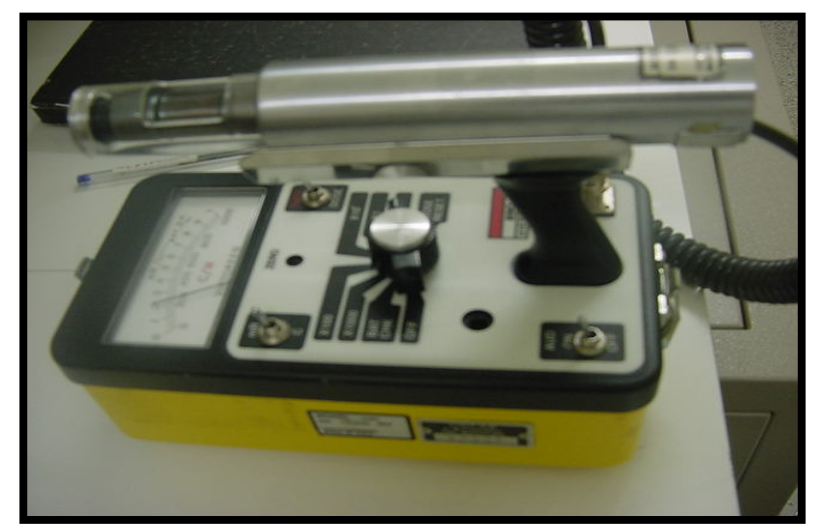

FIGURA 27 - Detector Geiger-Muller 
Após os processos descritos acima, as amostras foram levadas até o Instituto de Pesquisas Energéticas e Nucleares (IPEN) e no Laboratório de Medidas Nucleares da Unidade Critica (Reator IPEN/MB-01) do Centro de Energia Nuclear (CEN) foram feitas análises de Espectrometria Gama. O tempo entre a irradiação e o inicio das análises foram de 07 dias, tempo necessário para o transporte das amostras do local de irradiação até o laboratório de análises.

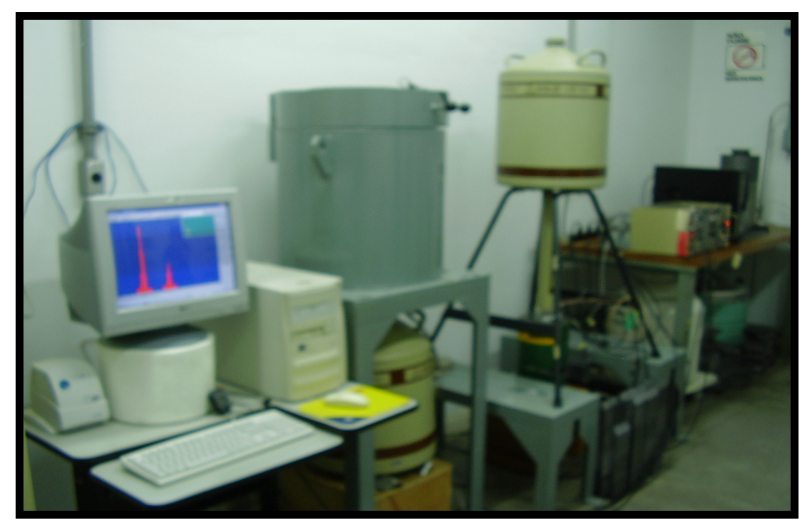

FIGURA 29 - Eletrônica do Detector de Germânio Hiper - puro

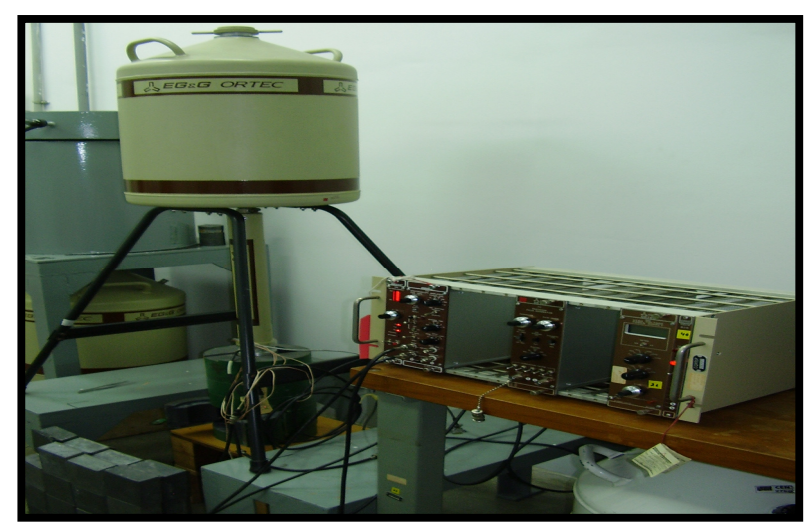

FIGURA 30 - Detector de Germânio Hiper - puro

Após a análise de Espectrometria Gama foram feitas análises de Fluorescência de Raios-X, porém o laboratório não forneceu imagens do equipamento utilizado.

E por ultimo, com o auxílio de um paquímetro e de uma balança de alta precisão foram feitas medidas da altura, espessura e massa de cada amostra.

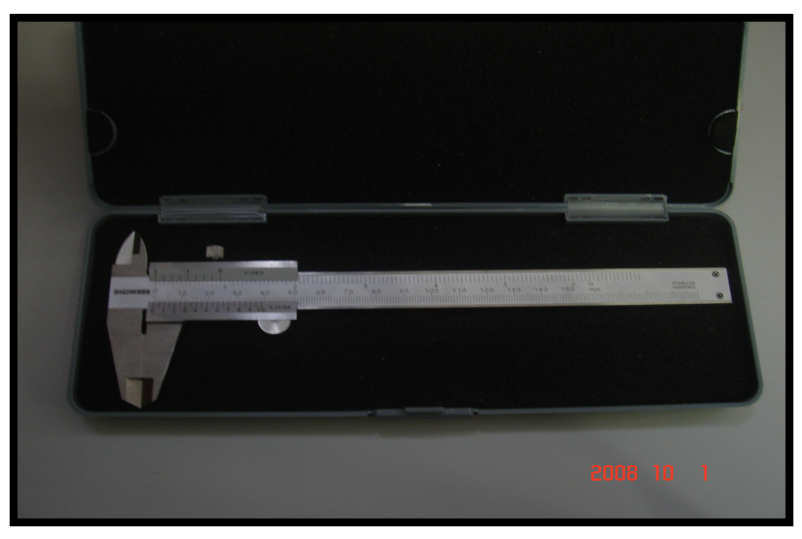

FIGURA 31 - Paquímetro utilizado para medir as amostras

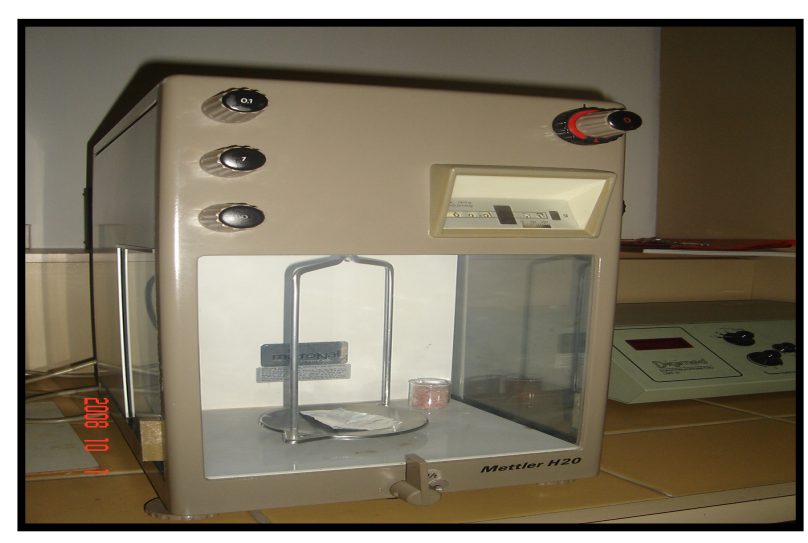

FIGURA 32 - Balança utilizada para pesar as amostras 
Amostras anteriormente irradiadas com feixe de cobalto-60 ${ }^{51}$ também foram reanalisadas com a finalidade de se verificar a possível alteração da composição química em função do tempo de irradiação. 


\section{CAPÍTULO 3 RESULTADOS E DISCUSSÕES}

\subsection{Análise dos Foto-Picos}

As Figuras 33 a 57 ilustram os gráficos da contagem das amostras confeccionadas e analisadas neste trabalho. Abaixo de cada gráfico encontra-se uma tabela que contém a energia e o radionuclideo correspondente a cada pico, que com o auxílio do programa Maestro foi discriminado no espectro.

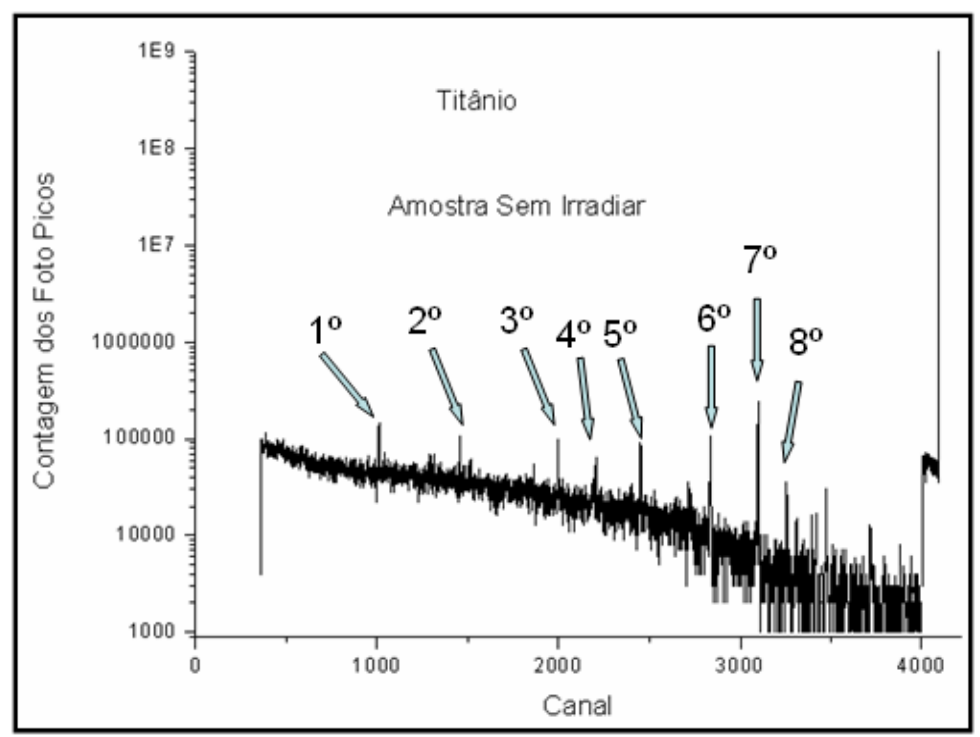

FIGURA 33 - Espectro da amostra de Titânio sem irradiar

Tabela 2: Energia e radionuclideo de cada pico para a amostra de Titânio sem irradiar Pico Energia (KeV)

$\begin{array}{lcl}1^{\circ} & 511,60 & \mathrm{Ag}-106 \\ 2^{\circ} & 744,42 & \mathrm{Tc}-98 \\ 3^{\circ} & 1026,27 & \mathrm{Sb}-120 \\ 4^{\circ} & 1133,91 & \mathrm{Sb}-122 \\ 5^{\circ} & 1262,85 & \mathrm{Eu}-154 \\ 6^{\circ} & 1463,72 & \mathrm{~K}-40 \\ 7^{\circ} & 1599,41 & \mathrm{La}-140 \\ \mathbf{8}^{\circ} & 1681,43 & \mathrm{Sb}-124\end{array}$




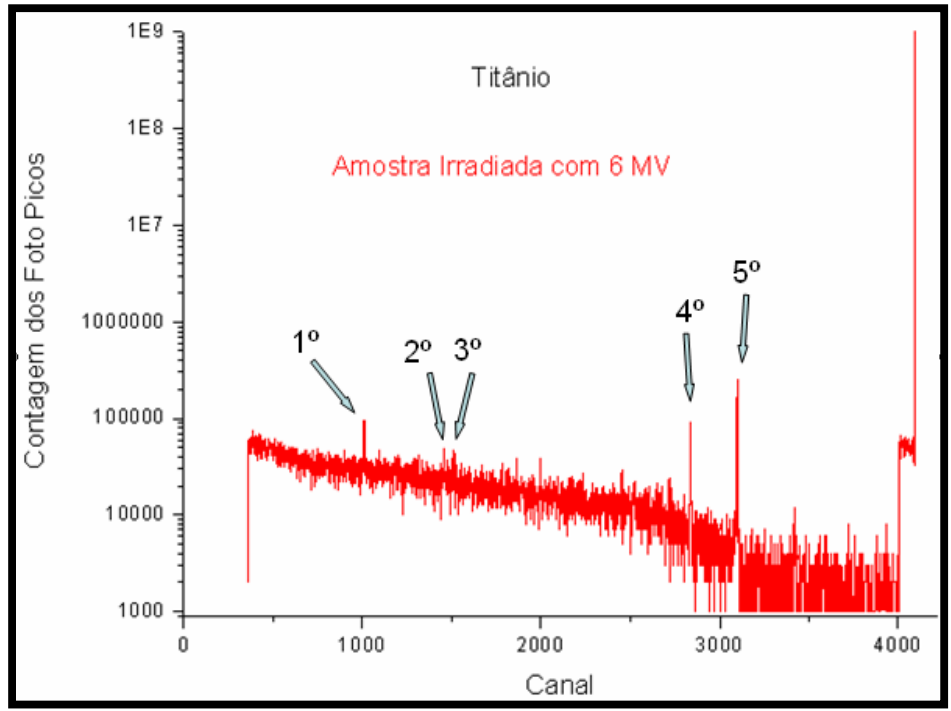

FIGURA 34 - Espectro da amostra de Titânio irradiado com 6 MV

Tabela 3: Energia e radionuclideo de cada pico para a amostra de Titânio irradiado com 6 MV.

$\begin{array}{ccc}\text { Pico } & \text { Energia }(\mathrm{KeV}) & \text { Radionuclide } \\ \mathbf{1}^{\circ} & 511,60 & \mathrm{Ag}-106 \\ \mathbf{2}^{\circ} & \mathbf{7 4 4 , 7 2} & \mathrm{Tc}-98 \\ \text { 3}^{\circ} & 774,1 & \mathrm{Te}-131 \\ \text { 4ㅇ }^{\circ} & 1453,69 & \mathrm{~K}-40 \\ 5^{\circ} & 1599,32 & \text { La }-140\end{array}$

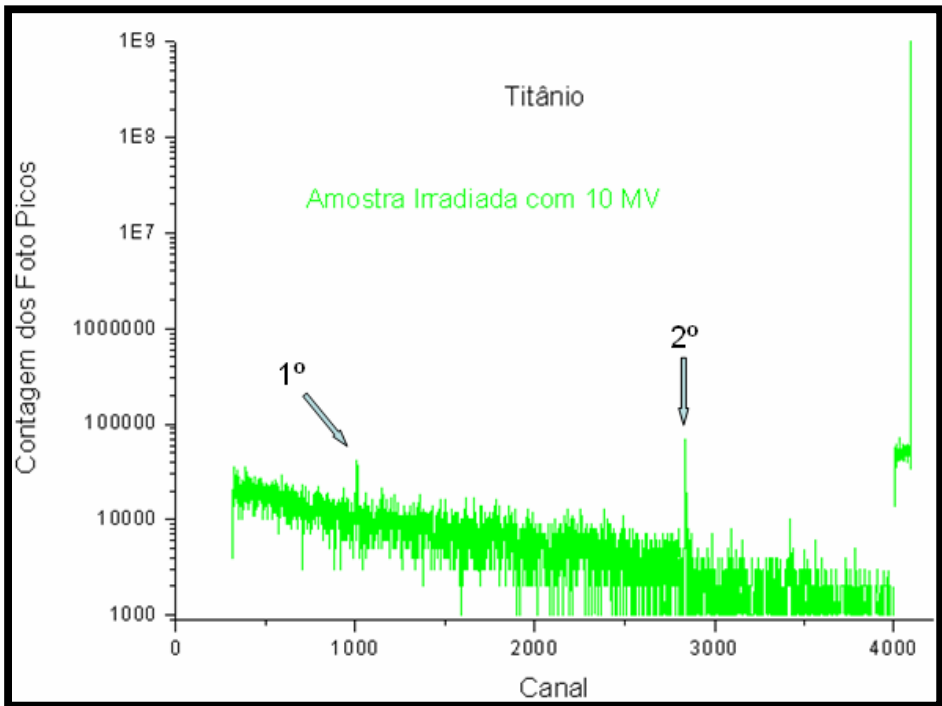

FIGURA 35 - Espectro da amostra de Titânio irradiada com 10 MV 
Tabela 4: Energia e radionuclideo de cada pico para a amostra de Titânio irradiado com 10 MV Pico Energia (KeV) Radionuclideo

1 은

511,60

$\mathrm{Ag}-106$

2요 $\quad 1465,69$

$\mathrm{K}-\mathbf{4 0}$

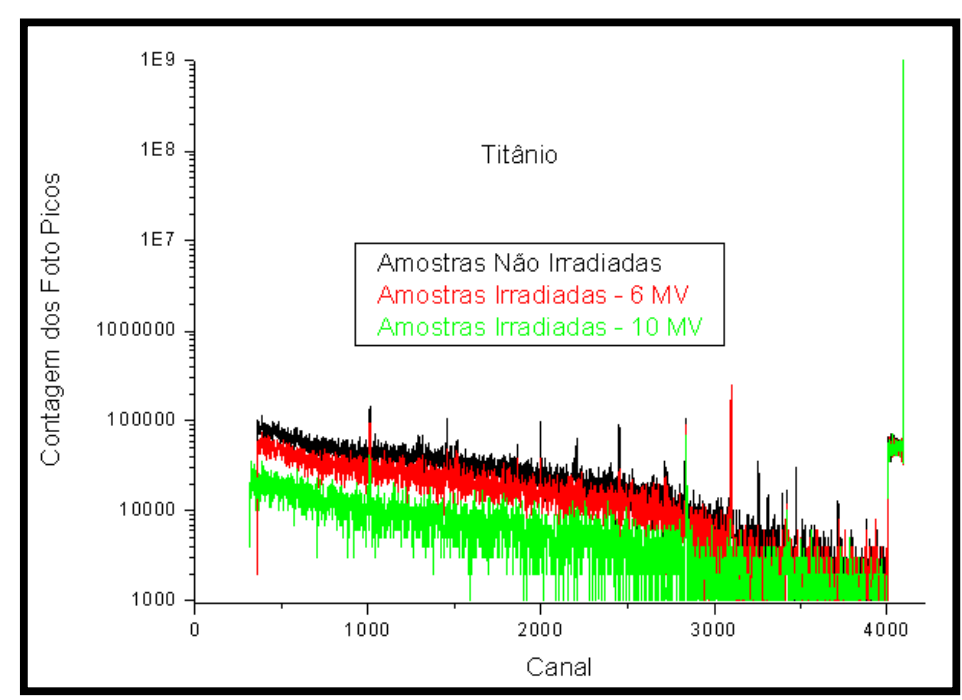

FIGURA 36 - Espectros sobre postos das amostras de Titânio sem irradiar e irradiadas

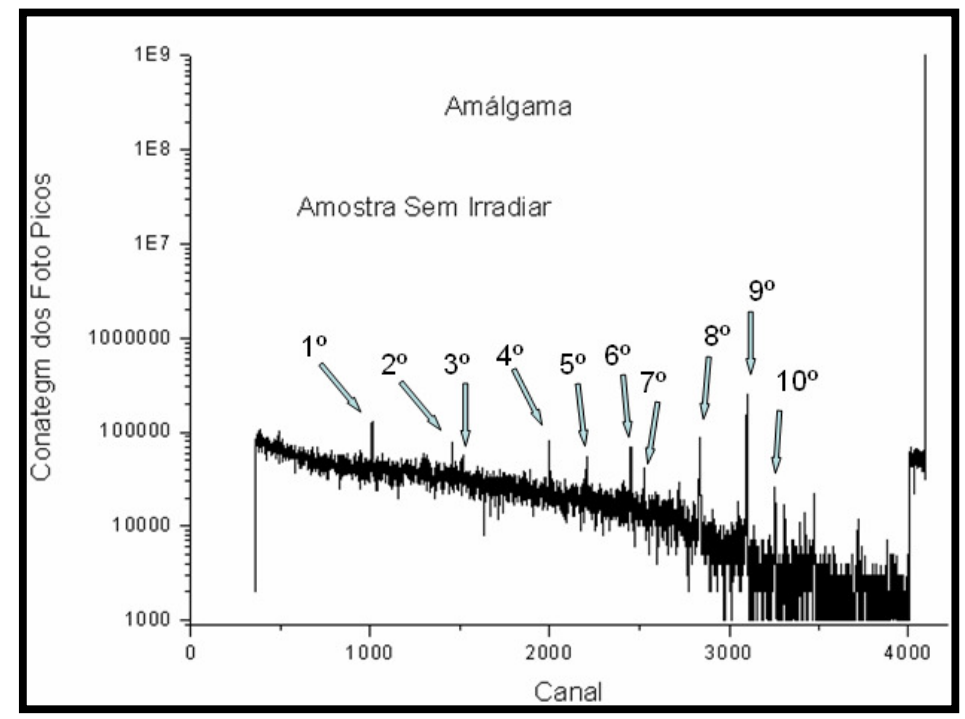

FIGURA 37 - Espectro da amostra de Amálgama sem irradiar

Tabela 5: Energia e radionuclideo de cada pico para a amostra de Amálgama sem irradiar

$\begin{array}{ccc}\text { Pico } & \text { Energia }(\mathrm{KeV}) & \text { Radionuclide } \\ 1^{\circ} & 511,60 & \mathrm{Ag}-106 \\ 2^{\circ} & 744,42 & \mathrm{Tc}-98 \\ 3^{\circ} & 774,42 & \mathrm{Te}-131 \\ 4^{\circ} & 1026,27 & \mathrm{Sb}-120 \\ 5^{\circ} & 1133,91 & \mathrm{Sb}-122 \\ 6^{\circ} & 1262,85 & \mathrm{Eu}-154 \\ 7^{\circ} & 1301,11 & \mathrm{Ca}-47 \\ \mathbf{8}^{\circ} & 1463,72 & \mathrm{~K}-40 \\ 9^{\circ} & 1599,41 & \mathrm{La}-140 \\ 10^{\circ} & 1681,43 & \mathrm{Sb}-124\end{array}$




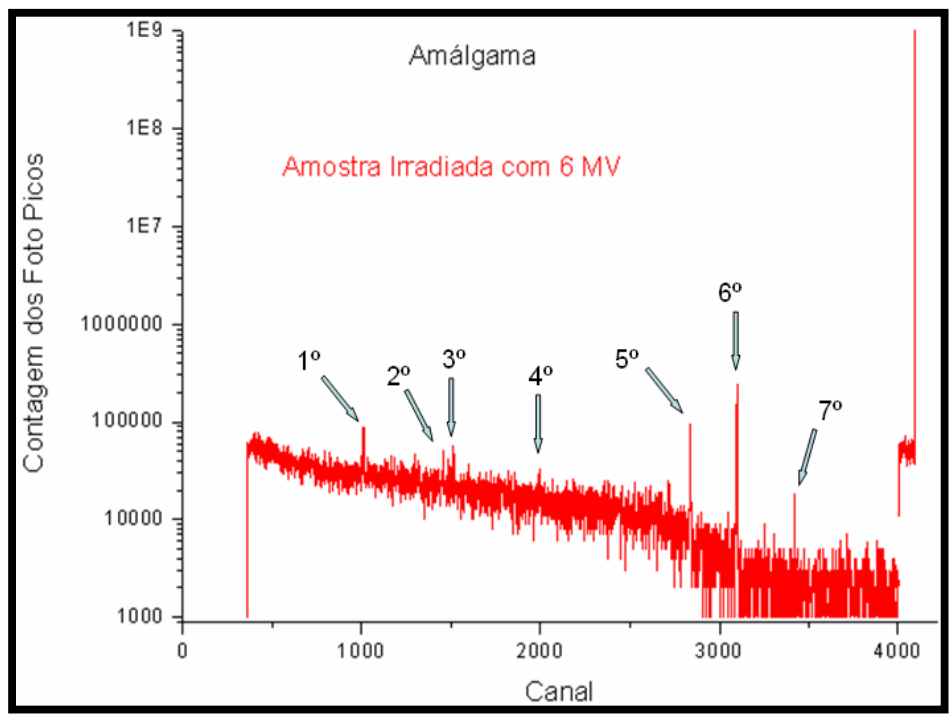

FIGURA 38 - Espectro da amostra de Amálgama irradiada com 6 MV

Tabela 6: Energia e radionuclideo de cada pico para a amostra de Amálgama irradiada com 6 MV

\begin{tabular}{|c|c|c|}
\hline Pico & Energia (KeV) & Radionuclide \\
\hline 10 & 511,60 & $\mathrm{Ag}-106$ \\
\hline $2^{\circ}$ & 744,30 & Tc - 98 \\
\hline 3음 & 773,76 & $\mathrm{Te}-131$ \\
\hline $4^{\circ}$ & 1026.44 & $S b-120$ \\
\hline 5은 & 1463,75 & $K-40$ \\
\hline $6^{\circ}$ & 1599,45 & La - 140 \\
\hline $7^{\circ}$ & 1768,65 & Bi - 205 \\
\hline
\end{tabular}

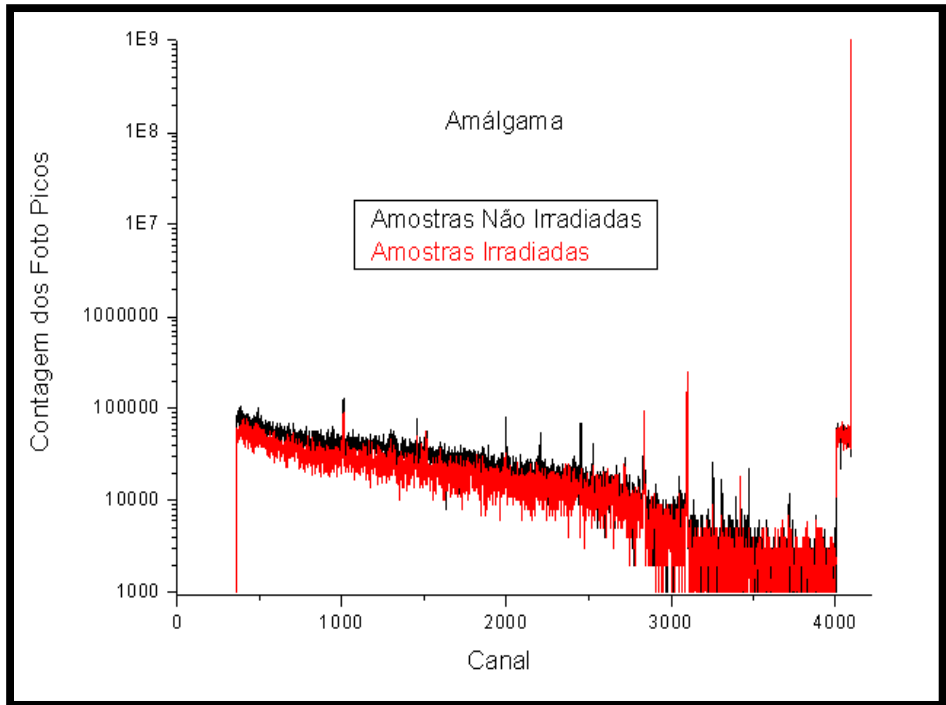

FIGURA 39 - Espectros sobre postos das amostras de Amálgama sem irradiar e irradiadas 


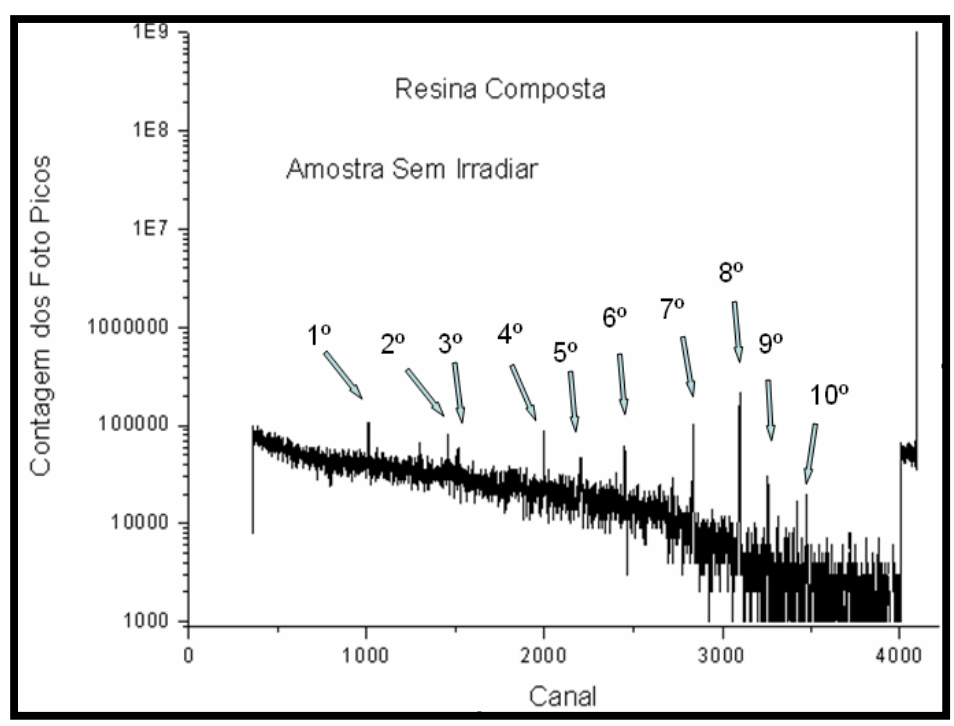

FIGURA 40 - Espectro da amostra de Resina Composta sem Irradiar

Tabela 7: Energia e radionuclideo de cada pico para a amostra de Resina Composta sem irradiar Pico Energia (KeV) Radionuclideo

$\begin{array}{ccc}1^{\circ} & 511,60 & \mathrm{Ag}-106 \\ 2^{\circ} & 744,30 & \mathrm{Tc}-98 \\ 3^{\circ} & 773,76 & \mathrm{Te}-131 \\ 4^{\circ} & 1026,44 & \mathrm{Sb}-120 \\ 5^{\circ} & 1262,87 & \mathrm{Eu}-154 \\ 6^{\circ} & 1360,10 & \mathrm{Rn}-211 \\ 7^{\circ} & 1463,68 & \mathrm{~K}-40 \\ \mathbf{8}^{\circ} & 1599,37 & \mathrm{La}-140 \\ 9^{\circ} & 1681,89 & \mathrm{Sb}-124 \\ 10^{\circ} & 1768,65 & \mathrm{Bi}-205\end{array}$

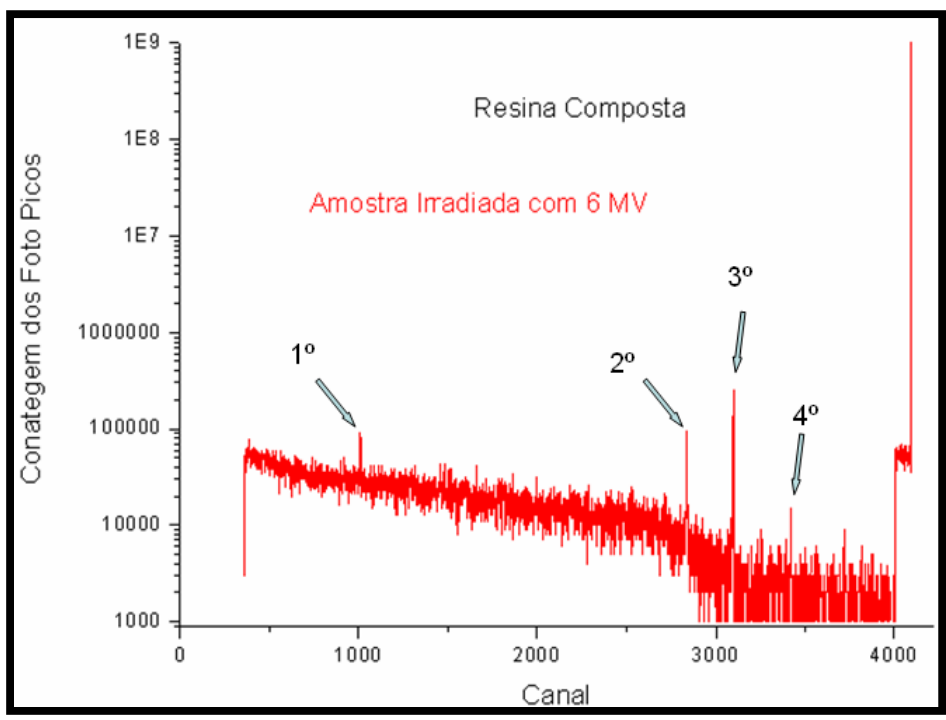

FIGURA 41 - Espectro da amostra de Resina Composta irradiada com 6 MV 
Tabela 8: Energia e radionuclideo de cada pico para a amostra de Resina Composta irradiada com 6 MV

\begin{tabular}{|c|c|c|}
\hline Pico & Energia (KeV) & Radionuclideo \\
\hline 19 & 511,60 & $\mathrm{Ag}-106$ \\
\hline $2^{\circ}$ & 1463,68 & K - 40 \\
\hline 3음 & 1599,44 & La - 140 \\
\hline $4^{\circ}$ & 1768,24 & Bi - 205 \\
\hline
\end{tabular}

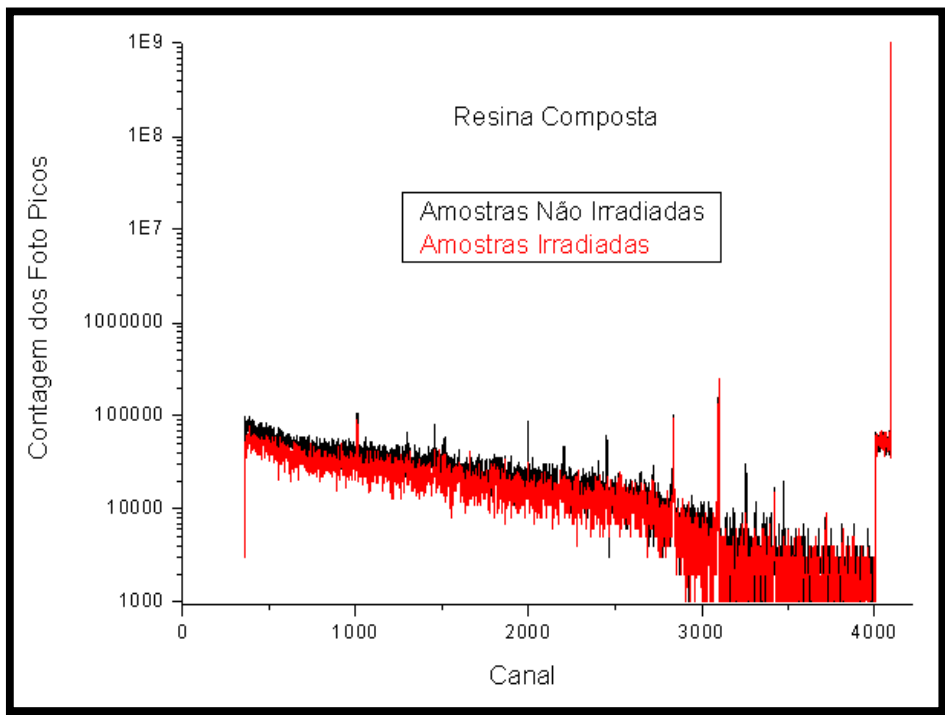

FIGURA 42 - Espectros sobre postos das amostras de Resina Composta sem irradiar e irradiada

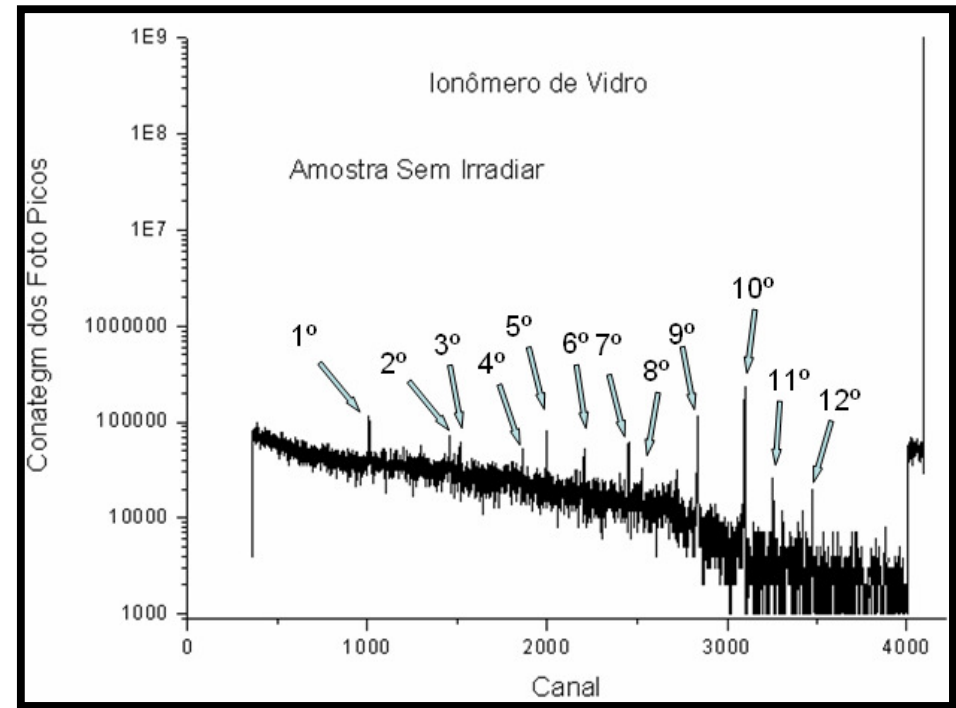

FIGURA 43 - Espectro da amostra de lonômero de Vidro sem irradiar

Tabela 9: Energia e radionuclideo de cada pico para a amostra de lonômero de Vidro sem irradiar

\begin{tabular}{|c|c|c|}
\hline Pico & Energia (KeV) & Radionuclideo \\
\hline 10 & 511,48 & $\mathrm{Ag}-106$ \\
\hline $2^{\circ}$ & 744,53 & Tc - 98 \\
\hline 30 & 774,26 & $\mathrm{Te}-131$ \\
\hline $4^{\circ}$ & 956,53 & $P a-230$ \\
\hline 50 & 1026,03 & $S b-120$ \\
\hline
\end{tabular}




$\begin{array}{ccc}6^{\circ} & 1133,22 & \mathrm{Sb}-122 \\ 7^{\circ} & 1262,85 & \mathrm{Eu}-154 \\ 8^{\circ} & 1300,41 & \mathrm{Ca}-47 \\ 9^{\circ} & 1463,72 & \mathrm{~K}-40 \\ 10^{\circ} & 1599,22 & \mathrm{La}-140 \\ 11^{\circ} & 1681,17 & \mathrm{Sb}-124 \\ 12^{\circ} & 1769,24 & \mathrm{Bi}-205\end{array}$

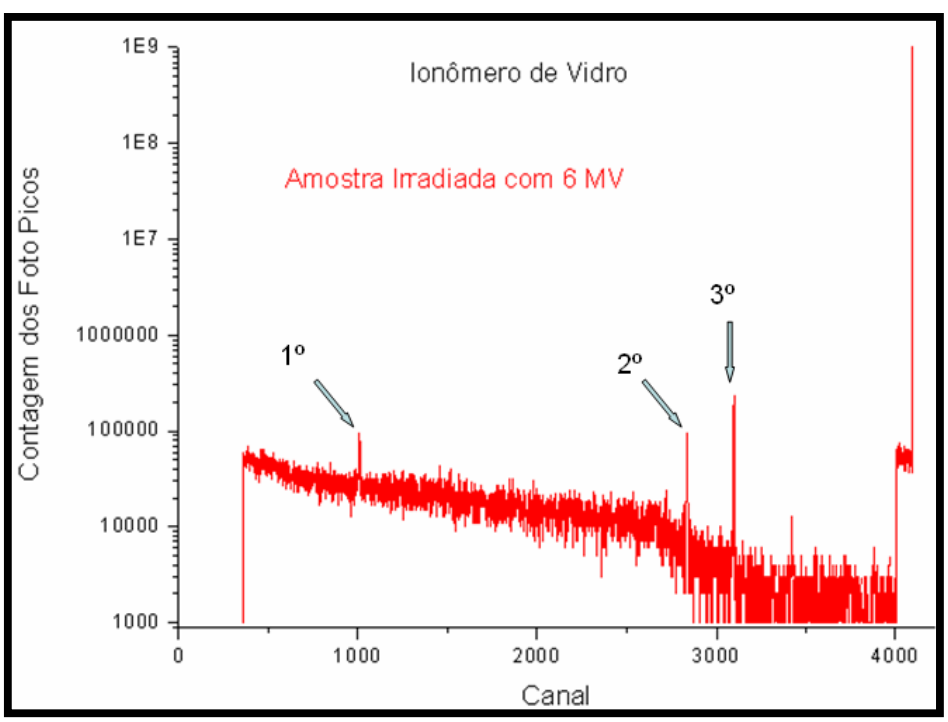

FIGURA 44 - Espectro da amostra de lonômero de Vidro irradiada com 6 MV

Tabela 10: Energia e radionuclideo de cada pico para a amostra de lonômero de Vidro irradiada com 6 MV

$\begin{array}{ccc}\text { Pico } & \text { Energia }(\mathrm{KeV}) & \text { Radionuclideo } \\ \mathbf{1}^{\circ} & \mathbf{5 1 1 , 4 8} & \mathrm{Ag}-\mathbf{1 0 6} \\ \mathbf{2} & \mathbf{1 4 6 3 , 4 2} & \mathrm{K}-\mathbf{4 0} \\ \mathbf{3} & \mathbf{1 5 9 9 , 1 5} & \mathrm{La}-\mathbf{1 4 0}\end{array}$

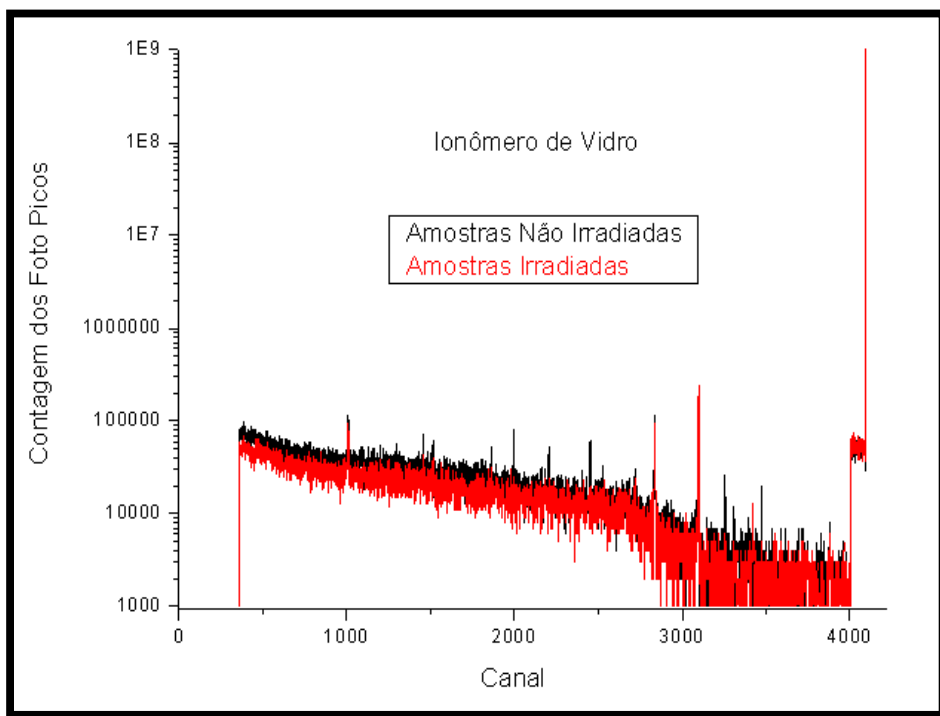

FIGURA 45 - Espectros da amostras de lonômero de Vidro sem irradiar e irradiada sobre postos 


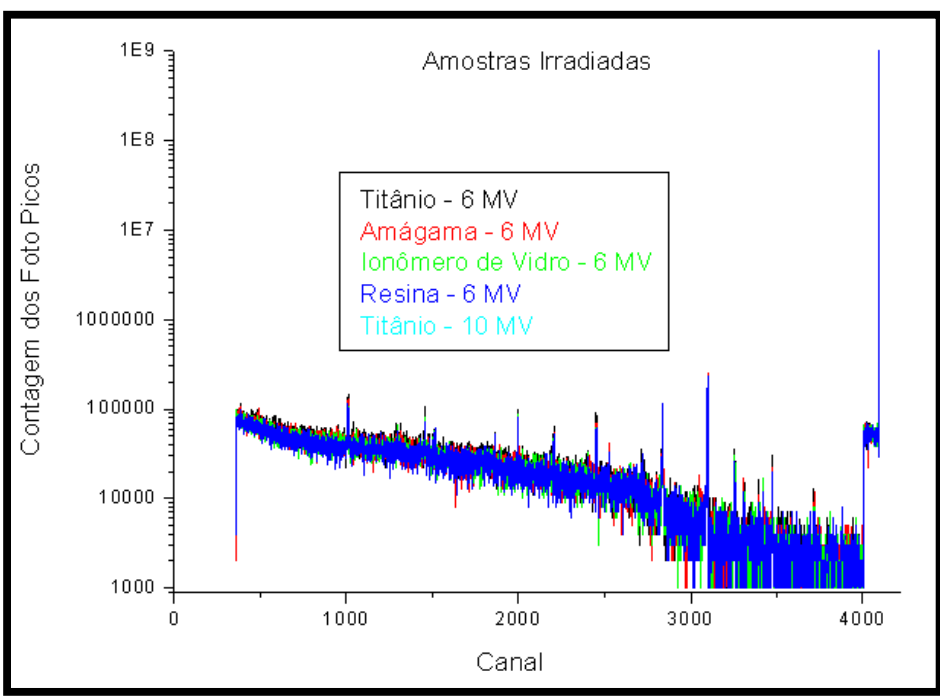

FIGURA 46 - Espectros sobre postos de todas as amostras irradiadas

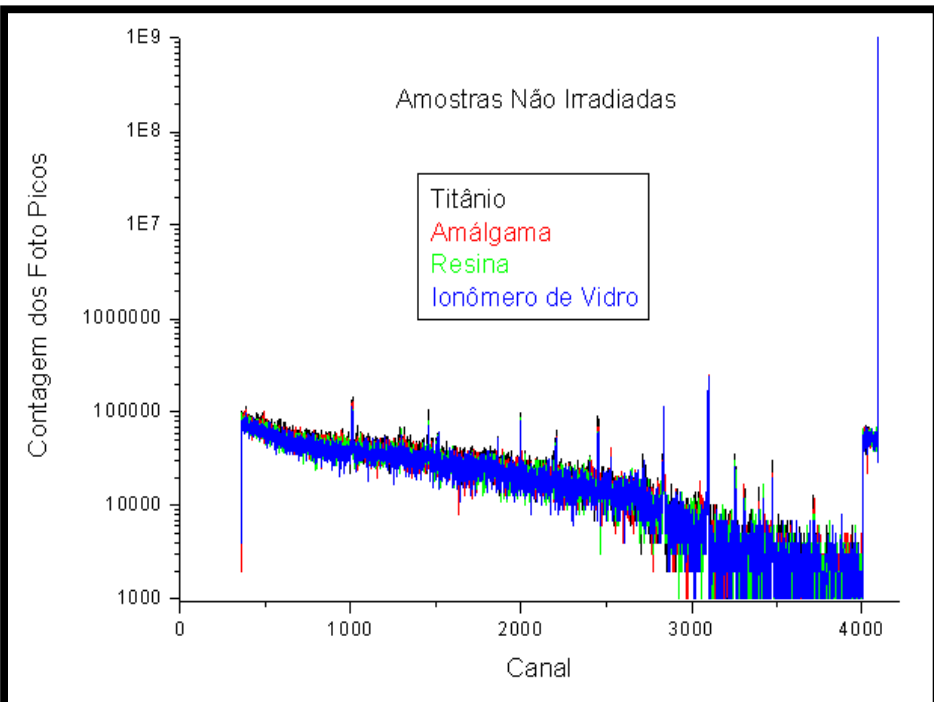

FIGURA 47 - Espectros sobre postos de todas as amostras sem irradiar

Observando as tabelas 2 a 10 podemos notar que os radionuclideos responsáveis pela emissão gama se repetem. Ou seja, os picos correspondem a radiação de fundo do local (Background). Alguns espectros apareceram um número maior de picos com relação a outros espectros, isso se dá pelo fato do tempo de contagem ter sido diferente entre eles conforme a disponibilidade do detector para as análises.

As Figuras 48 a 57 analisam o ocorrido com as amostras anteriormente irradiadas com feixe de cobalto - 60. Para essas amostras não temos os espectros com calibração em energia, por isso não foi possível discriminar o emissor gama dos picos que apareceram. Entretanto, espera-se uma situação similar à encontrada nas tabelas 2 a 10. 


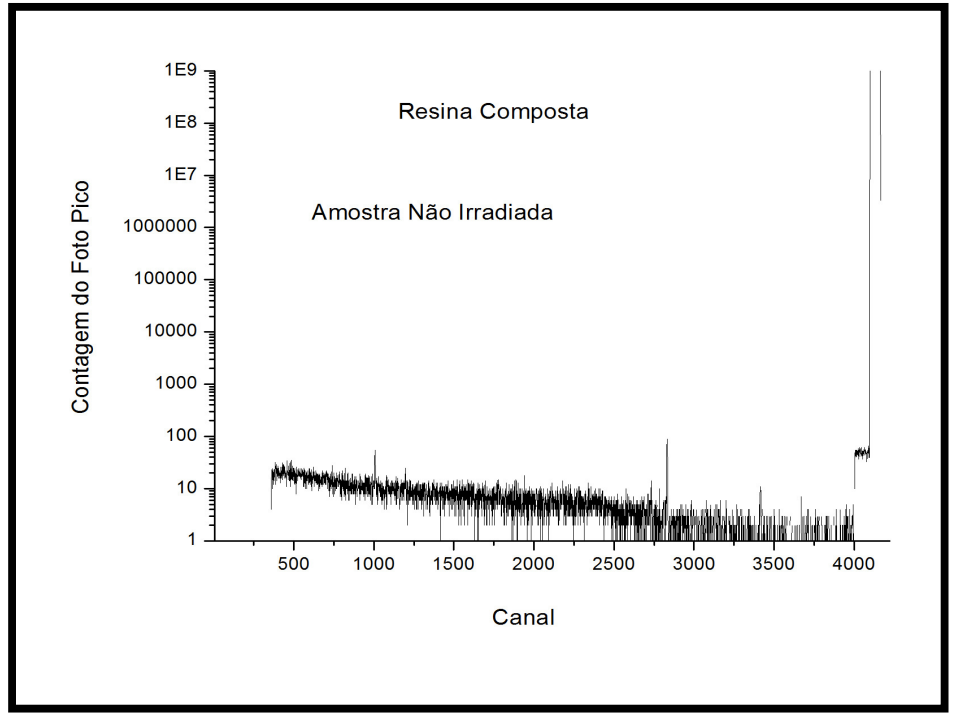

FIGURA 48 - Espectro da amostra de Resina Composta sem irradiar

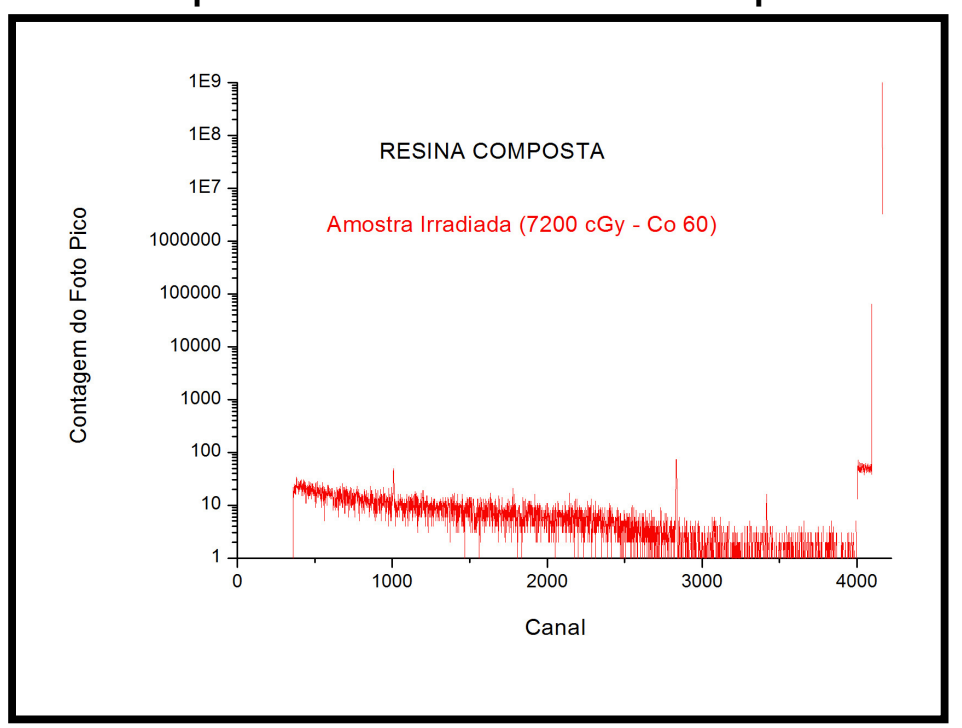

FIGURA 49 - Espectro da amostra de Resina Composta irradiada com Co - 60

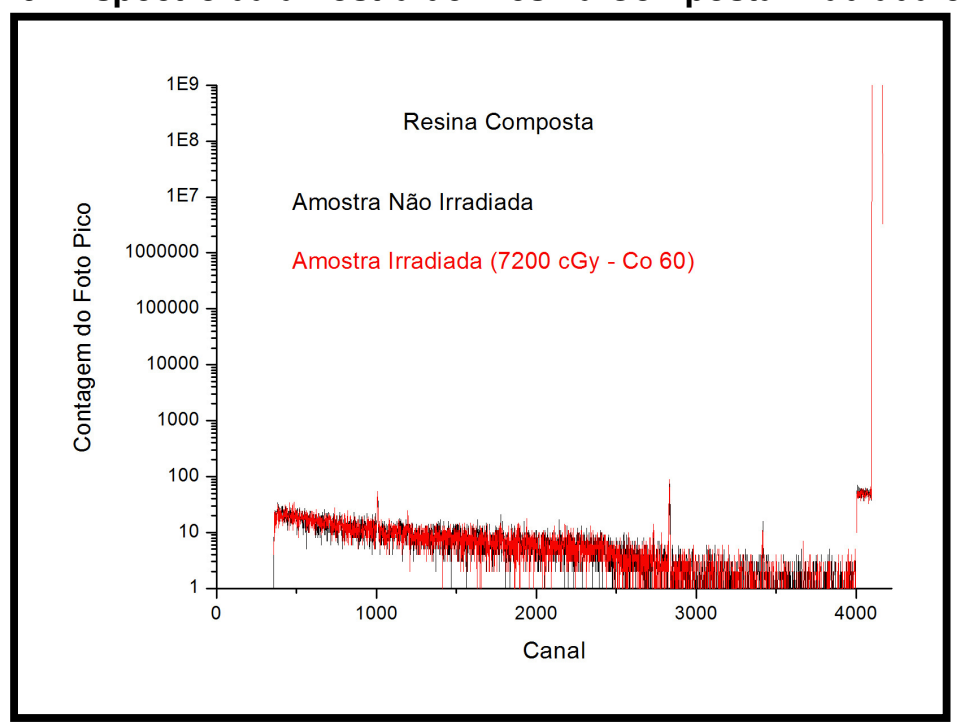

FIGURA 50 - Espectros sobre postos das amostras de Resina Composta sem irradiar e irradiadas 


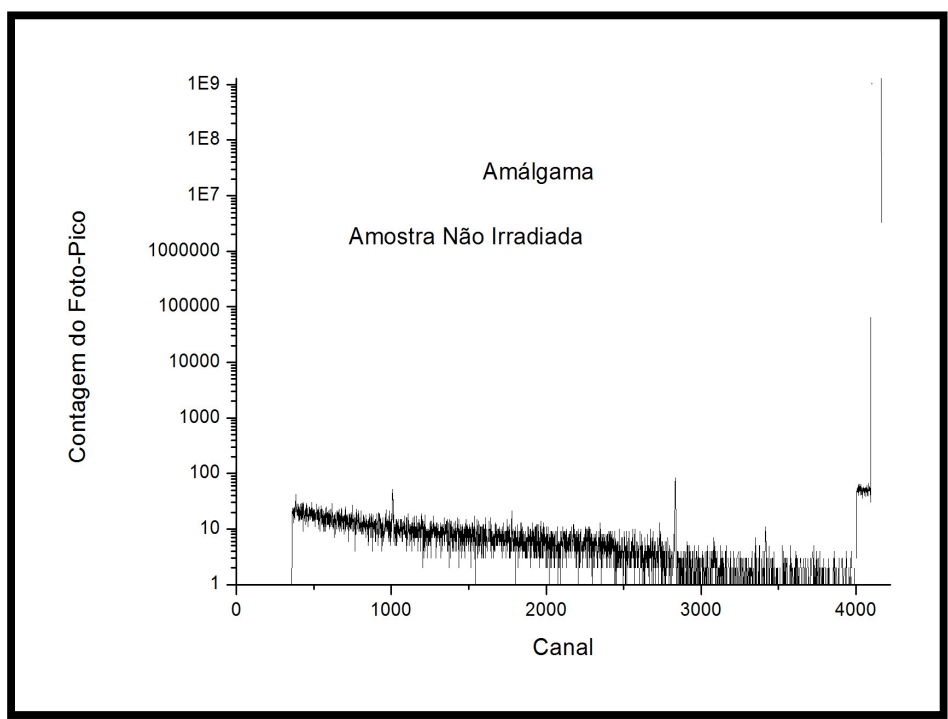

FIGURA 51 - Espectro da amostra de Amálgama sem irradiar

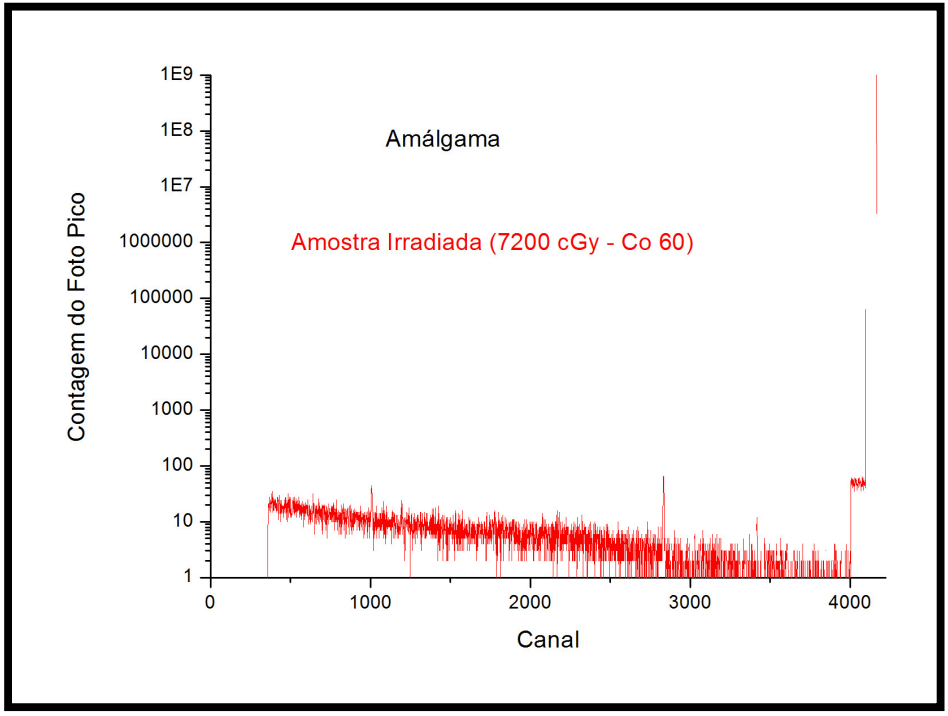

FIGURA 52 - Espectro da amostra de Amálgama irradiada com Co - 60

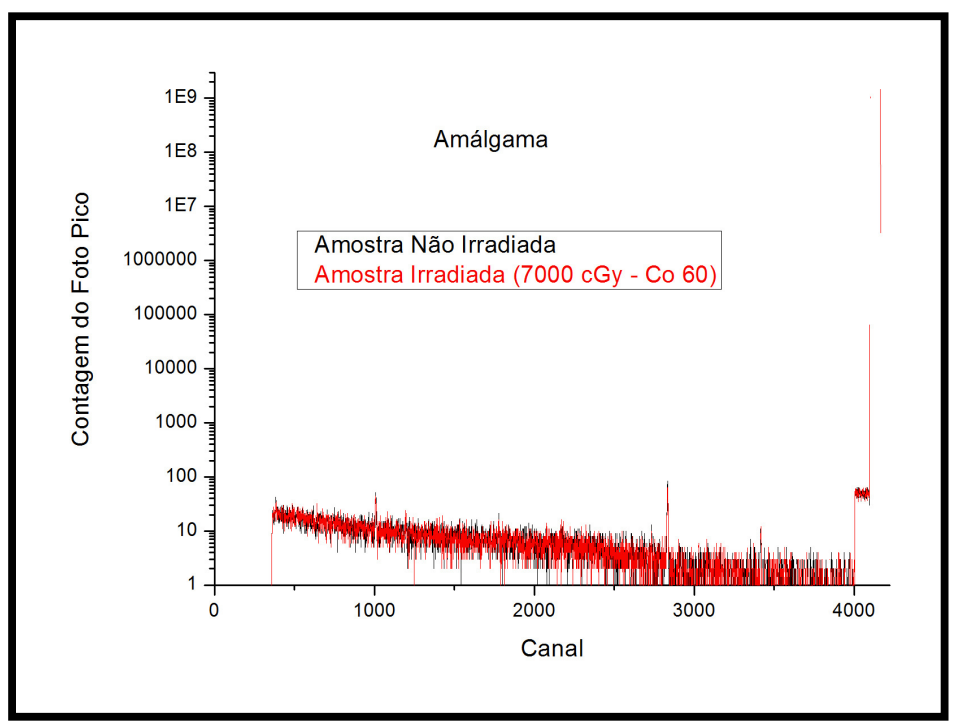

FIGURA 53 - Espectros sobre postos das amostras de Amálgama sem irradiar e irradiadas 


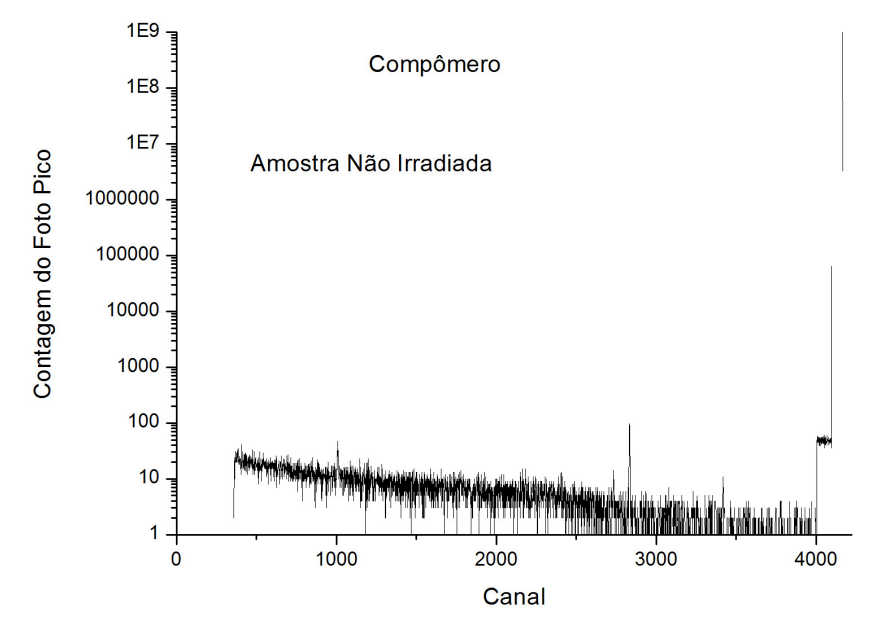

FIGURA 54 - Espectro da amostra de Compômero sem irradiar

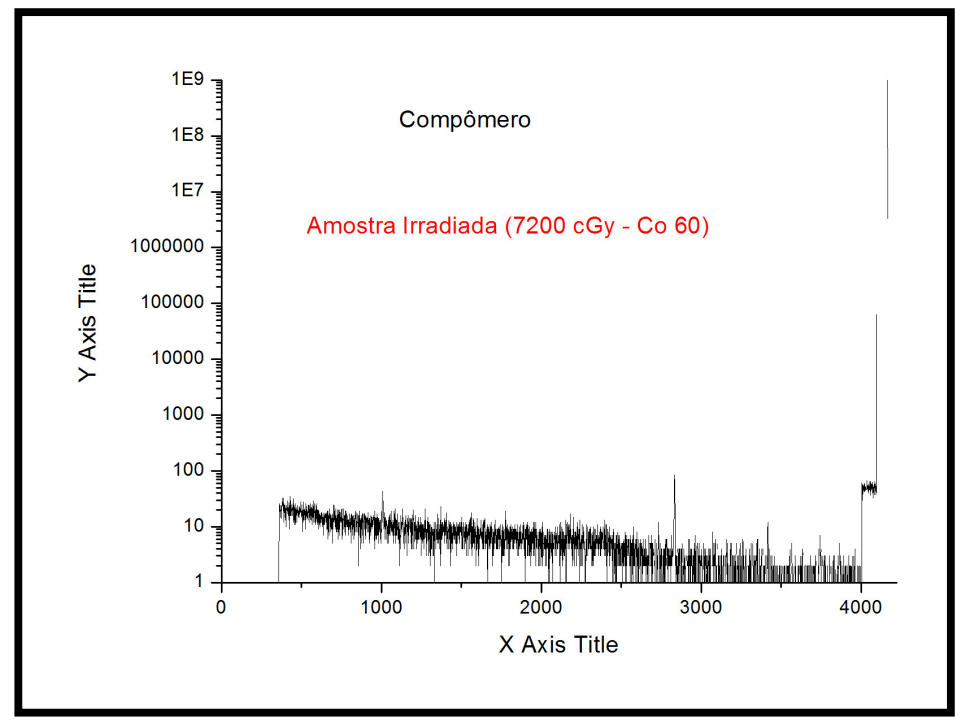

FIGURA 55 - Espectro da amostra de Compômero irradiadas com Co - 60

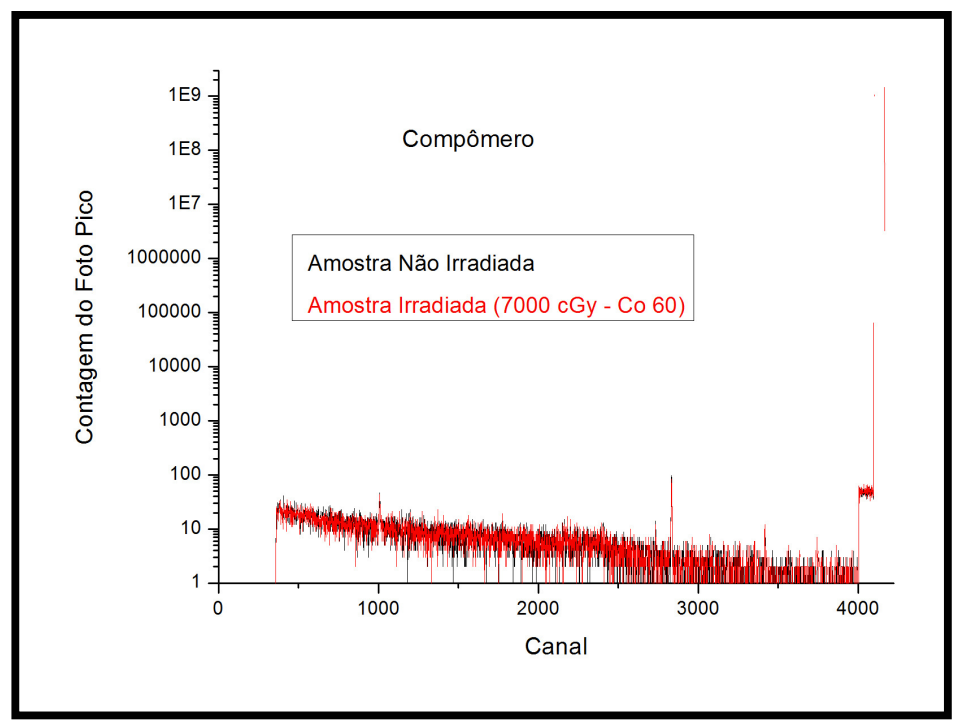

FIGURA 56 - Espectros sobre postos das amostras de Compômero sem irradiar e irradiado 


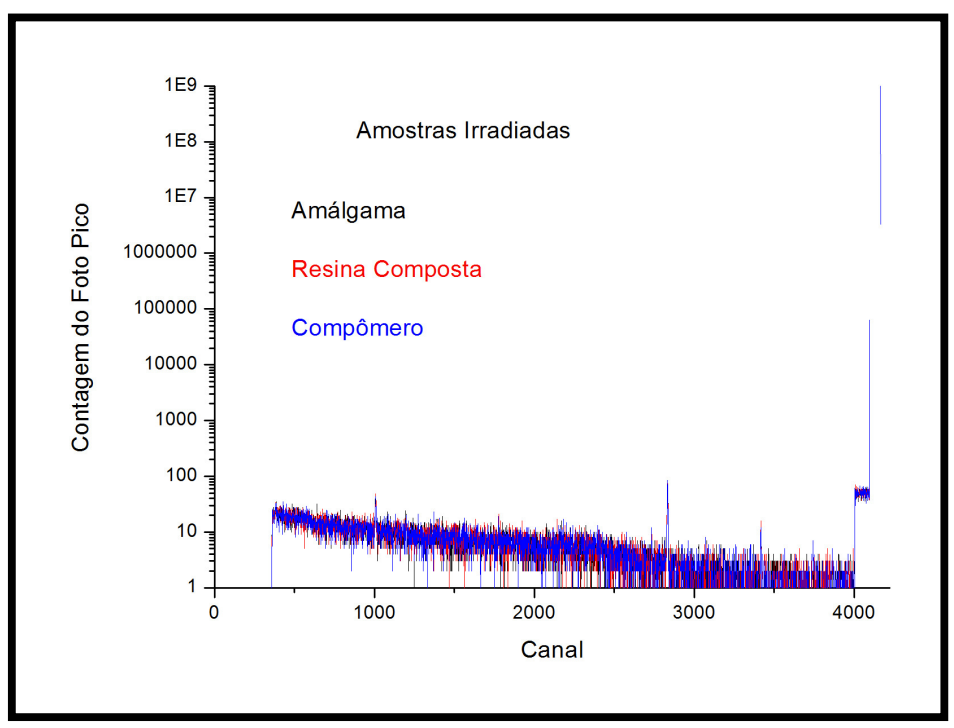

FIGURA 57 - Espectros sobre postos de todas as amostras irradiadas

\subsection{Medidas da densidade das Amostras}

A densidade das amostras foi determinada medindo-se suas respectivas propriedades físicas: alturas, diâmetro e massa:

$$
\text { Densidade }\left(\mathrm{g} / \mathrm{cm}^{3}\right)=\text { massa } / \text { volume }
$$

Nestas medidas utilizou-se um paquímetro da marca Mitutoyo $(0,25-0,01$ $\mathrm{mm}$ ) e uma balança de alta precisão, da marca Mettler H2O (d=0,01 mg). As Tabelas 11 a 19 apresentam os resultados das medidas da densidade das amostras antes e após a irradiação.

\subsubsection{Titânio}

TABELA 11 - Densidade das mostras de Titânio antes da irradiação

$\begin{array}{ccccc}\begin{array}{c}\text { Altura } \\ (\mathrm{mm})\end{array} & \begin{array}{c}\text { Diâmetro } \\ (\mathrm{mm})\end{array} & \begin{array}{c}\text { Volume } \\ \left(\mathrm{cm}^{3}\right)\end{array} & \begin{array}{c}\text { Massa } \\ (\mathrm{g})\end{array} & \begin{array}{c}\text { Densidade } \\ \left(\mathrm{g} / \mathrm{cm}^{3}\right)\end{array} \\ 3,01 & 6,12 & 0,0885 & 0,37 & 4,1795 \\ 3,02 & 6,11 & 0,0885 & 0,36 & 4,0664 \\ 3,02 & 6,11 & 0,0885 & 0,37 & 4,1793 \\ 3,00 & 6,09 & 0,0874 & 0,37 & 4,2348 \\ 3,03 & 6,12 & 0,0891 & 0,37 & 4,1519\end{array}$




$\begin{array}{lccccc} & 3,01 & 6,11 & 0,0882 & 0,37 & 4,1932 \\ & 3,02 & 6,11 & 0,0885 & 0,37 & 4,1793 \\ & 3,02 & 6,12 & 0,0888 & 0,37 & 4,1657 \\ & 3,03 & 6,09 & 0,0882 & 0,35 & 3,9663 \\ \text { Média } & 3,01 & 6,12 & 0,0885 & 0,36 & 4,0665 \\ \text { Desv Pad } & 3,017 & 6,11 & 0,08844 & 0,366 & 4,138 \\ & 0,009 & 0,011547 & 0,00046 & 0,007 & 0,080\end{array}$

TABELA 12 - Densidade das amostras de Titânio após irradiação (10 MV)

$\begin{array}{lccccc} & \text { Altura } & \text { Diâmetro } & \text { Volume } & \text { Massa } & \text { Densidade } \\ & (\mathrm{mm}) & (\mathrm{mm}) & \left(\mathrm{cm}^{3}\right) & (\mathrm{g}) & \left(\mathrm{g} / \mathrm{cm}^{3}\right) \\ & 2,90 & 6,10 & 0,0847 & 0,38 & 4,486 \\ & 3,05 & 6,00 & 0,0862 & 0,37 & 4,292 \\ & 3,00 & 6,05 & 0,0862 & 0,37 & 4,292 \\ & 2,90 & 6,10 & 0,0847 & 0,36 & 4,250 \\ & 2,90 & 6,05 & 0,0834 & 0,36 & 4,316 \\ \text { Média } & 2,90 & 6,10 & 0,0847 & 0,36 & 4,250 \\ \text { Desv Pad } & 3,00 & 6,05 & 0,0862 & 0,37 & 4,292 \\ & 2,950 & 6,064 & 0,0852 & 0,367 & 4,311 \\ & 0,065 & 0,038 & 0,0011 & 0,008 & 0,081\end{array}$

TABELA 13 - Densidade das amostras de Titânio após irradiação (6 MV)

$\begin{array}{ccccc}\text { Altura } & \text { Diâmetro } & \text { Volume } & \text { Massa } & \text { Densidade } \\ (\mathrm{mm}) & (\mathrm{mm}) & \left(\mathrm{cm}^{3}\right) & (\mathrm{g}) & \left(\mathrm{g} / \mathrm{cm}^{3}\right) \\ 3,05 & 6,10 & 0,0891 & 0,360 & 4,040 \\ 3,00 & 6,10 & 0,0877 & 0,360 & 4,107 \\ 3,05 & 6,10 & 0,0891 & 0,390 & 4,376 \\ 3,00 & 6,10 & 0,0877 & 0,360 & 4,107 \\ 2,90 & 6,10 & 0,0847 & 0,350 & 4,130 \\ 2,90 & 6,05 & 0,0834 & 0,360 & 4,319 \\ 3,00 & 6,05 & 0,0862 & 0,360 & 4,175 \\ 3,00 & 6,10 & 0,0877 & 0,370 & 4,221 \\ 3,00 & 6,00 & 0,0848 & 0,365 & 4,304 \\ 2,95 & 6,10 & 0,0862 & 0,365 & 4,235\end{array}$


$\begin{array}{llllll}\text { Média } & 2,985 & 6,080 & 0,0867 & 0,364 & 4,201 \\ \text { Desv Pad } & 0,053 & 0,035 & 0,0019 & 0,010 & 0,109\end{array}$

Comparando os resultados da média da densidade das amostras de Titânio irradiadas com 6 e $10 \mathrm{MV}$, com os resultados da média da densidade das amostras sem irradiar e considerando seus devidos desvios padrões, observa-se uma alteração de 3,5\%. Isso pode acontecer pelo fato do Titânio ser uma liga metálica homogeneizada, fazendo com que seus corpos de prova tenham formato similar e contenham menos irregularidades superficiais.

\subsubsection{Amálgama}

TABELA 14 - Densidade das amostras de Amálgama antes da irradiação

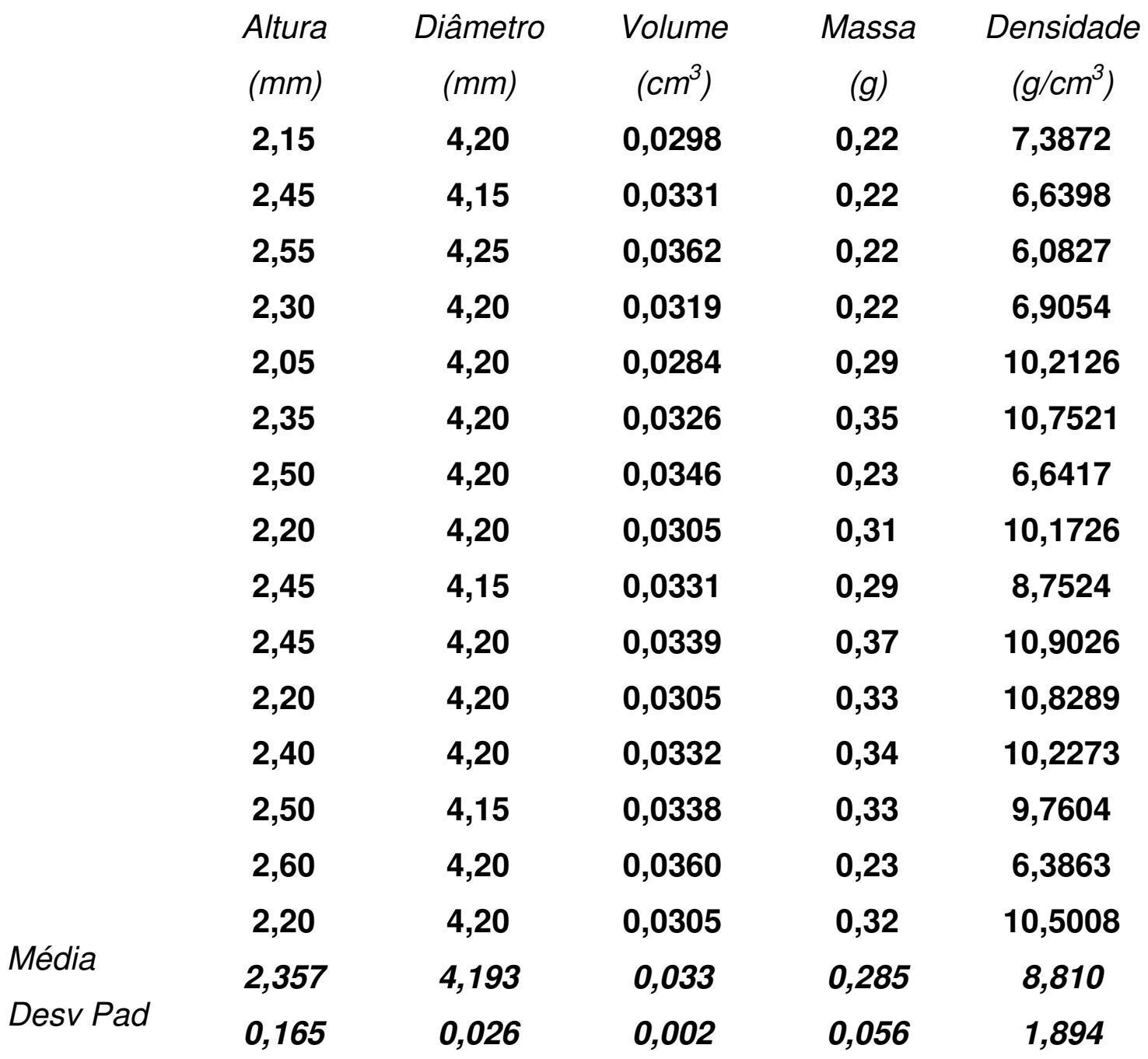




$\begin{array}{cccccc} & \text { Altura } & \text { Diâmetro } & \text { Volume } & \text { Massa } & \text { Densidade } \\ (\mathrm{mm}) & (\mathrm{mm}) & \left(\mathrm{cm}^{3}\right) & (\mathrm{g}) & \left(\mathrm{g} / \mathrm{cm}^{3}\right) \\ 2,15 & 4,20 & 0,0298 & 0,22 & 7,3872 \\ 2,45 & 4,15 & 0,0331 & 0,22 & 6,6398 \\ 2,50 & 4,15 & 0,0338 & 0,37 & 10,9435 \\ & 2,35 & 4,20 & 0,0326 & 0,35 & 10,7521 \\ & 2,05 & 4,20 & 0,0284 & 0,28 & 9,8605 \\ & 2,40 & 4,20 & 0,0332 & 0,36 & 10,8289 \\ & 2,45 & 4,20 & 0,0339 & 0,35 & 10,3132 \\ & 2,15 & 4,20 & 0,0298 & 0,31 & 10,4092 \\ & 2,25 & 4,15 & 0,0304 & 0,3 & 9,8590 \\ & 2,50 & 4,25 & 0,0355 & 0,37 & 10,4346 \\ & 2,25 & 4,10 & 0,0297 & 0,33 & 11,1111 \\ \text { Média } & 2,40 & 4,35 & 0,0357 & 0,34 & 9,5341 \\ \text { Desv Pad } & 2,36 & 4,15 & 0,0352 & 0,33 & 9,3850 \\ & 2,363 & 4,200 & 0,0327 & 0,322 & 9,830 \\ & 2,180 & 0,063 & 0,0026 & 0,049 & 1,259\end{array}$

Nas amostras de Amálgama comparando os resultados da média da densidade nas amostras sem irradiar e irradiadas com $6 \mathrm{MV}$, considerando a média do desvio padrão, pode-se notar uma alteração de 11,4\%. Apesar deste material ser uma liga metálica, o seu manuseio e modelagem é difícil. Por isso as amostras se mostraram tão irregulares e tiveram uma alteração relativamente alta.

\subsubsection{Resina Composta}

TABELA 16 - Densidade das amostras de Resina antes da irradiação

\begin{tabular}{|c|c|c|c|c|}
\hline $\begin{array}{l}\text { Altura } \\
(\mathrm{mm})\end{array}$ & $\begin{array}{c}\text { Diâmetro } \\
(\mathrm{mm})\end{array}$ & $\begin{array}{l}\text { Volume } \\
\left(\mathrm{cm}^{3}\right)\end{array}$ & $\begin{array}{c}\text { Massa } \\
\text { (g) }\end{array}$ & $\begin{array}{c}\text { Densidade } \\
\left(\mathrm{g} / \mathrm{cm}^{3}\right)\end{array}$ \\
\hline 2,20 & 4,15 & 0,030 & 0,05 & 1,681 \\
\hline 2,55 & 4,15 & 0,034 & 0,07 & 2,030 \\
\hline
\end{tabular}




\begin{tabular}{|c|c|c|c|c|c|}
\hline & 2,50 & 4,15 & 0,034 & 0,06 & 1,775 \\
\hline & 2,40 & 4,20 & 0,033 & 0,06 & 1,805 \\
\hline & 2,55 & 4,10 & 0,034 & 0,06 & 1,783 \\
\hline & 2,60 & 4,15 & 0,035 & 0,06 & 1,706 \\
\hline & 2,40 & 4,40 & 0,036 & 0,06 & 1,644 \\
\hline & 2,50 & 4,15 & 0,034 & 0,06 & 1,775 \\
\hline & 2,20 & 4,10 & 0,029 & 0,05 & 1,722 \\
\hline & 2,45 & 4,25 & 0,035 & 0,06 & 1,727 \\
\hline & 2,65 & 4,20 & 0,037 & 0,07 & 1,907 \\
\hline & 2,20 & 4,15 & 0,030 & 0,05 & 1,681 \\
\hline & 2,25 & 4,10 & 0,030 & 0,05 & 1,683 \\
\hline & 2,35 & 4,20 & 0,033 & 0,06 & 1,843 \\
\hline & 2,25 & 4,05 & 0,029 & 0,06 & 2,070 \\
\hline Média & 2,403 & 4,167 & 0,033 & 0,059 & 1,789 \\
\hline Desv Pad & 0,155 & 0,082 & 0,003 & 0,006 & 0,127 \\
\hline
\end{tabular}

TABELA 17 - Densidade das amostras de Resina após irradiação (6 MV)

$\begin{array}{ccccc}\text { Altura } & \text { Diâmetro } & \text { Volume } & \text { Massa } & \begin{array}{c}\text { Densidade } \\ (\mathrm{mm})\end{array} \\ (\mathrm{mm}) & \left(\mathrm{cm}^{3}\right) & (\mathrm{g}) & \left(\mathrm{g} / \mathrm{cm}^{3}\right) \\ 2,20 & 4,15 & 0,030 & 0,05 & 1,681 \\ 2,55 & 4,15 & 0,034 & 0,07 & 2,030 \\ 2,50 & 4,15 & 0,034 & 0,06 & 1,775 \\ 2,40 & 4,20 & 0,033 & 0,06 & 1,805 \\ 2,55 & 4,10 & 0,034 & 0,06 & 1,783 \\ 2,60 & 4,15 & 0,035 & 0,06 & 1,706 \\ 2,40 & 4,40 & 0,036 & 0,06 & 1,644 \\ 2,50 & 4,15 & 0,034 & 0,06 & 1,775 \\ 2,20 & 4,10 & 0,029 & 0,05 & 1,722 \\ 2,45 & 4,25 & 0,035 & 0,06 & 1,727 \\ 2,65 & 4,20 & 0,037 & 0,07 & 1,907 \\ 2,20 & 4,15 & 0,030 & 0,05 & 1,681 \\ 2,25 & 4,10 & 0,030 & 0,05 & 1,683 \\ 2,35 & 4,20 & 0,033 & 0,06 & 1,843 \\ 2,25 & 4,05 & 0,029 & 0,06 & 2,070\end{array}$


$\begin{array}{llllll}\text { Média } & 2,403 & 4,167 & 0,033 & 0,059 & 1,789 \\ \text { Desv Pad } & 0,155 & 0,082 & 0,003 & 0,006 & 0,127\end{array}$

Nas amostras de Resina Composta, verifica-se que não houve alterações na média da densidade. Isso pode acontecer pelo fato dessas amostras passarem por um processo de umidificação e isso fazer com que fique mais fácil o manuseio das mesmas, sendo possível uma melhor modelagem.

\subsubsection{Ionômero de Vidro}

TABELA 18 - Densidade das amostras de lonômero de Vidro antes da irradiação

$\begin{array}{cccccc} & \text { Altura } & \text { Diâmetro } & \text { Volume } & \text { Massa } & \text { Densidade } \\ (\mathrm{mm}) & (\mathrm{mm}) & \left(\mathrm{cm}^{3}\right) & (\mathrm{g}) & \left(\mathrm{g} / \mathrm{cm}^{3}\right) \\ & 2,20 & 4,15 & 0,030 & 0,05 & 1,681 \\ 2,55 & 4,15 & 0,034 & 0,07 & 2,030 \\ & 2,50 & 4,15 & 0,034 & 0,06 & 1,775 \\ & 2,40 & 4,20 & 0,033 & 0,06 & 1,805 \\ & 2,55 & 4,10 & 0,034 & 0,06 & 1,783 \\ & 2,60 & 4,15 & 0,035 & 0,06 & 1,706 \\ & 2,40 & 4,40 & 0,036 & 0,06 & 1,644 \\ & 2,50 & 4,15 & 0,034 & 0,06 & 1,775 \\ & 2,20 & 4,10 & 0,029 & 0,05 & 1,722 \\ & 2,45 & 4,25 & 0,035 & 0,06 & 1,727 \\ & 2,65 & 4,20 & 0,037 & 0,07 & 1,907 \\ \text { Média } & 2,20 & 4,15 & 0,030 & 0,05 & 1,681 \\ & 2,25 & 4,10 & 0,030 & 0,05 & 1,683 \\ & 2,35 & 4,20 & 0,033 & 0,06 & 1,843 \\ & 2,25 & 4,05 & 0,029 & 0,06 & 2,070 \\ & 2,403 & 4,167 & 0,033 & 0,059 & 1,789 \\ & 0,155 & 0,082 & 0,003 & 0,006 & 0,127\end{array}$

TABELA 19 - Densidade das amostras de lonômero de Vidro após irradiação (6 MV)

$\begin{array}{ccccc}\text { Altura } & \text { Diâmetro } & \text { Volume } & \text { Massa } & \text { Densidade } \\ (\mathrm{mm}) & (\mathrm{mm}) & \left(\mathrm{cm}^{3}\right) & (\mathrm{g}) & \left(\mathrm{g} / \mathrm{cm}^{3}\right)\end{array}$




\begin{tabular}{|c|c|c|c|c|c|}
\hline & 2,20 & 4,15 & 0,030 & 0,05 & 1,681 \\
\hline & 2,55 & 4,15 & 0,034 & 0,07 & 2,030 \\
\hline & 2,20 & 4,20 & 0,030 & 0,06 & 1,969 \\
\hline & 2,60 & 4,10 & 0,034 & 0,07 & 2,040 \\
\hline & 2,20 & 4,10 & 0,029 & 0,06 & 2,066 \\
\hline & 2,35 & 4,10 & 0,031 & 0,06 & 1,934 \\
\hline & 2,45 & 4,20 & 0,034 & 0,07 & 2,063 \\
\hline & 2,50 & 4,10 & 0,033 & 0,07 & 2,121 \\
\hline & 2,45 & 4,10 & 0,032 & 0,06 & 1,855 \\
\hline & 2,50 & 4,00 & 0,031 & 0,06 & 1,910 \\
\hline & 2,60 & 4,10 & 0,034 & 0,07 & 2,040 \\
\hline & 2,50 & 4,15 & 0,034 & 0,07 & 2,070 \\
\hline & 2,40 & 4,10 & 0,032 & 0,06 & 1,894 \\
\hline & 2,70 & 4,10 & 0,036 & 0,08 & 2,245 \\
\hline & 2,60 & 4,15 & 0,035 & 0,07 & 1,991 \\
\hline & 2,453 & 4,120 & 0,033 & 0,065 & 1,994 \\
\hline & 0,158 & 0,049 & 0,002 & 0,007 & 0,131 \\
\hline
\end{tabular}

Para as amostras de lonômero de Vidro, notou-se uma alteração na média da densidade das amostras antes e após irradiação de 11,4\%, assim como nas amostras de Amálgama. Essas amostras também são de difícil modelagem, pode ser por este fato que as alterações das amostras de lonômero de Vidro, são idênticas as das amostras de Amálgama.

\subsection{Análise da Composição Química}

A composição química das amostras irradiadas foi analisada pela técnica de fluorescência de raios- $X$, no laboratório de química da Associação Brasileira de Cimento Portaland (ABCP), para essa análise foi utilizado uma amostra de cada grupo, ou seja, uma amostra do grupo piloto e outra do grupo irradiada.

Os resultados foram comparados com aqueles da análise dos corpos pilotos (não irradiados).

\subsubsection{Amostras de Titânio}


TABELA 20 - Composição química das amostras de Titânio

\begin{tabular}{|c|c|c|c|}
\hline $\begin{array}{l}\text { Composição } \\
\text { Química }\end{array}$ & Amostra Piloto & $\begin{array}{c}\text { Amostra Irradiada } \\
\qquad(10 \mathrm{MV})\end{array}$ & $\begin{array}{c}\text { Amostra Irradiada } \\
(6 \mathrm{MV})\end{array}$ \\
\hline Abundância \% & $\%$ & $\%$ & $\%$ \\
\hline $\mathrm{Na}_{2} \mathrm{O}$ & $0,15 \pm 0,01$ & $0,14 \pm 0,01$ & $0,20 \pm 0,01$ \\
\hline $\mathrm{MgO}$ & $0,11 \pm 0,01$ & $0,14 \pm 0,01$ & $0,09 \pm 0,01$ \\
\hline $\mathrm{Al}_{2} \mathrm{O}_{3}$ & $8,30 \pm 0,01$ & $8,26 \pm 0,01$ & $8,38 \pm 0,01$ \\
\hline $\mathrm{SiO}_{2}$ & $0,15 \pm 0,01$ & $0,17 \pm 0,01$ & $0,16 \pm 0,01$ \\
\hline $\mathrm{P}_{2} \mathrm{O}_{5}$ & $0,09 \pm 0,01$ & $0,06 \pm 0,01$ & $0,09 \pm 0,01$ \\
\hline $\mathrm{SO}_{3}$ & $0,05 \pm 0,01$ & $0,05 \pm 0,01$ & $0,05 \pm 0,01$ \\
\hline $\mathrm{Cl}$ & - & $0,02 \pm 0,01$ & - \\
\hline $\mathrm{CaO}$ & $0,03 \pm 0,01$ & $0,05 \pm 0,01$ & $0,04 \pm 0,01$ \\
\hline $\mathrm{TiO}_{2}$ & $86,20 \pm 0,01$ & $86,36 \pm 0,01$ & $86,14 \pm 0,01$ \\
\hline $\mathrm{V}_{2} \mathrm{O}_{5}$ & $4,55 \pm 0,01$ & $4,53 \pm 0,01$ & $4,56 \pm 0,01$ \\
\hline $\mathrm{Fe}_{2} \mathrm{O}_{3}$ & $0,20 \pm 0,01$ & $0,18 \pm 0,01$ & $0,21 \pm 0,01$ \\
\hline $\mathrm{NiO}$ & $0,06 \pm 0,01$ & $0,05 \pm 0,01$ & $0,08 \pm 0,01$ \\
\hline
\end{tabular}

Considerando o erro percentual, a comparação da amostra piloto com as irradiadas com diferentes energias, para o titânio, a tabela mostra que não houve alterações significativas na composição química destas amostras. Esse material é atualmente o mais utilizado em implantes dentários, e conforme discussão com especialistas em odontologia acreditava-se que por ser um metal, ele sofreria interferência e ficaria radioativo quando implantado em pacientes que eram submetidos a radioterapia.

\subsubsection{Amostras de Amálgama}

TABELA 21 - Composição química das amostras de Amálgama

$\begin{array}{ccc}\text { Composição Química } & \text { Amostra Piloto } & \text { Amostra Irradiada (6 MV) } \\ \text { Abundância \% } & \% & \% \\ \mathrm{Al}_{2} \mathrm{O}_{3} & 0,04 \pm 0,01 & 0,04 \pm 0,01 \\ \mathrm{SiO}_{2} & 0,21 \pm 0,01 & 0,10 \pm 0,01 \\ \mathrm{Fe}_{2} \mathrm{O}_{3} & - & 0,08 \pm 0,01 \\ \mathrm{NiO} & 0,10 \pm 0,01 & 0,05 \pm 0,01 \\ \mathrm{CuO} & 2,21 \pm 0,01 & 2,03 \pm 0,01 \\ \mathrm{ZnO} & 0,96 \pm 0,01 & 0,92 \pm 0,01 \\ \mathrm{Ag}_{2} \mathrm{O} & 27,88 \pm 0,01 & 31,55 \pm 0,01 \\ \mathrm{SrO} & 0,34 \pm 0,01 & - \\ \mathrm{SnO}_{2} & 12,98 \pm 0,01 & 16,86 \pm 0,01\end{array}$




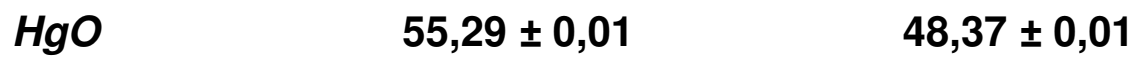

Para os corpos de prova das amostras de Amálgama, considerando o erro percentual, é possível observar diminuição no Óxido de Mercúrio e aumento no Óxido de Prata, fato já relatado em artigos anteriores que mencionam essa liberação de mercúrio na amálgama de prata. Esse material foi o mais utilizado em restaurações dentárias pelo fato de ser resistente, porém a liberação do mercúrio e por não ser estético fez com que ele fosse substituído pela Resina Composta.

\subsubsection{Amostras de Resina Composta}

TABELA 22 - Composição química das amostras de Resina Composta

$\begin{array}{ccc}\text { Composição Química } & \text { Amostra Piloto } & \text { Amostra Irradiada (6 MV) } \\ \text { Abundância \% } & \% & \% \\ \mathrm{Na}_{2} \mathrm{O} & 0,49 \pm 0,01 & 0,29 \pm 0,01 \\ \mathrm{Al}_{2} \mathrm{O}_{3} & 0,46 \pm 0,01 & 0,32 \pm 0,01 \\ \mathrm{SiO}_{2} & 50,87 \pm 0,01 & 35,85 \pm 0,01 \\ \mathrm{P}_{2} \mathrm{O}_{5} & 0,06 \pm 0,01 & - \\ \mathrm{SO}_{3} & 0,24 \pm 0,01 & 0,12 \pm 0,01 \\ \mathrm{CaO} & 0,15 \pm 0,01 & 0,19 \pm 0,01 \\ \mathrm{Fe}_{2} \mathrm{O}_{3} & 0,08 \pm 0,01 & 0,07 \pm 0,01 \\ \mathrm{NiO}_{\mathrm{ZrO}} & 0,07 \pm 0,01 & 0,04 \pm 0,01 \\ \mathrm{HfO}_{2} & 46,98 \pm 0,01 & 62,54 \pm 0,01\end{array}$

Nas amostras de Resina Composta, nota-se uma diminuição do Óxido de Silício e aumento de Óxido de Zircônio. A Resina Composta é o material mais utilizado atualmente em restaurações dentárias, por ser estético e ter alta resistividade.

\subsubsection{Amostras de lonômero de Vidro}

TABELA 23 - Composição química das amostras de lonômero de Vidro 


$\begin{array}{ccc}\text { Composição Química } & \text { Amostra Piloto } & \text { Amostra Irradiada }(6 \\ \text { Abundância \% } & \% & \% \\ \mathrm{Na}_{2} \mathrm{O} & 0,37 \pm 0,01 & 0,4 \pm 0,01 \\ \mathrm{Al}_{2} \mathrm{O}_{3} & 16,3 \pm 0,01 & 17,92 \pm 0,01 \\ \mathrm{SiO}_{2} & 22,15 \pm 0,01 & 24,39 \pm 0,01 \\ \mathrm{P}_{2} \mathrm{O}_{5} & 1,85 \pm 0,01 & 2,04 \pm 0,01 \\ \mathrm{SO}_{3} & 0,27 \pm 0,01 & 0,3 \pm 0,01 \\ \mathrm{~F} & 7,19 \pm 0,01 & - \\ \mathrm{CaO} & 0,15 \pm 0,01 & 0,16 \pm 0,01 \\ \mathrm{Fe}_{2} \mathrm{O}_{3} & 0,11 \pm 0,01 & 0,1 \pm 0,01 \\ \mathrm{NiO} & 0,02 \pm 0,01 & 0,02 \pm 0,01 \\ \mathrm{SrO} & 51,22 \pm 0,01 & 54,23 \pm 0,01 \\ \mathrm{BaO} & 0,39 \pm 0,01 & 0,33 \pm 0,01\end{array}$

$\mathrm{Na}$ análise dos corpos de provas das amostras de lonômero de Vidro, notase uma liberação de Flúor. Fato este, também relatado em literaturas anteriores, por este motivo e por ele ser estético alguns profissionais recomendam o uso deste material, porém a sua baixa resistividade faz com que ele seja pouco utilizado.

\subsubsection{Amostras Irradiadas com Cobalto - 60}

As Tabelas 24 a 26 mostram os resultados obtidos para as amostras de amálgama anteriormente (2001) confeccionadas e irradiadas com cobalto - $60 \mathrm{e}$ analisadas no Laboratório CLA (Centro de Laser e Aplicações) em diferentes datas. Pretende-se aqui verificar se ocorre alteração dos constituintes das amostras ao longo tempo (efeito tardio da radiação).

TABELA 24 - Composição química das amostras de Amálgama Irradiadas com Cobalto - 60 Elemento Presente Amostra Piloto

Abundância \%

$\mathrm{Hg}$

Ag

Sn
$\%$

$53,5 \pm 0,05$

$23,3 \pm 0,05$

$14,6 \pm 0,05$
Amostra Irradiada (análise em 2001)

$\%$

$53,9 \pm 0,05$

$23,0 \pm 0,05$

$14,1 \pm 0,05$
Amostra Irradiada (análise em 2008)

$\%$

$37,5 \pm 0,05$

$21,9 \pm 0,05$

$16,5 \pm 0,05$ 


$\begin{array}{cccc}S i & 0,49 \pm 0,05 & & 0,77 \pm 0,05 \\ \mathrm{Cu} & 7,3 \pm 0,05 & 7,6 \pm 0,05 & 9,7 \pm 0,05 \\ \mathrm{Zn} & 0,17 \pm 0,05 & 0,09 \pm 0,05 & \\ \mathrm{Co} & 0,03 \pm 0,05 & & \\ \mathrm{Na} & & 0,50 \pm 0,05 & \\ \mathrm{Mn} & & 0,07 \pm 0,05 & \\ \mathrm{Cr} & 0,1 \pm 0,05 & 0,07 \pm 0,05 & \\ \mathrm{Co} & & 0,04 \pm 0,05 & \\ O & & & 12,97 \pm 0,05 \\ \mathrm{Mg} & & & 0,11 \pm 0,05 \\ \mathrm{Al} & 0,11 \pm 0,05 & & 0,36 \pm 0,05 \\ P & 0,05 \pm 0,05 & & 0,02 \pm 0,05 \\ \text { S } & & & 0,08 \pm 0,05 \\ \mathrm{Fe} & 0,09 \pm 0,05 & 0,1 \pm 0,05 & 0,19 \pm 0,05 \\ \mathrm{Ni} & 0,04 \pm 0,05 & 0,03 \pm 0,05 & 0,06 \pm 0,05\end{array}$

TABELA 25 - Composição química das amostras de Resina Composta Irradiadas com Cobalto - 60

Elemento Presente Amostra Piloto

Abundância \%

$\begin{array}{ll}\text { Zr } & 24,2 \pm 0,05 \\ \mathrm{Si} & 40,1 \pm 0,05 \\ \mathrm{Hf} & 0,73 \pm 0,05\end{array}$

Fé

$P$

0

$\mathrm{Na}$

Al

$\mathrm{Ca}$

Fé

$\mathrm{Ni}$

Cl

$S$

Mg$$
0,07 \pm 0,05
$$

$\%$

Amostra Irradiada (análise em 2001)

$$
\begin{aligned}
& 23,3 \pm 0,05 \\
& 37,8 \pm 0,05
\end{aligned}
$$$$
0,05 \pm 0,05
$$$$
0,35 \pm 0,05
$$$$
0,06 \pm 0,05
$$$$
0,006 \pm 0,05
$$$$
0,21 \pm 0,05
$$$$
0,17 \pm 0,05
$$
$\%$$$
0,06 \pm 0,05
$$$$
37,8 \pm 0,05
$$$$
0,33 \pm 0,05
$$$$
0,35 \pm 0,05
$$$$
0,27 \pm 0,05
$$

Amostra Irradiada (análise em 2008) $\%$

$40,23 \pm 0,05$

$20,07 \pm 0,05$

$0,49 \pm 0,05$

$0,11 \pm 0,05$

$0,04 \pm 0,05$

$37,94 \pm 0,05$

$0,23 \pm 0,05$

$0,38 \pm 0,05$

$0,4 \pm 0,05$

$\mathbf{0 , 1 1} \pm \mathbf{0 , 0 5}$

$0,01 \pm 0,05$

$0,04 \pm 0,05$ 


$$
\begin{array}{llll}
M n & 0,004 \pm 0,05 & 0,02 \pm 0,05 & \\
C r & 0,001 \pm 0,05 & & 0,02 \pm 0,05 \\
\text { Sr } & & & \\
\text { Co } & & 0,007 \pm 0,05 & \\
\mathrm{Zn} & & 0,001 \pm 0,05 & \\
\mathrm{Cu} & & 0,004 \pm 0,05 &
\end{array}
$$

\begin{tabular}{|c|c|c|c|}
\hline Elemento Presente & $\begin{array}{l}\text { Amostra } \\
\text { Piloto }\end{array}$ & $\begin{array}{l}\text { Amostra Irradiada } \\
\text { (análise em 2001) }\end{array}$ & $\begin{array}{l}\text { Amostra Irradiada } \\
\text { (análise em 2008) }\end{array}$ \\
\hline $\begin{array}{c}\text { Abundância \% } \\
\text { Na }\end{array}$ & $\begin{array}{c}\% \\
1,6 \pm 0,05\end{array}$ & $\begin{array}{c}\% \\
1,6 \pm 0,05\end{array}$ & $\begin{array}{c}\% \\
0,8 \pm 0,05\end{array}$ \\
\hline Al & $8,6 \pm 0,05$ & $9,7 \pm 0,05$ & $4,97 \pm 0,05$ \\
\hline Si & $15,7 \pm 0,05$ & $17,0 \pm 0,05$ & $5,85 \pm 0,05$ \\
\hline $\mathbf{P}$ & $2,1 \pm 0,05$ & $2,6 \pm 0,05$ & $1,28 \pm 0,05$ \\
\hline S & $0,28 \pm 0,05$ & $0,14 \pm 0,05$ & $0,05 \pm 0,05$ \\
\hline $\mathrm{Ca}$ & $0,46 \pm 0,05$ & $0,46 \pm 0,05$ & $0,32 \pm 0,05$ \\
\hline $\mathrm{Cl}$ & $0,36 \pm 0,05$ & $0,28 \pm 0,05$ & \\
\hline K & $0,23 \pm 0,05$ & & \\
\hline $\mathrm{Fe}$ & $0,1 \pm 0,05$ & $0,03 \pm 0,05$ & $0,08 \pm 0,05$ \\
\hline $\mathrm{Ni}$ & $0,01 \pm 0,05$ & $0,01 \pm 0,05$ & $0,02 \pm 0,05$ \\
\hline $\mathrm{Cu}$ & $0,02 \pm 0,05$ & $0,02 \pm 0,05$ & $0,03 \pm 0,05$ \\
\hline $\mathrm{Sr}$ & $34,6 \pm 0,05$ & $43,2 \pm 0,05$ & $61,8 \pm 0,05$ \\
\hline Mg & $0,1 \pm 0,05$ & & \\
\hline Mn & $0,03 \pm 0,05$ & $0,25 \pm 0,05$ & \\
\hline Co & $0,02 \pm 0,05$ & $0,01 \pm 0,05$ & \\
\hline $\mathrm{Zn}$ & $0,01 \pm 0,05$ & $0,02 \pm 0,05$ & \\
\hline $\mathrm{Ba}$ & & & $0,32 \pm 0,05$ \\
\hline $\mathrm{Cr}$ & & $0,02 \pm 0,05$ & \\
\hline $\mathbf{F}$ & $6,6 \pm 0,05$ & & \\
\hline 0 & $29,0 \pm 0,05$ & $24,9 \pm 0,05$ & $24,6 \pm 0,05$ \\
\hline
\end{tabular}

TABELA 26 - Composição química das amostras de Compômero Irradiadas com Coabalto 60

Observando os resultados apresentados nas Tabelas 24 a 26 nota-se que as amostras de Amálgama, Resina Composta e Compômero irradiadas e analisadas em 2001 não apresentam alterações significativas em suas 
composições químicas comparadas com os respectivos grupos pilotos (não irradiados). No entanto, as mesmas amostras foram novamente submetidas a análise em 2008, e verificou-se uma sensível mudança nos percentuais dos seus constituintes. As maiores variações correspondem aos elementos de maior abundância no composto. O elemento mercúrio $(\mathrm{Hg})$ maior abundância nas amostras de Amálgama mostrou redução de cerca de $30 \%$ em sua quantidade. $O$ elemento silício ( $\mathrm{Si}$ ) mais abundante nas amostras de Resina Composta e Compômero apresenta uma redução de 50\% em sua quantidade após 7 anos de irradiação. Este fato sugere que a estrutura química das amostras sofreram mudanças com o passar do tempo após a irradiação, no entanto será necessário a repetição de algumas análises para se comprovar a reprodutibilidade dos resultados.

\subsection{MCNPX}

Os resultados apresentam a dose absorvida para Fótons e Elétrons em cada camada do dente. Foram realizadas duas simulações para cada material estudado.

O feixe e o campo de irradiação utilizados não são reais, porém para este trabalho, onde $o$ interesse era apenas saber em qual camada haveria maior absorção de fóton e elétron foi suficiente.

Para resultados mais próximos da realidade, seria necessário modelar toda a arcada dentária utilizando espectro e feixe de irradiação reais. 


\subsubsection{Titânio}

Simulação de irradiação com fóton de 6 MV

TABELA 27 - Quantidade de Fóton absorvido para energia de 6 MV para o Titânio Camadas do Dente Dose/Atividade (Gray/Bq.s)

1 - Dentina Radicular

2 - Nervo e Raiz

3 - Dentina Radicular voltada para o Cépto Radicular

4 - Esmalte

12 - Restauração

$8,45125 \mathrm{E}-11 \pm 2,62 \mathrm{E}-13$

$3,92021 \mathrm{E}-11 \pm 4,70 \mathrm{E}-14$

$5,97081 \mathrm{E}-11 \pm 4,18 \mathrm{E}-14$

$3,31502 \mathrm{E}-10 \pm 2,32 \mathrm{E}-13$

$1,74938 \mathrm{E}-12 \pm 1,22 \mathrm{E}-15$

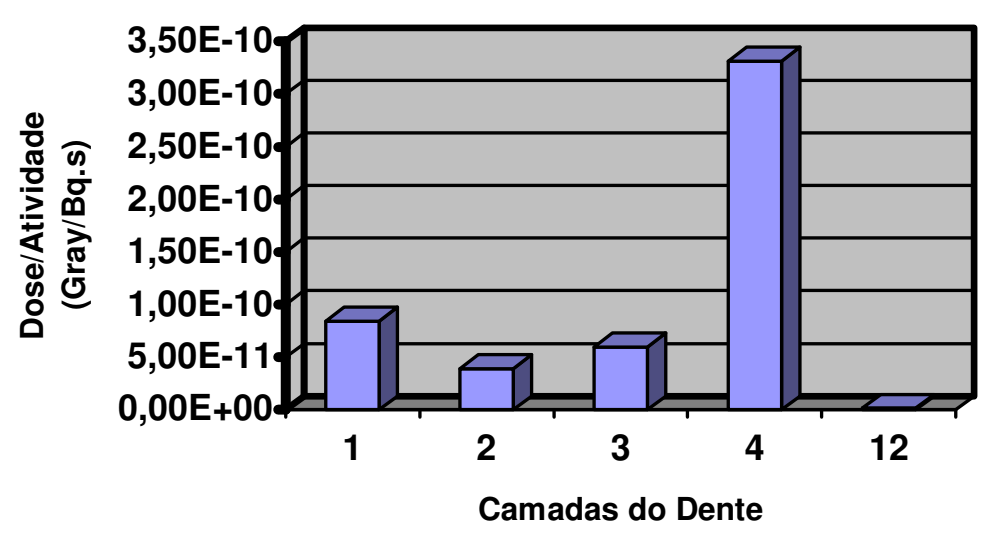

FIGURA 58 - Quantidade de Fóton absorvido nas camadas do dente com irradiação de 6 MV para o Titânio

TABELA 28 - Quantidade de Elétron absorvido para energia de 6 MV para o Titânio Camadas do dente

Dose/Atividade (Gray/Bq.s)

1 - Dentina Radicular

2 - Nervo e Raiz

3 - Dentina Radicular voltada para o Cépto Radicular

4 - Esmalte

12 - Restauração

2,29533E-11 $\pm 3,19 \mathrm{E}-13$

1,39715E-11 $\pm 1,02 \mathrm{E}-13$

$1,27937 \mathrm{E}-11 \pm 5,88 \mathrm{E}-14$

$6,78314 \mathrm{E}-11 \pm 2,85 \mathrm{E}-13$

$6,89246 \mathrm{E}-14 \pm 1,29 \mathrm{E}-15$ 


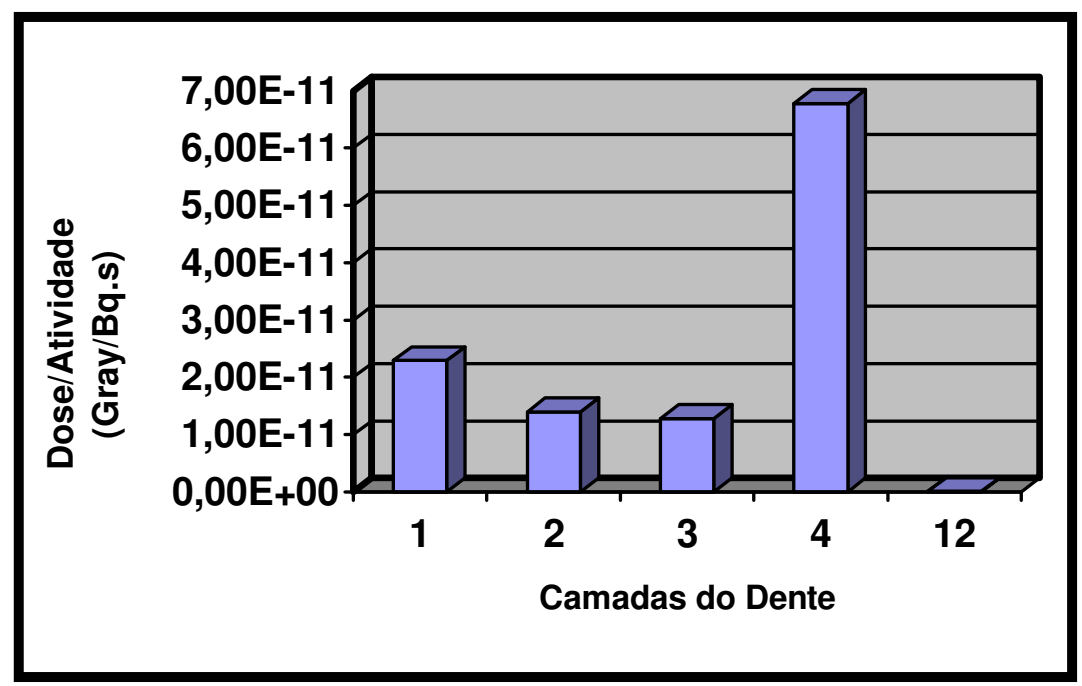

FIGURA 59 - Quantidade de Elétron absorvido nas camadas do dente com irradiação de 6 MV para o Titânio

As tabelas 27 e 28 mostram os resultados da simulação com restauração de Titânio, quando irradiado com fóton de 6 MV. Nas figuras 58 e 59, esses resultados estão ilustrados em forma de gráfico para uma melhor visualização.

Os resultados para Fóton mostram que o esmalte, representado pela camada 4, é a camada que recebe maior dose. Em seguida a dentina radicular, representada pela camada 1 , a dentina radicular voltada para o cépto radicular, representada pela camada 3 , o nervo e a raiz, representada pela camada 2 e por ultimo, quem recebe menor dose é a camada 12, que representa a restauração dentária.

Os resultados do elétron para a simulação com restauração de Titânio quando irradiados com fóton de $6 \mathrm{MV}$ mostram também que a camada 4, representado pelo esmalte continua sendo a camada que recebe maior dose. Em seguida vem a camada 1, que representa a dentina radicular, seguida do nervo e raiz, representado pela camada 2. Logo após, a camada que recebe maior dose é a camada 3, correspondente a dentina radicular voltada para o cépto radicular e por ultimo a camada 12, equivalente a restauração dentária.

Observamos que para o Titânio irradiado com 6 MV, a única diferença nos resultados de fóton e elétron é que para os resultados com fóton a dentina radicular voltada para o cépto radicular fica em terceiro lugar das camadas que recebem maior dose, já para os resultados com elétron o terceiro lugar é ocupado pelo nervo e raiz. 
TABELA 29 - Quantidade de Fóton absorvido para energia de 10 MV para o Titânio

Camadas do dente

1 - Dentina Radicular

2 - Nervo e Raiz

3 - Dentina Radicular voltada para o Cépto Radicular

4 - Esmalte

12 - Restauração
Dose/Atividade (Gray/Bq.s)

$1,47229 \mathrm{E}-10 \pm 4,56 \mathrm{E}-13$

$5,78798 \mathrm{E}-11 \pm 6,95 \mathrm{E}-14$

$1,03992 \mathrm{E}-10 \pm 7,28 \mathrm{E}-14$

$5,35095 \mathrm{E}-10 \pm 3,75 \mathrm{E}-13$

$2,80456 \mathrm{E}-12 \pm 1,96 \mathrm{E}-15$

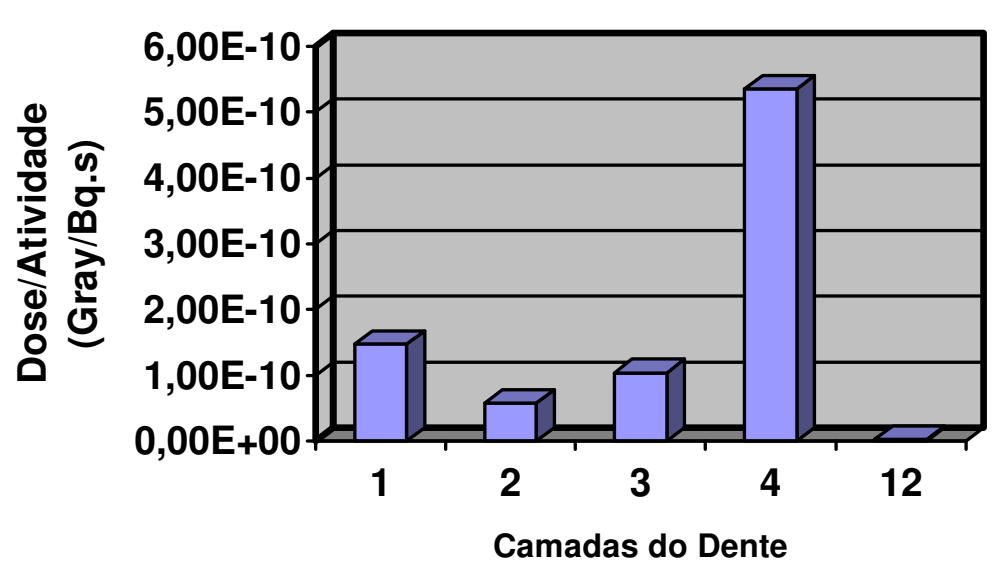

FIGURA 60 - Quantidade de Fóton absorvido nas camadas do dente com irradiação de 10 MV para o Titânio

TABELA 30 - Quantidade de Elétron absorvido para energia de 10 MV para o Titânio

Camadas do dente

Dose/Atividade (Gray/Bq.s)

1 - Dentina Radicular

2 - Nervo e Raiz

3 - Dentina Radicular voltada para o Cépto Radicular

4 - Esmalte

12 - Restauração

$2,40340 \mathrm{E}-11 \pm 3,84 \mathrm{E}-13$

1,43222E-11 $\pm 1,17 \mathrm{E}-13$

1,36993E-11 $\pm 6,85 \mathrm{E}-14$

7,26678E-11 $\pm 3,41 \mathrm{E}-13$

$5,77362 \mathrm{E}-14 \pm 1,23 \mathrm{E}-15$ 


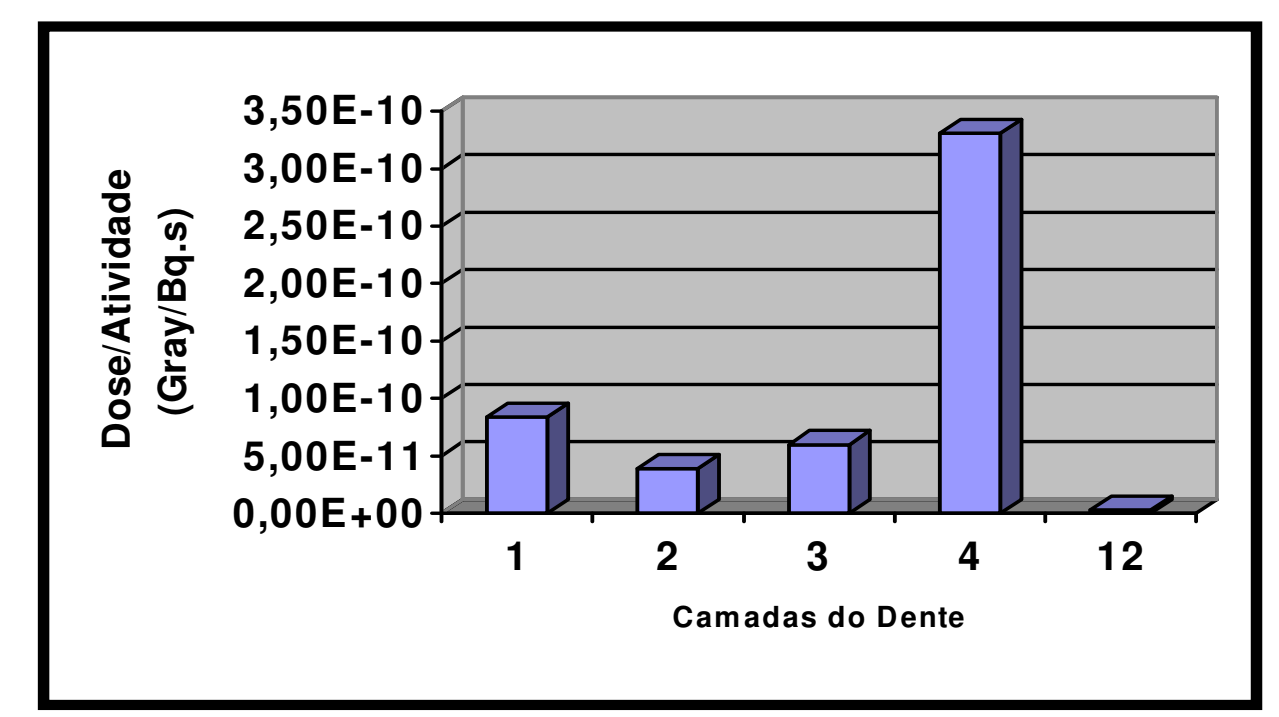

Figura 61 - Quantidade de Elétron absorvido nas camadas do dente com irradiação de 10 MV para o Titânio

Os resultados das simulações do Titânio irradiados com Fóton de $10 \mathrm{MV}$ estão representados na tabela 29 e 30 . Nas figuras 60 e 61 estão esses resultados na forma de gráfico.

Os resultados com fóton, representados na tabela 60 , mostram que 0 esmalte, representado pela camada 4 é a camada que recebe maior dose. Seguido da dentina radicular, equivalente a camada 1. Logo após a dentina radicular voltada para o cépto radicular, a camada 3 e em seguida o nervo e raiz representados pela camada 2. Por ultimo a camada 12, que equivale a restauração dentária (Titânio), sendo assim a camada que recebe menor dose.

Para os resultados com elétron, tabela 61 , com exceção do nervo e raiz representado pela camada 2 que passa a receber maior dose que a camada 3 equivalente a dentina radicular voltada para o cépto radicular, os resultado são os mesmos apresentados para fóton, mostrados anteriormente. 


\subsubsection{Amálgama}

Simulação de irradiação com fóton de 6 MV

TABELA 31 - Quantidade de Fóton absorvido para energia de 6 MV para a Amálgama Camadas do Dente

Dose/Atividade (Gray/Bq.s)

1 - Dentina Radicular

$8,39927 \mathrm{E}-11 \pm 2,60 \mathrm{E}-13$

2 - Nervo e Raiz

3 - Dentina Radicular voltada para o Cépto Radicular

$3,89473 \mathrm{E}-11 \pm 4,68 \mathrm{E}-14$

4 - Esmalte

$5,95585 \mathrm{E}-11 \pm 4,17 \mathrm{E}-14$

12 - Restauração

$3,31026 \mathrm{E}-10 \pm 2,32 \mathrm{E}-13$

$2,86505 \mathrm{E}-12 \pm 2,01 \mathrm{E}-15$

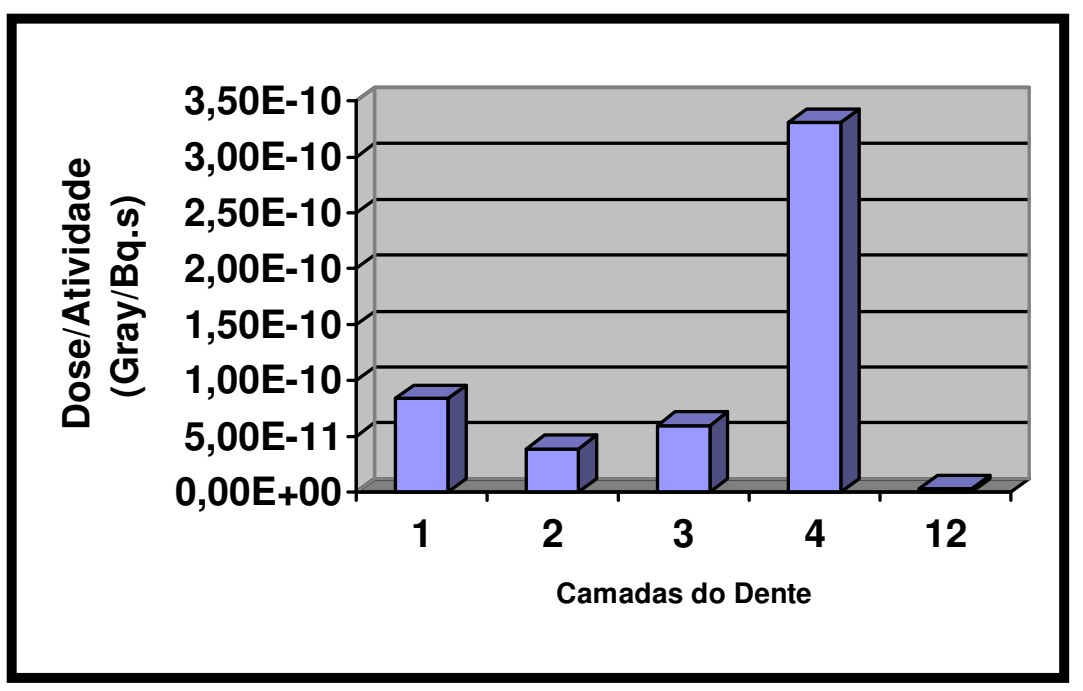

FIGURA 62 - Quantidade de Fóton absorvido nas camadas do dente com irradiação de 6 MV para a Amálgama

TABELA 32 - Quantidade de Elétron absorvido para energia de 6 MV para o Titânio Camadas do Dente

Dose/Atividade (Gray/Bq.s)

1 - Dentina Radicular

2 - Nervo e Raiz

3 - Dentina Radicular voltada para o Cépto Radicular

4 - Esmalte

12 - Restauração

$2,47794 \mathrm{E}-11 \pm 3,30 \mathrm{E}-13$

1,56672E-11 $\pm 1,08 \mathrm{E}-13$

$1,53319 \mathrm{E}-11 \pm 6,75 \mathrm{E}-14$

7,54957E-11 $\pm 3,02 \mathrm{E}-13$

$2,45359 \mathrm{E}-13 \pm 2,65 \mathrm{E}-15$ 


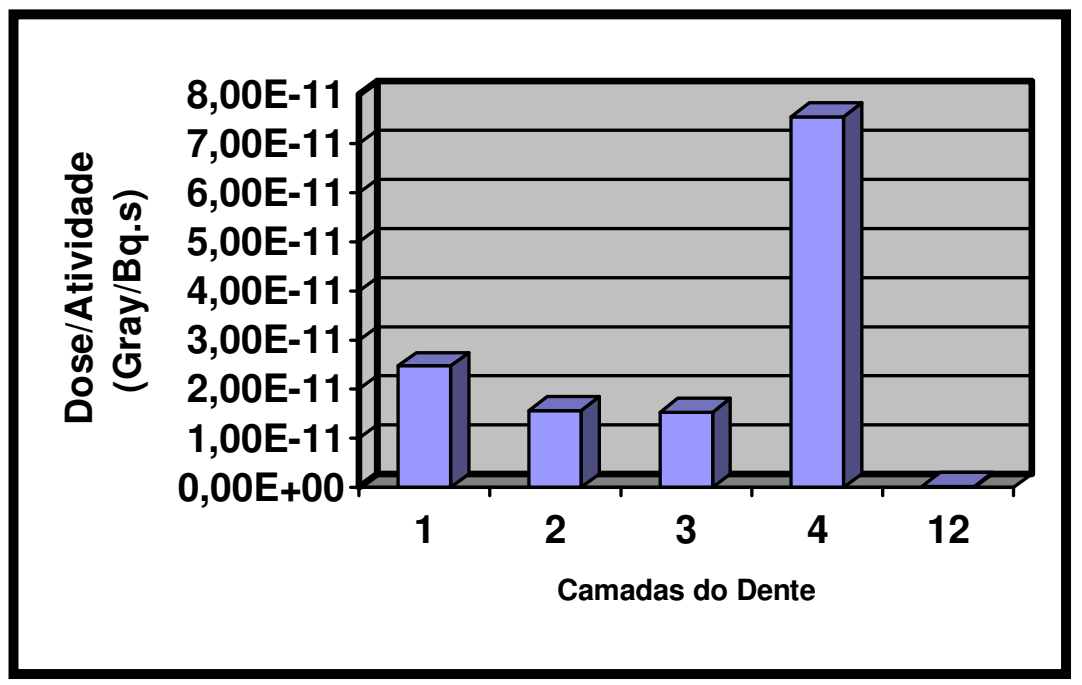

Figura 63 - Quantidade de Elétron absorvido nas camadas do dente com irradiação de 6 MV para a Amálgama

Para a amálgama irradiada com fóton de $6 \mathrm{MV}$, os resultados estão representados nas tabelas 31 e 32 . E os gráficos com esses resultados estão representados nas figuras 62 e 63.

Os resultados com fótons, mostram que o esmalte, representado pela camada 4 recebe maior dose, em seguida a camada 1 que é a dentina radicular, logo após a camada 3 equivalente a dentina radicular voltada para o cépto radicular, e a próxima foi a camada 2 que representa o nervo e raiz. Por ultimo, a camada que recebeu menor dose foi a camada 12, a restauração dentária (Amálgama).

Nos resultados com elétron, houve uma pequena diferença com os resultados com fóton. No elétron o nervo e a raiz, camada 2, recebeu um pouco mais de dose do que a camada 3, que é a dentina radicular voltada para o cépto radicular.

Para as outras camadas, os resultados mantiveram-se os mesmos.

\section{Simulação de irradiação com fóton de $10 \mathrm{MV}$}

TABELA 34 - Quantidade de Fóton absorvido para energia com 10 MV para a Amálgama Camadas do Dente

Dose/Atividade (Gray/Bq.s)

1 - Dentina Radicular

2 - Nervo e Raiz

3 - Dentina Radicular voltada para o Cépto Radicular 
4 - Esmalte

$5,34077964 \mathrm{E}-10 \pm 3,74 \mathrm{E}-13$

12 - Restauração

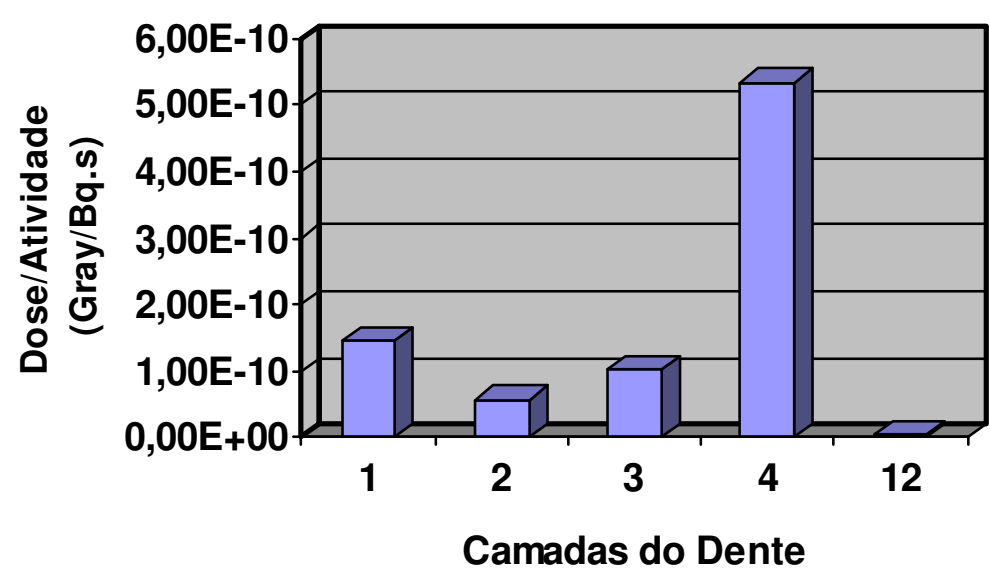

FIGURA 64 - Quantidade de Fóton absorvido nas camadas do dente com irradiação de 10 MV para a Amálgama

TABELA 34 - Quantidade de Elétron absorvido para energia de 10 MV para a Amálgama Camadas do Dente

Dose/Atividade (Gray/Bq.s)

1 - Dentina Radicular

2 - Nervo e Raiz

3 - Dentina Radicular voltada para o Cépto Radicular

4 - Esmalte

12 - Restauração

$2,87274 \mathrm{E}-11 \pm 4,16 \mathrm{E}-13$

$1,80766 \mathrm{E}-11 \pm 1,32 \mathrm{E}-13$

$1,77644 \mathrm{E}-11 \pm 7,99 \mathrm{E}-14$

$8,51775 \mathrm{E}-11 \pm 3,66 \mathrm{E}-13$

$2,44515 \mathrm{E}-13 \pm 3,03 \mathrm{E}-15$

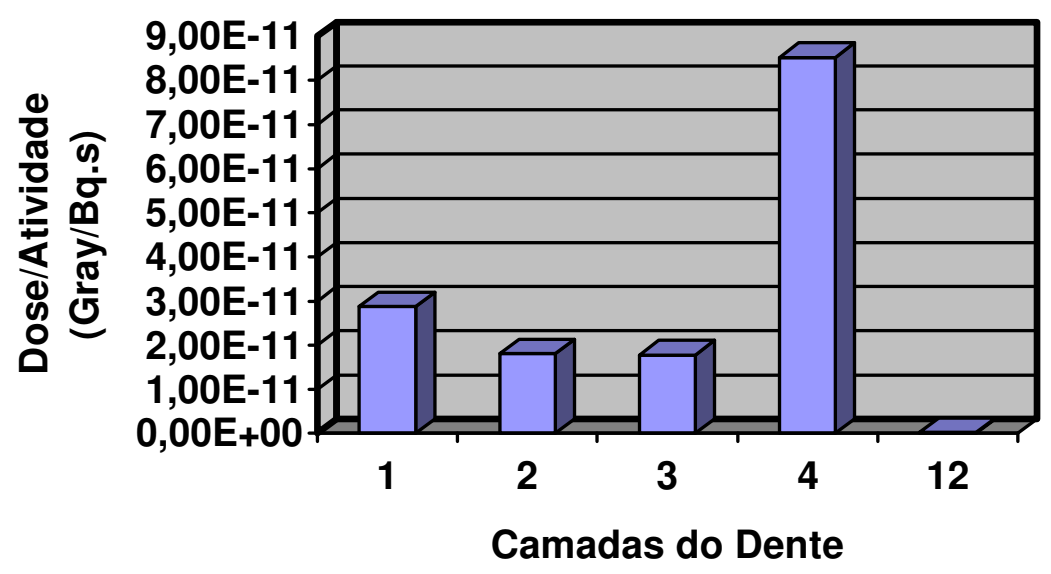

Figura 65 - Quantidade de Elétron absorvido nas camadas do dente com irradiação de 10 MV para a Amálgama

Nas simulações com fóton de $10 \mathrm{MV}$, os resultados se repetem aos anteriores com fótons de $6 \mathrm{MV}$, ou seja, a camada que obteve maior energia 
depositada foi a 4, que representa o esmalte. Seguida da dentina radicular, camada 1. Na seqüência vem a camada 3 , dentina radicular voltada para o cépto radicular e a camada 2, que é o nervo e raiz. Por ultimo, a camada 12 correspondente a restauração dentária (Amálgama) é a camada que recebe menos dose. Esses resultados estão ilustrados nas tabelas 34 e 35 e ilustrados nas figuras 64 e 65.

Nos resultados com elétrons, a diferença com relação aos resultados com fótons foi que a camada 2, nervo e raiz, obteve maior dose do que a camada 3 , dentina radicular voltada para o cépto radicular. As demais camadas mantiveramse iguais aos resultados anteriores.

\subsubsection{Resina Composta}

\section{Simulação de irradiação com fóton de 6 MV}

TABELA 35 - Quantidade de Fóton absorvido para energia com 6 MV para a Resina Composta Camadas do Dente

Dose/Atividade (Gray/Bq.s)

1 - Dentina Radicular

2 - Nervo e Raiz

3 - Dentina Radicular voltada para o Cépto Radicular

4 - Esmalte

$8,46487 \mathrm{E}-11 \pm 2,62 \mathrm{E}-13$

12 - Restauração

$3,92612 \mathrm{E}-11 \pm 4,71 \mathrm{E}-14$

$5,97389 \mathrm{E}-11 \pm 4,18 \mathrm{E}-14$

$3,31606 \mathrm{E}-10 \pm 2,32 \mathrm{E}-13$

$1,92001 \mathrm{E}-12 \pm 1,34 \mathrm{E}-15$ 


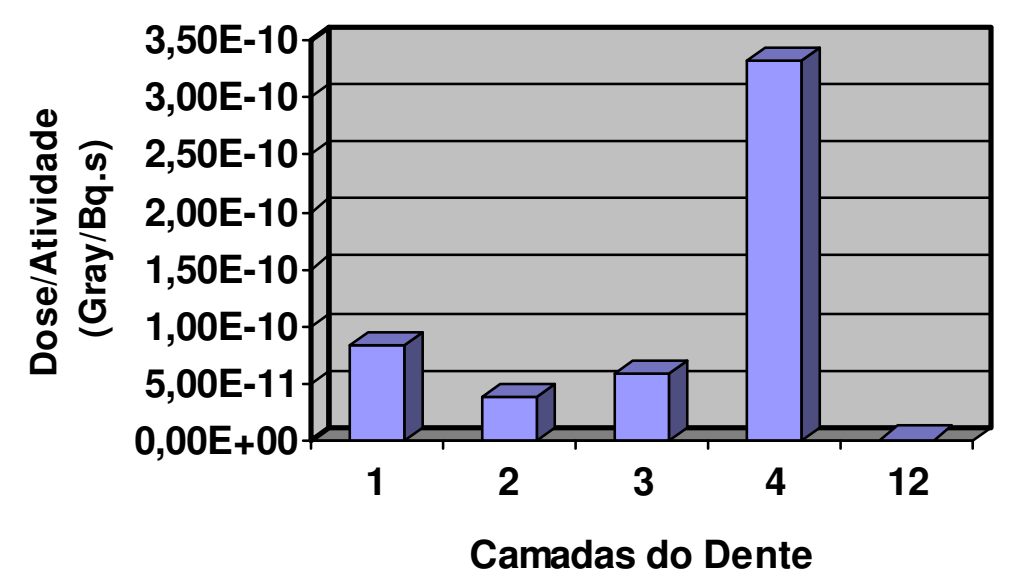

FIGURA 66 - Quantidade de Fóton absorvido nas camadas do dente com irradiação de 6 MV para a Resina Composta

TABELA 36 - Quantidade de Elétron absorvido para energia de 6 MV para a Resina Composta Camadas do Dente

Dose/Atividade (Gray/Bq.s)

1 - Dentina Radicular

2 - Nervo e Raiz

3 - Dentina Radicular voltada para o Cépto

2,22069E-11 $\pm 3,13 \mathrm{E}-13$

$1,34071 \mathrm{E}-11 \pm 1,00 \mathrm{E}-12$

Radicular

4 - Esmalte

12 - Restauração

1,22198E-11 \pm 5,74E-14

6,61399E-11 $\pm 3,10 \mathrm{E}-13$

4,15439E-14 \pm 1,15E-15

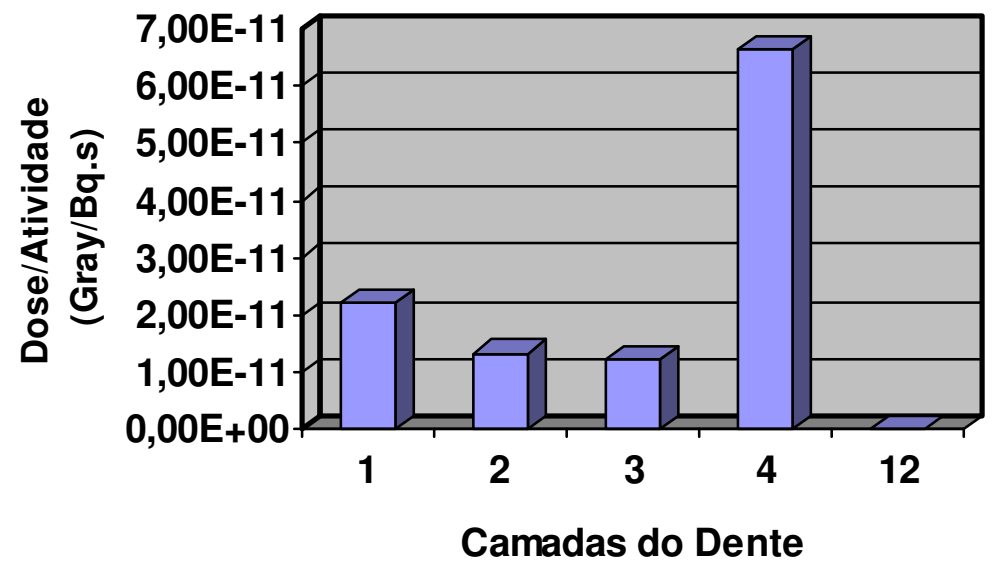

FIGURA 67 - Quantidade de Elétron absorvido nas camadas do dente com irradiação de 6 MV para a Resina Composta 
Para a Resina Composta, os resultados das simulações com fótons de 6 MV, ilustrados nas tabelas 35 e 36 e figuras 66 e 67 mostram que para fótons a camada 4, equivalente ao esmalte teve maior energia depositada. Em seguida a camada 1 que representa a dentina radicular, a próxima é a camada 3 , a dentina radicular voltada para o cépto radicular e a camada 2 , o nervo e raiz. A camada 12, está em ultimo lugar, sendo a camada que recebeu menor dose.

Para os resultados com elétrons de $6 \mathrm{MV}$, os resultados repetem aos dos fótons com $6 \mathrm{MV}$, mudando apenas as camadas 2 que é o nervo e raiz passou a ter maior dose depositada do que a camada 3 dentina radicular voltada para 0 cépto radicular. As demais camadas se mantiveram na mesma ordem.

\section{Simulação de irradiação com fóton de 10 MV}

TABELA 37 - Quantidade de Fóton absorvido para energia com 10 MV para a Resina Composta Camadas do Dente

Dose/Atividade (Gray/Bq.s)

1 - Dentina Radicular

1,47229E-10 \pm 4,71E-13

2 - Nervo e Raiz

3 - Dentina Radicular voltada para o Cépto

$5,78798 \mathrm{E}-11 \pm 6,95 \mathrm{E}-14$

Radicular

$1,03992 \mathrm{E}-10 \pm 7,28 \mathrm{E}-14$

4 - Esmalte

$5,35095 \mathrm{E}-10 \pm 3,75 \mathrm{E}-13$

12 - Restauração

2,80456E-12 \pm 1,96E-15

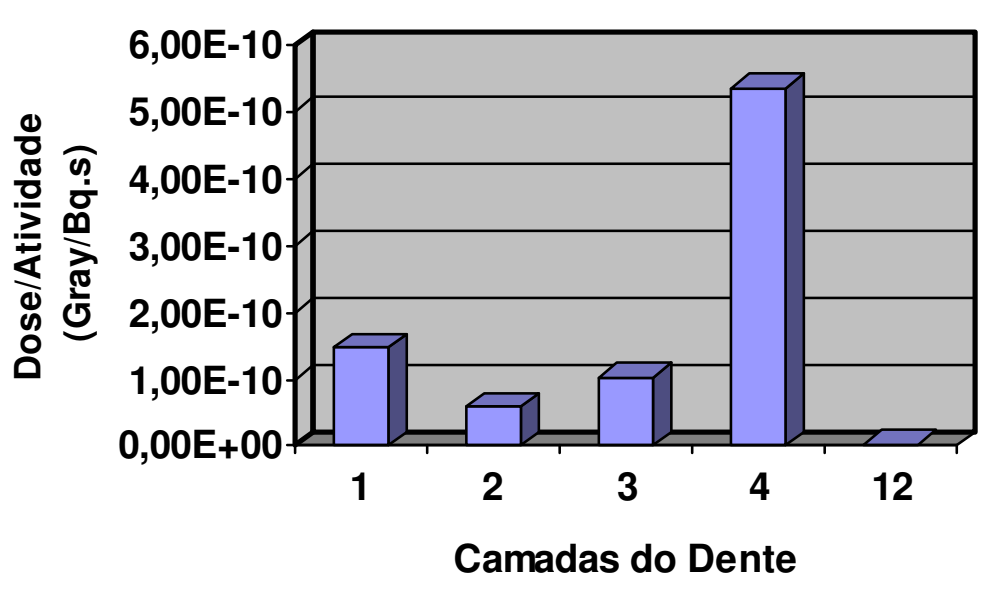

FIGURA 68 - Quantidade de Fóton absorvido nas camadas do dente com irradiação de 10 MV para a Resina Composta 
TABELA 38 - Quantidade de Elétron absorvido para energia de 10 MV para a Resina Composta Camadas do Dente

Dose/Atividade (Gray/Bq.s)

1 - Dentina Radicular

2 - Nervo e Raiz

2,32367E-11 $\pm 3,78 \mathrm{E}-13$

3 - Dentina Radicular voltada para o Cépto

$1,36229 \mathrm{E}-11 \pm 1,14 \mathrm{E}-13$

Radicular

4 - Esmalte

$1,31480 \mathrm{E}-11 \pm 6,57 \mathrm{E}-14$

12 - Restauração

$7,10181 \mathrm{E}-11 \pm 3,34 \mathrm{E}-13$

$3,44843 \mathrm{E}-14 \pm 1,38 \mathrm{E}-15$

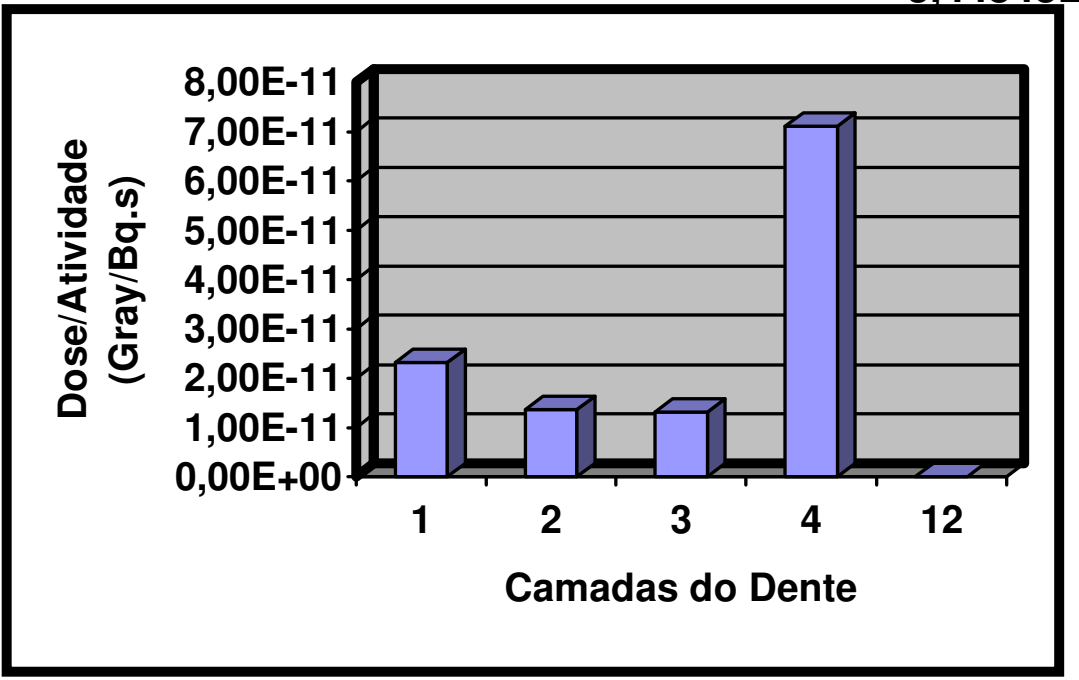

FIGURA 69 - Quantidade de Elétron absorvido nas camadas do dente com irradiação de 10 MV para a Resina Composta

Para a simulação com Fóton de $10 \mathrm{MV}$, tabelas 37 e 38 e figuras 68 e 69, o mesmo se repete com relação a simulação anterior com fóton de $6 \mathrm{MV}$.

Para fóton, a camada 4 que representa o esmalte obteve maior dose, em seguida a camada 1 que representa a dentina radicular, logo após a camada 3 que é a dentina radicular voltada para o cépto radicular e a camada 2 equivalente ao nervo e raiz. Por fim a camada 12, representante da restauração dentária (Resina Composta) é a camada que recebe menos dose.

O mesmo acontece com os resultados para elétrons, a única diferença é que a camada 2, o nervo e raiz, recebe mais dose do que a camada 3 que representa a dentina radicular voltada para o cépto radicular. As outras camadas se mantiveram na mesma ordem que a simulação anterior. 


\subsection{4 lonômero de Vidro}

Simulação de irradiação com fóton de 6 MV

TABELA 39 - Quantidade de Fóton absorvido para energia com 6 MV para o lonômero de Vidro Camadas do Dente

Dose/Atividade (Gray/Bq.s)

1 - Dentina Radicular

2 - Nervo e Raiz

3 - Dentina Radicular voltada para o Cépto

8,46450E-11 $\pm 2,71 \mathrm{E}-13$

Radicular

4 - Esmalte

5,97376E-11 \pm 4,18E-14

12 - Restauração

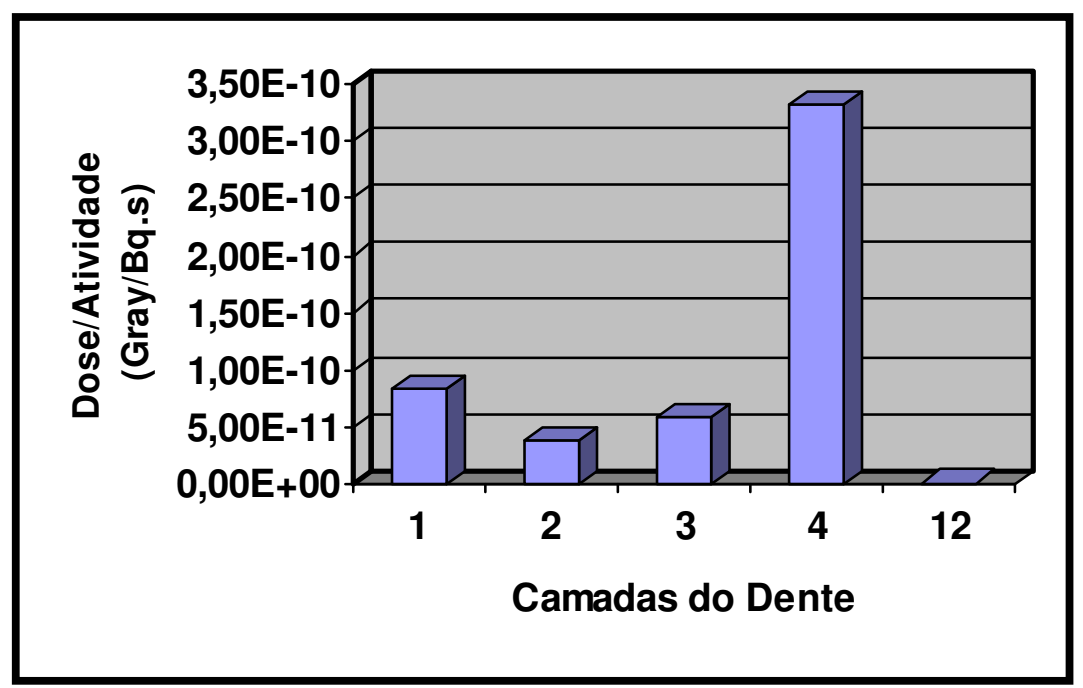

FIGURA 70 - Quantidade de Fóton absorvido nas camadas do dente com irradiação de 6 MV para o lonômero de Vidro

Tabela 40 - Quantidade de Elétron absorvido para energia de 6 MV para o lonômero de Vidro Camadas do Dente

Dose/Atividade (Gray/Bq.s)

1 - Dentina Radicular

2 - Nervo e Raiz

3 - Dentina Radicular voltada para o Cépto Radicular

4 - Esmalte

12 - Restauração

2,23091E-11 \pm 3,14E-13

1,34117E-11 $\pm 1,00 \mathrm{E}-13$

$1,22508 \mathrm{E}-11 \pm 5,75 \mathrm{E}-14$

$6,62908 \mathrm{E}-11 \pm 2,85 \mathrm{E}-13$

$4,32836 \mathrm{E}-14 \pm 1,20 \mathrm{E}-15$ 


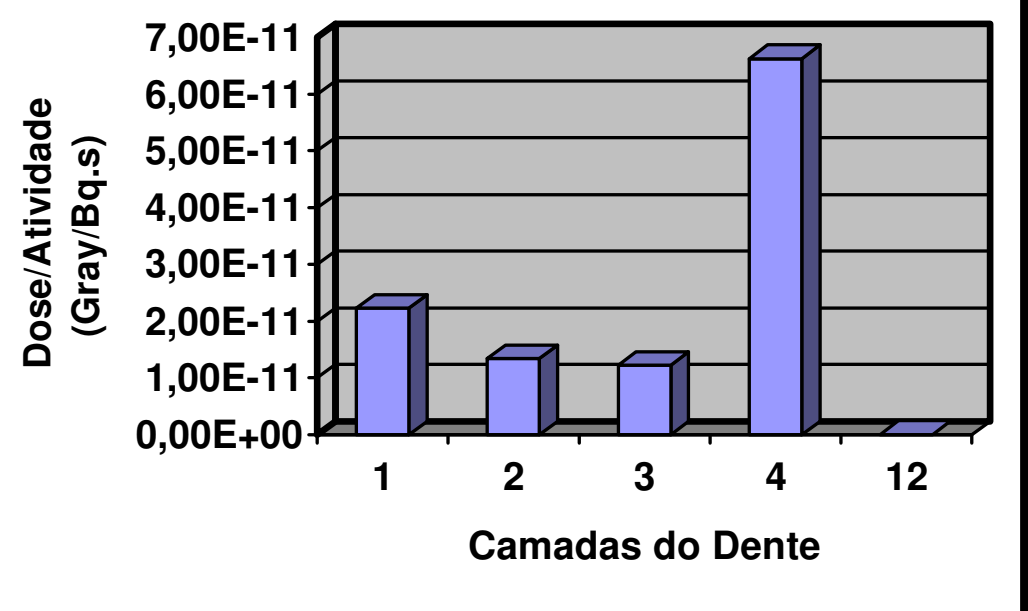

Figura 71 - Quantidade de Elétron absorvido nas camadas do dente com irradiação de 6 MV para o lonômero de Vidro

Nas tabelas 39 e 40 e nas figuras 70 e 71 representam as simulações para o lonômero de Vidro com fóton de $6 \mathrm{MV}$.

Para os resultados com fóton, o esmalte que é a camada 4 foi o que recebeu maior dose. Em seguida a camada 1 que representa dentina radicular, seguida da camada 3 representante da dentina radicular voltada para o cépto radicular e em seguida a camada 2 correspondente ao nervo e raiz. Por fim a camada 12, é a camada que recebeu menos dose e equivale a restauração (lonômero de vidro).

Nos resultados com elétron, nota-se uma semelhança com os resultados de fóton mostrados anteriormente. A única mudança é na camada 2 representante do nervo e raiz, que recebeu maior dose do que a camada 3 dentina interna voltada para o cépto radicular. As demais camadas mantiveram-se iguais.

\section{Simulação de irradiação com fóton de 10 MV}

TABELA 41 - Quantidade de Fóton absorvido para energia de com 10 MV de lonômero de Vidro Camadas do Dente

Dose/Atividade (Gray/Bq.s)

1 - Dentina Radicular

2 - Nervo e Raiz

3 - Dentina Radicular voltada para o Cépto Radicular

4 - Esmalte 


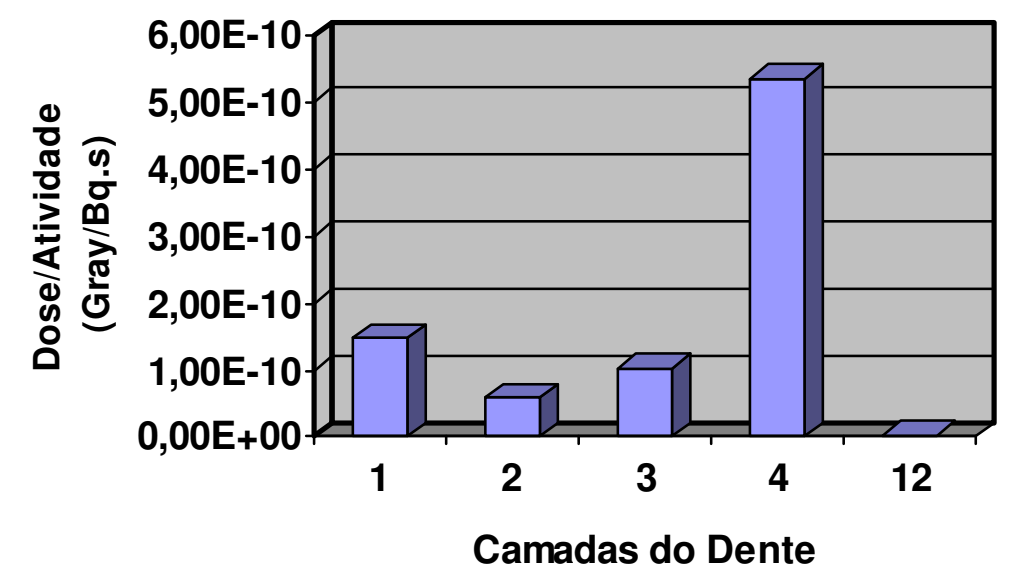

FIGURA 72 - Quantidade de Fóton absorvido nas camadas do dente com irradiação de 10 MV para o lonômero de Vidro

TABELA 42 - Quantidade de Elétron absorvido para energia de 10 MV para o lonômero de Vidro Camadas do Dente Dose/Atividade (Gray/Bq.s)

1 - Dentina Radicular

2 - Nervo e Raiz

$1,47411 \mathrm{E}-10 \pm 2,40 \mathrm{E}-12$

3 - Dentina Radicular voltada para o Cépto

$5,79467 \mathrm{E}-11 \pm 4,86 \mathrm{E}-13$

Radicular

4 - Esmalte

12 - Restauração

$1,04039 \mathrm{E}-10 \pm 5,20 \mathrm{E}-13$

$5,35231 \mathrm{E}-10 \pm 2,51 \mathrm{E}-12$

$3,27888 \mathrm{E}-12 \pm 1,03 \mathrm{E}-13$

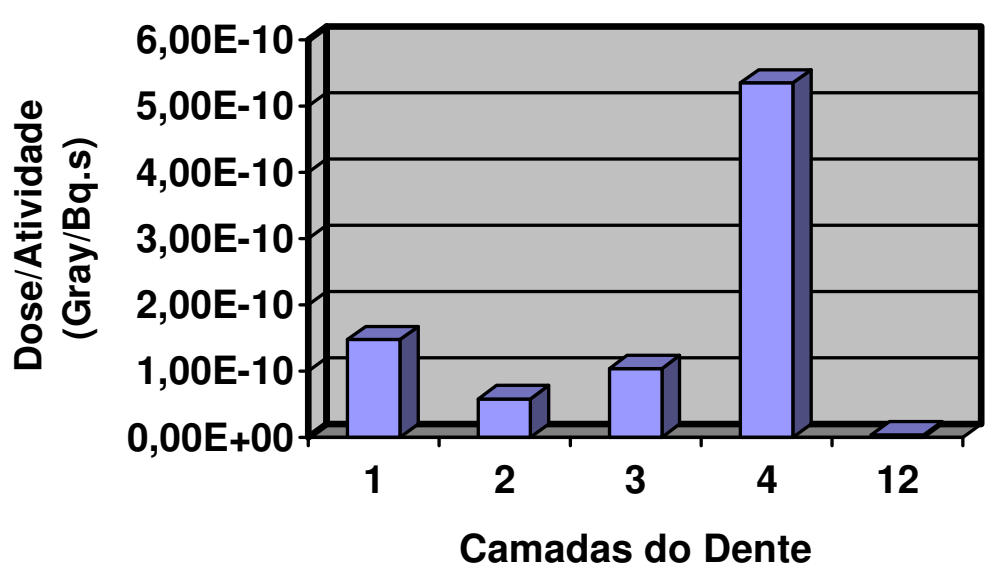

Figura 73 - Quantidade de Elétron absorvido nas camadas do dente com irradiação de 10 MV para o lonômero de Vidro 
As tabelas 41 e 42 e os gráficos 72 e 73 contêm os resultados da simulação para o lonômero de Vidro sendo irradiado com fóton de $10 \mathrm{MV}$.

Para os resultados com fóton, observamos que o esmalte, representado pela camada 4, é onde contém a maior dose. Em seguida está a camada 1, que equivale a dentina radicular. A próxima é a dentina radicular voltada para o cépto radicular, representada pela camada 3 e na seqüência, encontra-se a camada 2 , que é o nervo e raiz. Por fim, a camada 12 que representa a restauração dentária (lonômero de Vidro) foi a camada que teve menos dose depositada.

Nos resultados com elétron, observamos uma diferença com relação aos resultados com fótons. A camada 2 , que representa o nervo e a raiz recebeu maior dose do que a camada 3 que é a dentina radicular voltada para o cépto radicular. As demais camadas se mantiveram na mesma ordem que na simulação anterior.

\subsubsection{Compômero}

Simulação de irradiação com fóton de 6 MV

TABELA 43 - Quantidade de Fóton absorvido para energia de 6 MV de Compômero Camadas do Dente

Dose/Atividade (Gray/Bq.s)

1 - Dentina Radicular

2 - Nervo e Raiz

3 - Dentina Radicular voltada para o Cépto

8,46412E-11 \pm 2,62E-13

Radicular

4 - Esmalte

$3,92580 \mathrm{E}-11 \pm 4,71 \mathrm{E}-14$

12 - Restauração

5,97370E-11 \pm 4,18E-14

3,31601E-10 \pm 2,32E-13

1,92062E-12 $\pm 1,35 E-15$ 


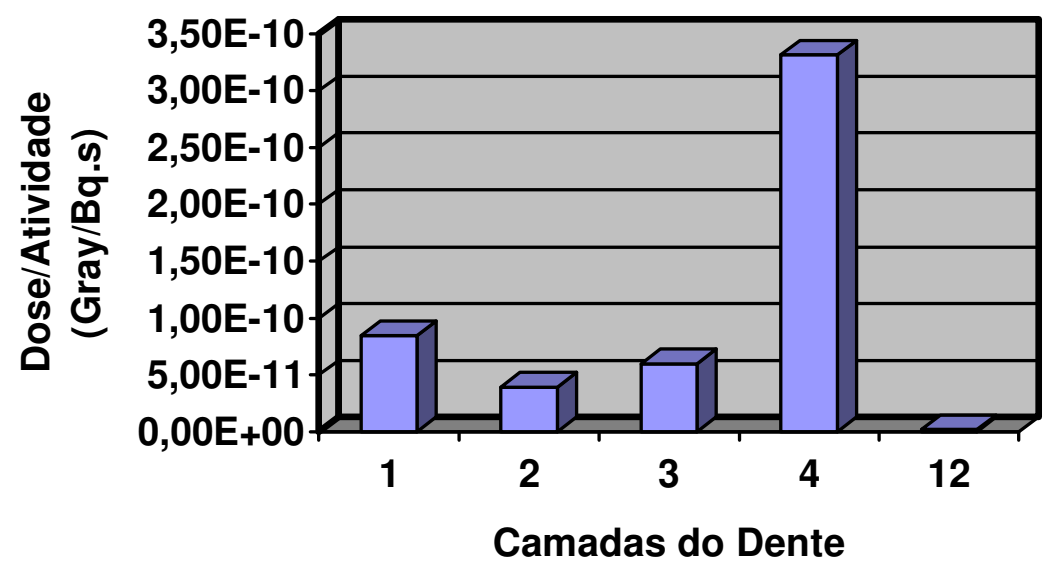

FIGURA 74 - Quantidade de Fóton absorvido nas camadas do dente com irradiação de 6 MV para o Compômero

TABELA 44 - Quantidade de Elétron absorvido para energia de 6 MV para o Compômero

Camadas do Dente

1 - Dentina Radicular

2 - Nervo e Raiz

3 - Dentina Radicular voltada para o Cépto

Radicular

4 - Esmalte

12 - Restauração
Dose/Atividade (Gray/Bq.s)

2,22873E-11 $\pm 3,16 \mathrm{E}-13$

$1,34437 \mathrm{E}-11 \pm 1,00 \mathrm{E}-13$

$1,22601 \mathrm{E}-11 \pm 5,76 \mathrm{E}-14$

$6,62760 \mathrm{E}-11 \pm 2,85 \mathrm{E}-13$

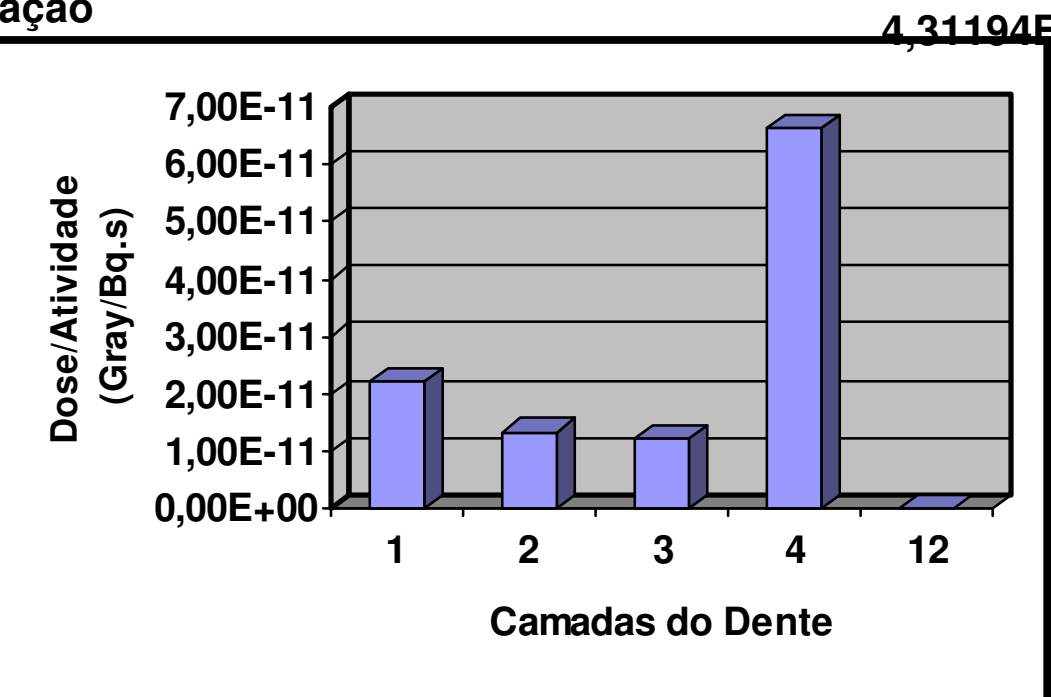

Figura 75 - Quantidade de Elétron absorvido nas camadas do dente com irradiação de 6 MV para o Compômero 
Nas tabelas 43 e 44 e gráficos 74 e 75, estão os resultados para as simulações do Compômero com irradiação de fótons de $6 \mathrm{MV}$.

Para os resultados com fótons observamos que a camada 4, representante do esmalte recebeu maior dose. Em seguida veio a camada 1, que representa a dentina radicular. Na seqüência a dentina radicular voltada para o cépto radicular, formado pela camada 3 e o nervo e raiz equivalente a camada 2. Por ultimo a camada 12, que é a restauração dentária (Compômero), recebeu a menor dose.

Nos resultados com elétron, observamos que a camada 3 representante da dentina radicular voltada para o cépto radicular recebeu menos dose do que a camada 2, nervo e raiz. As outras camadas continuaram na mesma ordem que no resultado com fóton.

\section{Simulação de irradiação com fóton de 10 MV}

TABELA 45 - Quantidade de Fóton absorvido para energia de 10 MV de Compômero

\section{Camadas do Dente}

1 - Dentina Radicular

2 - Nervo e Raiz

3 - Dentina Radicular voltada para o Cépto

\section{Radicular}

4 - Esmalte

12 - Restauração
Dose/Atividade (Gray/Bq.s)

1,47407E-10 \pm 4,57E-13

$5,79447 \mathrm{E}-11 \pm 6,95 \mathrm{E}-14$

1,04037E-10 \pm 7,28E-14

$5,35228 \mathrm{E}-10 \pm 3,75 \mathrm{E}-13$

$3,33765 \mathrm{E}-12 \pm 2,34 \mathrm{E}-15$

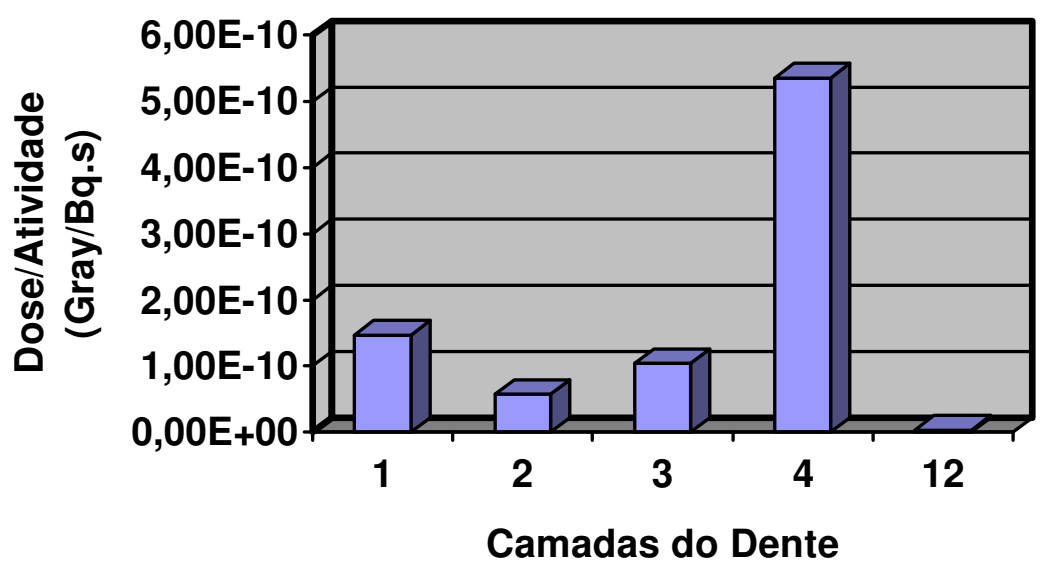


FIGURA 76 - Quantidade de Fóton absorvido nas camadas do dente com irradiação de 10 MV para o Compômero

TABELA 46 - Quantidade de Elétron absorvido para energia de 10 MV para o Compômero Camadas do Dente

Dose/Atividade (Gray/Bq.s)

1 - Dentina Radicular

2 - Nervo e Raiz

3 - Dentina Radicular voltada para o Cépto

$2,31616 \mathrm{E}-11 \pm 1,94 \mathrm{E}-13$

$1,36666 \mathrm{E}-11 \pm 6,83 \mathrm{E}-14$

Radicular

4 - Esmalte

$1,32134 \mathrm{E}-11 \pm 6,60 \mathrm{E}-14$

12 - Restauração

$7,11797 \mathrm{E}-11 \pm 3,34 \mathrm{E}-13$

$3,53148 \mathrm{E}-14 \pm 1,23 \mathrm{E}-15$

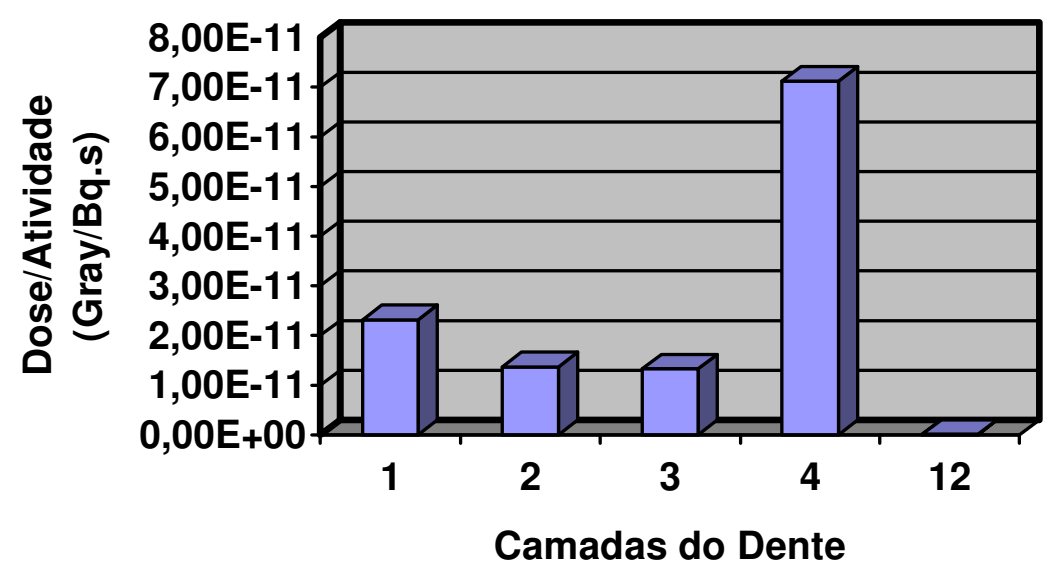

Figura 77 - Quantidade de Elétron absorvido nas camadas do dente com irradiação de 10 MV para o Compômero

Nas simulações com Compômero para fótons de $10 \mathrm{MV}$ observamos que a camada 4, representante do esmalte continua recebendo maior dose. Seguida da camada 1 (dentina radicular), depois da camada 3 (dentina radicular voltada para o cépto radicular) e da camada 2 (nervo e raiz). Por ultimo, observamos a camada 12, que equivale a restauração dentária (Compômero) sendo assim a camada que menos teve dose.

Nos resultados com elétrons, notamos que a camada 2 (nervo e raiz) recebeu mais dose do que a camada 3 (dentina radicular voltada para o cépto radicular). Notamos que as demais camadas se mantiveram na mesma ordem, mencionadas no resultado anterior.

Analisando os resultados da simulação com o Método de Monte Carlo (MCNPX), Tabelas 27 a 46, verifica-se que a região do esmalte, 
representado pela camada 4, é a que apresenta maior absorção de dose de radiação. Conforme discussão com especialista em cariodontia, a cárie por radiação se inicia no esmalte do dente, por ser uma superfície lisa, corroborando assim com os resultados das simulações.

\subsection{Câmera de lonização e detector Geiger - Muller}

Os resultados da Câmera de lonização e do detector Geiger-Müller, antes de irradiar e após irradiar as amostras foram idênticos. Ou seja, correspondente a radiação de fundo do local. 


\section{CAPITULO 4 CONCLUSÕES}

Os materiais utilizados em restaurações dentárias analisados neste trabalho, pelo menos para os feixes de radiação, energia e dose utilizados, não apresentam propriedades de radio-indução, ou seja, não apresentaram radiação residual quando irradiados.

A amálgama e o ionômero de vidro, talvez por serem submetidos a processos de umidificação durante a cristalização são os materiais que apresentaram maior variação de densidade após irradiação.

Contrariando o pensamento de alguns especialistas em odontologia as amostras de titânio analisadas neste trabalho não sofreram alterações significativas na sua composição química quando submetido à dose de radiação com feixes de raios- $X$ de uso em radioterapia de tumores de cabeça e pescoço.

Os espectros dos feixes de raios- $X$ de megavoltagem simulados com 0 Método MCNPX, apresentam região de equilíbrio eletrônico em 1,5cm (6MV) e $2,4 \mathrm{~cm}$ (10MV), como a região do esmalte do dente está a uma profundidade da pele da face (entrada do campo de radiação) maior que estes valores, é natural de se esperar que a região mais externa do dente (esmalte) absorva maior dose que as regiões mais internas. Quando se pensa na modelagem do dente isoladamente (feixe de radiação diretamente no dente), também se espera que a região mais externa absorva maior dose, devido à dimensão total do dente, frente a espessura da região de equilíbrio eletrônico, além das características e dureza desta região. Estes conceitos são reforçados com os resultados obtidos com o MCNPX.

A metodologia desenvolvida neste trabalho mostrou-se exeqüivel e eficaz na verificação das alterações da densidade e composição química sofridas pelos materiais utilizados em restaurações dentárias quando submetidos a feixes de radiação ionizante preconizados aos pacientes de tumores de cabeça e pescoço. 


\section{ANEXO I - DADOS DE ENTRADA DO MCNPX}

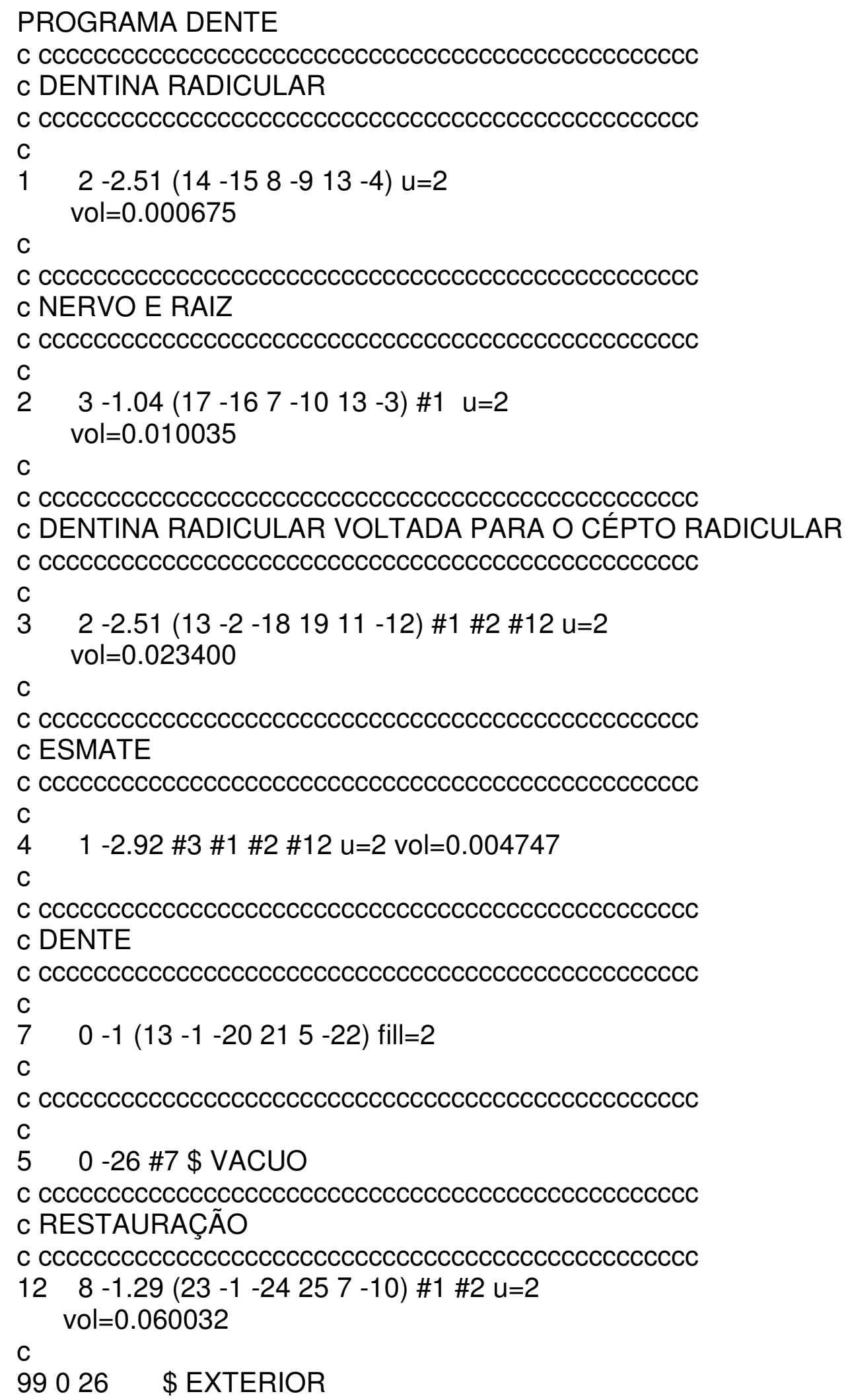


C

$9990-999$

C

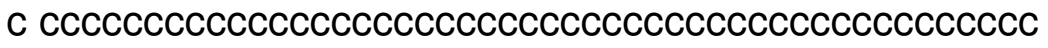

$1 \mathrm{pz} 0.432$

$2 \mathrm{pz} 0.40$

$3 \mathrm{pz} 0.30$

$4 \mathrm{pz} 0.25$

5 py 0

7 py 0.09

8 py 0.13

9 py 0.184

10 py 0.224

11 py 0.04

12 py 0.274

22 py 0.314

$13 \mathrm{pz} 0$

$14 \mathrm{px} 0$

$15 \mathrm{px} 0.05$

$16 \mathrm{px} 0.1$

$17 \mathrm{px}-0.05$

$18 \mathrm{px} 0.15$

$19 \mathrm{px}-0.1$

$20 \mathrm{px} 0.2$

21 px -0.15

23 pz 0.400

$24 \mathrm{px} 0.7$

$25 \mathrm{px}-0.7$

26 so 40.0

999 sq $11.11111 .1110000-10.020 .150$

C

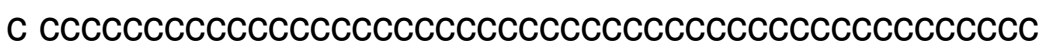

imp:p,n,h,e 111111101

mode $\mathrm{penh}$

phys:n 6

phys:p 6

phys:h 6

phys:e 6 j 0

histp

sdef $\operatorname{dir}=-1 \mathrm{vec}=001 \mathrm{x}=\mathrm{d} 1 \mathrm{y}=\mathrm{d} 2 \mathrm{z}=1$ erg=6 par=p $\mathrm{CCC}=999$

sp1 -41.7064460

sp2 -41.7064460

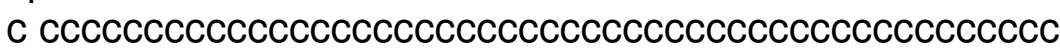

C TALLY CARDS

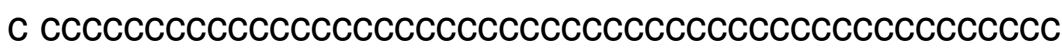

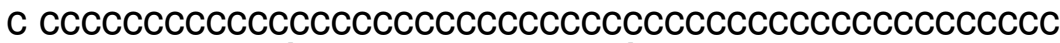

c ENERGIA MÉDIA EM CADA CÉLULA

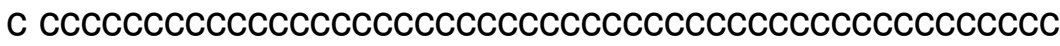

f6:e 123412 
f16:p 123412

f26:n 123412

f36:h 123412

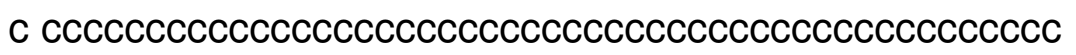

c MATERIAIS UTILIZADOS

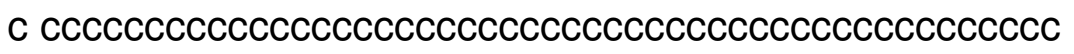

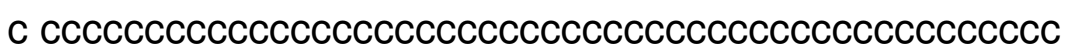

C ESMALTE $\$$ Densidade 2.92

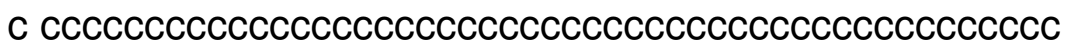

m1 $1001-0.0715031-0.5320000-0.178016-0.23$

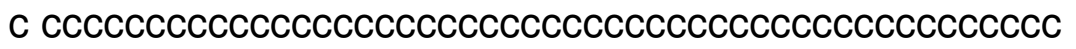

c DENTINA \$ Densidade 2.51

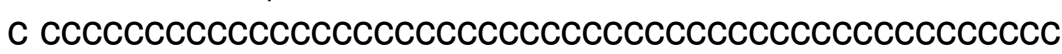

m2 $1001-0.0415031-0.0516032-0.0817000-0.06$

$20000-0.0735079-0.125011-0.0253127-0.21$

$7014-0.028016-0.309019-0.036012-0.03$

c cccccccccccccccccccccccccccccccccccccccccccccc

c NERVO E RAÍZ \$ Densidade 1.04

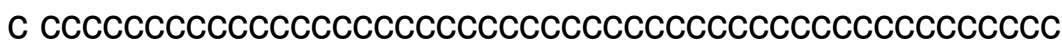
m3 $1001-0.1015031-0.0220000-0.017014-0.17$

$8016-0.7$

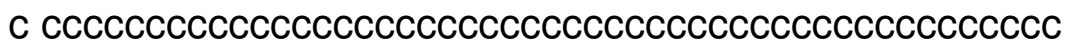

C TITANIO \$ Densidade 4.17

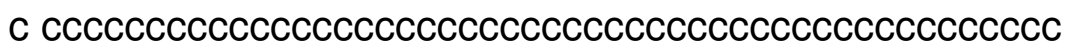

c m4 $1001-0.029019-0.3022000-0.326000-0.08 \&$

c $7014-0.038016-0.25$

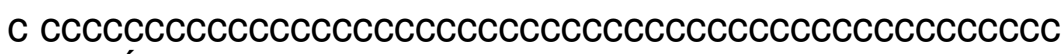

C AMÁLGAMA $\$$ Densidade 8.22

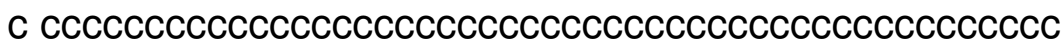

c m5 $29000-0.0747000-0.2450000-0.1580000-0.54 \&$

c $14000-0.00530000-0.00113027-0.002$

c cccccccccccccccccccccccccccccccccccccccccccccccc

C RESINA COMPOSTA \$ Densidade 1.86

C cCcCCCCCCCCCCCCCCCCCCCCCCCCCCCCCCCCCCCCCCCCCCCCCC

c m6 $14000-0.4040000-0.248016-0.3372000-0.007$

c $13027-0.00411023-0.00417000-0.003$ \&

C $20000-0.003$

c cccccccccccccccccccccccccccccccccccccccccccccccc

c COMPOMERO \$Densidade 1.98

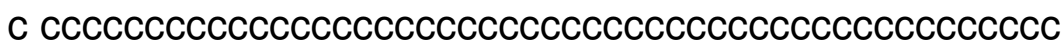

c m7 $13027-0.0814000-0.168016-0.3 \&$

c $9019-0.0615031-0.0211023-0.0220000-0.004 \&$

c $17000-0.00316032-0.00338000-0.35$

c ccccccccccccccccccccccccccccccccccccccccccccccc

c IONOMERO DE VIDRO \$ Densidade 1.973

C ccccccccccccccccccccccccccccccccccccccccccccccc

c m8 $14000-0.1715488000-0.37573438000-0.309487 \&$

c $13027-0.1377656138-0.00474626000-0.000211 \&$

C $58000-0.000514$

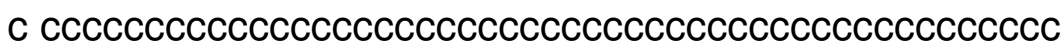


C nps 20000000 


\section{BIBLIOGRAFIA}

1 INCA - Instituto Nacional do Câncer, "Falando Sobre o Câncer de Boca." Disponível em: <http://www.inca.gov.br>. Acesso em 06 de jan. 2009.

2 INCA - Instituto Nacional do Câncer, "Fumo, Cigarro e suas Consequências." Disponível em: <http://www.inca.gov.br>. Acesso em 15 de jan. 2009.

3 INCA - Instituto Nacional do Câncer, "Estimativas para 2008 - Incidência de Câncer no Brasil." Disponível em: <http://www.inca.gov.br> . Acesso em 03 de fev. 2009.

4 INCA - Instituto Nacional do Câncer, "Estimativa da Incidência e Mortalidade por Câncer no Brasil." Disponível em: <http://www.inca.gov.br>. Acesso em 07 de fev. 2009.

5 INCA - Instituto Nacional do Câncer, "O Problema do Câncer No Brasil." Disponível em: <http://www.inca.gov.br>. Acesso em 15 de fev. 2009.

6 INCA - Instituto Nacional do Câncer, "Atlas de mortalidade por Câncer no Brasil” Disponível em: <http://www.inca.gov.br>. Acesso em 20 de fev. 2009.

7 FOSP - Fundação Oncocentro de São Paulo, "Estratégias para o Controle do Câncer." Disponível em: <http://www.fosp.saude.sp.gov.br>. Acesso em 23 de fev. 2009.

8 PINDBORG, J.J.; “Atlas das Doenças da Mucosa Oral.” Editorial Médica Pan-americana, p.70-116, 1981.

9 WHO - World Health Organization, "National Cancer Control Programmes: Policies And Managerial Guidelines." Disponível em: <http://www.who.int $>$. Acesso em 23 de fev. 2009.

10 SILVERMAN, S.; CHIERICI, G. "Radiation Therapy of Oral Carcinoma. Effects on Oral Tissues and Management of the Periodontium." J. Periodont. v.36, p.478-484, 1965.

11 FRANCK, R. M.; HERDLY, J.; PHILLIPPE, E. “Acquired Dental Defects and Salivary Gland Lesions after Irradiation for Carcinoma." The Journal of the American Dental Association, v.70, p.868-883, 1965.

12 FERLAY, J.; BRAY, F.; PARKIN, D.M.; PISANI, P. "Globocon 2000: Cancer Incidence and Mortality Worldwide". International Agency for Research on Cancer, n.5, p.182-187, 2001. 
13 LEITE, I.C.G; KOIFMAN, S. "Survival Analysis in a Sample of Oral Cancer Patients et al Reference Hospital in Rio De Janeiro, Brazil." Oral Oncology European Journal of Cancer, v.34, p.347-352, 1998.

14 SCALA, M. et al. "Il Ruolo del Medico Genericoe del Odontostomatologo nella Diagnosis Precoce delle Lesion Freneoplastiche y Neoplastiche del Cavo Orale." Minerva Stomatol, v. 46, n.3, p.133-137, 1997.

15 CARVALHO, M. R. "História Natural do Câncer da Cavidade Oral." In Raport A-Câncer de Boca, Pancast edition. p.17-29, 1997.

16 BARASCH, A. et al. "Squamous Cell Carcinoma of the Gingiva." Oral Surg Oral Med Pathol, v.80, p.183-187, 1995.

17 CADY, B.; CATIN, D. "Epidermoid Carcinoma of the Gum." A 20 year survey. Câncer, v.23, p.551-569, 1969.

18 KARMIOL, M.; WALSH, R. F. "Dental Caries After Radiotherapy Of The Oral Regions." The Journal of the American Dental Association, v.91, p.838-845, 1975.

19 EPSTEIN, J.B. et al. "Quality Of Life And Oral Function. Following Radiotherapy For Head And Neck Cancer." Head \& Neck, v.21, p.1-11, 1999.

20 SAMBA, S.E. et al. "The Head and Neck Radiotherapy Patient:Part 1- Oral Manifestations of Radiation Teraphy." Compend. Contin. Educ. Dent., v.15, p.250-261, 1994.

21 MERAW, S.J.; REEVE, C.M. "Dental Considerations and Treatment of the Oncology Patient Receiving Radiation Therapy." Jada, v.129, p.201-205, 1998.

22 TELFER, J.R.C.; BAINBRIDGE, L.C.; SOUTAR, D.S. "Recurrence of Intraoral Squamous Cell Carcinoma at the Base of Nasolabial Flaps Used for Intraoral Reconstruction: A Report of Two Cases." An Internacional Journal of Surgical Reconstruction, v.46, n.3, p.266-267, 1993.

23 CAMPOS-FILHO, N.; FRANCO, E.L.F.A. "A Microcomputer Program For multiple Logistic Regression by Unconditional and Conditional Maximum Lilehood Methods." American Journal of Epidemiology, v.129, p.439-444, 1989.

24 JHAM; B.C.; FREIRE, A.R.S. "Complicações Bucais da Radioterapia em Cabeça e Pescoço." Revista Brasileira de Otorrinolaringologia, v.72, n.5, p.704-708, 2006.

25 MARCIANI, R.D. et al. "Treating Patients Before and After Irradiation." Jada, v.123, p.108-112, 1992. 
26 MEALEY, B.L. et al. "The Head and Neck Radiotherapy Patient: Part 2Manegement Of Oral Complications." Compendium of Continuing Education in Dentistry, v.15, p.442-458, 1994.

27 PARULEKAR, W. et al. "Scoring Oral Mucositis." Oral Oncology, v.34, p.63$71,1998$.

28 BEUMER, J. et al. "Preradiation Dental Extractions and the Incidence of Bone Necrosis.” Head \& Neck Surgery, v.5, p.514-521, 1983.

29 GHALICHEBAF, M. et al. "A New Technique for Fabrication of Fluoride Carriers in Patients Receiving Radiotherapy to the Head and Neck." Compendium of Continuing Education in Dentistry, v.15, p.470-476, 1994.

30 CARL, W. et al. "Oral Care of Patients Irradiated for Cancer of the Head and Neck." Cancer, v.30, p.448-453, 1972.

31 GIBBS, F.A. et al. "The Metal Tissue Interface Effect in Radiation of the Oral Cavity.” Radiology, v.119, p.705-707, 1976.

32 KOHRI M.; COOPER E.P.; FERRACANE J.L.; WAITE D.F. “Comparative Study of Hydroxyapatite and Titanium Dental Implants." Journal of Oral and Maxillofacial Surgery, v.48, n.12, p.1265-1273, 1990.

33 MENARD, C.M.; BEWS, J.; SKORACKI, I.R.; CHOWDHURY, A.D. “HighEnergy Electron and Photon Therapy to the Parotid Bed: Radiation Dose Perturbations With a Titanium Mandibular Implant." Australasian Radiology, v.43, p.495-499, 1999.

34 ELIZAUR, A.B.C.; FULLER, J.B.; SALGADO, P.E.; GABRIELLI, F.; DINELLI, W.; GABRIELLI, A.P.R. "Amalgama Dental: Estudo " In Vitro " da Liberação de Mercúrio, através de Espectrofotometria de Absorção Atômica, em Função do Tipo de Ligas, Polimento e Tempo." Revista Odontológica da Universidade de São Paulo, v.9, p.39-43, 1995.

35 PÉCORA, J.D.; GUIMARÃES, L.F.L.; SPANO, J.C.E.; BARBIN, E.L.; SILVA, R. S. "Análise Qualitativa da Presença de Mercúrio em Cápsulas de Amálgama Utilizadas.” Robrac, v.11, p.27-29, 2002.

36 BAUER, J.G.; FIRST, H.A. "The Toxicity of Mercury in Dental Amalgam." Journal of the California Dental Association, v.10, p.47-61, 1982.

37 FIALHO, E.S.; SILVA, E.V.; GRAFF, C.S.; LOGUERCIO, A.D.; CAMACHO, G.; BUSATO, A.L.S. "Avaliação da Infiltração Marginal de Restaurações de Amálgama: Mercúrio Versus Gálio.” Pesquisa Odontológica Brasileira v.14, n.1, p. 59-63, 2000.

38 PÉCORA, J.D. "Guia Prático Sobre Resíduos de Amálgama Odontológico." Disponível em: <http://www.forp.usp.br/restauradora/lagro/guia-pratico.html $>$. Acesso em 25 de fev. 2009. 
39 UNEMORI, M.; MATSUYA, Y.; AKASHI, A.; GOTO, Y.; AKAMINE, A. "Composite resin restoration and postoperative sensitivity: clinical follow-up in an undergraduate program" Journal of Dentistry, v.29, p.7-13, 2001.

40 WILSON, M.A.; COWAN, A.J.; RANDALL, R.C.; CRISP, R.J.; WILSON, N.H.F. "A Practice-Based, Randomized, Controlled Clinical Trial of a New Resin Composite Restorative: One-Year Results." Operative Dentistry, v. 27, n. 5, p. 423-429, 2002.

41 BUSATO, A.L.S.; REICHERT, L.A.; VALIN, R.R.; AROSSI, G.A.; SILVEIRA, C.M. "Comparação de Fluorescência entre Resinas Compostas Restauradoras e a Estrutura Dental Hígida - In Vivo." Revista Odontológica de Araçatuba, v.27, n.2, p.142-147, 2006.

42 Lee Y.; Lu H.; Powers J.M. "Changes in Opalescence and Fluorescence Properties of Resin Composites after Accelerated Aging." Dental Materials, v.22, p.653-660, 2006.

43 SOUSA, R.F.; MARRA, E.M.O.; GOMIDE, A.H. "Avaliação das Propriedades Físicas, de Materiais Utilizados para Selamento de Fóssulas e Fissuras. Estudo In Vitro." Horizonte Científico, v.1, p.1-21, 2007.

44 BUSSADORI, S.K. "Dentística Odontopediátrica - Técnicas de Trabalho e uso de Materiais Dentários." $1^{\underline{a}}$ ed. São Paulo: Santos Livraria e Editora, p.169, 2000.

45 FOOK, A.C.B.M.; AZEVEDO, V.V.C.; BARBOSA, W.P.F.; FIDÉLES, T.B.; FOOK, M.V.L. "Materiais Odontológicos: Cimentos de lonômero de Vidro." Revista Eletrônica de Materiais e Processos, v.3.1, p.40-45, 2008.

46 ABATE, P.F. et al. "Barcol Hardness of Resin Modified Glass Ionomer Cements and a Compomer." Quintessence Int.,v.28, n.5, p.345-348, 1997.

47 TERADA, R.S.S.; NAVARRO, M.F.L.; CARVALHO, R.M.; TAGA E.; FERNANDES, R.B.D. "Avaliação In Vitro da Liberação de Flúor de Cimentos de lonômero de Vidro e outros Materiais que Contêm Flúor." Revista Odontológica da Universidade de São Paulo, v.12, n.1, 1998.

48 TRAITEL, M. "Compômero x Resina: A Evolução Dos Materiais Restauradores." Revista Brasileira de Odontologia, v.56, n.4, p.165-169, 1999.

49 MORENO, V.B.; RIBEIRO, M.; MELO, A.T. "Compômero: Principais Propriedades e Indicações.” Revista Biociências, v.6, n.2, 2000.

50 "The Code MCNPX." Disponível em: <http://www.mcnpx.lanl.gov>. Acesso em 05 de mar. 2009. 
51 FERNANDES, M.A.R.; PAULA, D.; OKIDA, R.; BIAZOLLA, E.R.; SANTOS, A.; FANARO, L.C.C.B.; SALVADOR, V. "Estudos dos Efeitos da Exposição à Radiação Gama do Cobalto-60 sobre Materiais Utilizados em Restauração Dentária." Anais do V Encontro da Sociedade Brasileira de Radioterapia, Natal-RN, 2003.

52 SASSE, A. "Guia do Paciente em Radioterapia." Disponível em: <http://www.cevon.com.br>. Acesso em 08 de mar. 2009.

53 CROSP - Conselho Regional de Odontologia, "Campanha de Prevenção e Diagnóstico Precoce de Câncer Bucal." Disponível em: <http://www.crosp.org.br>. Acesso em 09 de mar. 2009.

54 SILVA, L.C.F.; PAULINELLI, M.N.; MEIRA, R.A. “Avaliação dos Fatores de Risco Dentais e de Malignidade em Radioterapia da Cabeça e do Pescoço." Revista de Cirurgia e Traumatologia Buco-Maxilo-Facial, v.4, n.3, p.187-195, 2004.

55 INCA - Instituto Nacional do Câncer, "Manual de Detecção de Lesões Suspeitas." Disponível em: <http://www.inca.gov.br>. Acesso em 09 de mar. 2009.

56 Merck Sharp \& Dohme, "Causas E Riscos Do Câncer." Disponível em: <http://www.msd-brazil.com>. Acesso em 12 de mar. 2009.

57 Merck Sharp \& Dohme, “Linfomas - MSD.” Disponível em: <http://www.msdbrazil.com>. Acesso em 12 de mar. 2009.

58 Merck Sharp \& Dohme, "Câncer e o Sistema Imune." Disponível em: <http://www.msd-brazil.com>. Acesso em 13 de mar. 2009.

59 Merck Sharp \& Dohme, "Diagnóstico de Câncer." Disponível em: <http://www.msd-brazil.com>. Acesso em 13 de mar. 2009.

60 Merck Sharp \& Dohme, "Complicações do Câncer." Disponível em: <http://www.msd-brazil.com>. Acesso em 13 de mar. 2009.

61 Merck Sharp \& Dohme, “Tratamento do Câncer.” Disponível em: <http://www.msd-brazil.com>. Acesso em 13 de mar. 2009.

62 Merck Sharp \& Dohme, "Cânceres da Cabeça e do Pescoço.” Disponível em: <http://www.msd-brazil.com>. Acesso em 14 de mar. 2009.

63 CNEN - Comissão Nacional de Energia Nuclear, "Certificação de Qualidade de Supervisores de Radioproteção." Disponível em: <http://www.cnen.gov.br>. Acesso em 14 de mar. 2009.

64 CNEN - Comissão Nacional de Energia Nuclear, "Diretrizes Básicas da Proteção Radiológica.” Disponível em: <http://www.cnen.gov.br>. Acesso em 14 de mar. 2009. 
65 CNEN - Comissão Nacional de Energia Nuclear, "Radiações Ionizantes." Disponível em: <http://www.cnen.gov.br>. Acesso em 15 de mar. 2009.

66 Fundep - Fundação de Desenvolvimento da Pesquisa, "Câncer de Boca Sob Análise.” Disponível em: <http://www.fundep.br>. Acesso em 18 de mar. 2009.

67 DRUMMOND, S.N.; GÓMEZ, R.S.; NORONHA, J.C.M.; PORDEUS, I.A.; BARBOSA, A.A.; MARCO, L. "Association Between Gstt-1 Gene Deletion and the Susceptibility to Oral Squamous Cell Carcinoma in CigaretteSmoking Subjects." Oral Oncology, v.41, n.5, p.515-519, 2005.

68 Fundação do Câncer, "Aspirina pode Prevenir Câncer de Boca, Garganta e Esôfago." Disponível em: <http://www.fundacaodocancer.org.br>. Acesso em 20 de mar. 2009.

69 Sala Médica, "Câncer de Língua - O Fumo e o Álcool Aumentam o Risco da Doença." Disponível em: <http://www.salamedica.com.br>. Acesso em 20 de mar. 2009.

70 D'SOUZA, G.; KREIMER, R.A.; VISCIDI, R.; PAWLITA, M.; FAKHRY, C.; $\mathrm{KOCH}, \mathrm{M} . W . ;$ WESTRA, H.W.; Gillison, M.L. "Case Control Study of Human Papillomavirus and Oropharyngeal Cancer." The New England Journal of Medicine, v.356, n.19, p.1944-1956, 2007.

71 ANTUNES, R.C.P; RIBEIRO, A.P.V.; Filho, G.M. “Abordagem Multidisciplinar Preventiva das Complicações Orais da Radioterapia e Quimioterapia.” Pratica Hospitalar, Ano IV, n.33, 2004.

72 INCA - Instituto Nacional do Câncer, "Perguntas e Respostas sobre o Câncer" Disponível em: <http://www.inca.gov.br>. Acesso em 21 de mar. 2009.

73 "Controle do Câncer: Uma Proposta de Integração Ensino-Serviço." 3a ed. RJ: CEDC/INCA, v.1, p.65-71, 2008.

74 JHAM, B.C.; FREIRE, A.R.S.; “Complicações Bucais da Radioterapia em Cabeça e Pescoço." Revista Brasileira de Otorrinolaringologia, v.72, p.704708, 2006.

75 TORRES, E.M.; CARREIRO, A.F.P.; LIRA, C.M.N.; Ribeiro, R.F. "The Use of Titanium for the Fabrication of Removable Partial Denture Frameworks." Revista Gaúcha de Odontologia, v.55, p.181-189, 2007.

76 TOMYIAMA, O. "Câncer de Laringe: Um bom Motivo para Parar de Fumar." Disponível em: <http://www.salamedica.com.br>. Acesso em 21 de mar. 2009. 